كلية القانون/ الجامعة العر اقية

\title{
تجريم المخالفات الجسيمة في اتفاقيات جنيف في قانون العقوباث وقانون العقوبات العسكري العراقي
}

\author{
م.د. بصـائر علي محمد البيـاتي
}

كلية القانون والعلوم السياسية

الجامعة العراقية 


\section{فهرست البحث}

المبحث الاول: نظرة عامة على القانون الدولي الانساني وعلاقته بالقانون الجنائي. المبحث الثاني: الموائمات التشريعية للمخالفات الجسيمة في النظم القانونية لاول العالم.

المطلب الاول/ اساليب الدول في تجريم نظام المخالفات الجسيمة.

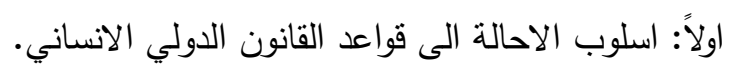
ثانياً: اسلوب القاعدة القانونية المستقلة.

المطلب الثاني/دور اللجنة الدولية للصليب الاحمر في الموائمة التشريعية للمخالفات الجسيمة في النشريعات الوطنية.

المبحث الثالث: المعالجة التشريعية للمخالفات الجسيمة في قانون العقويات العراقي وقانون العقويات العكري.

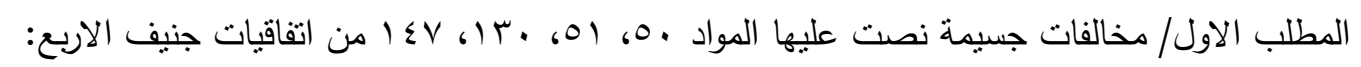

$$
\text { 1- (القتل العمد. }
$$

r- التعذيب او المعاملة اللاانسانية.

r- مظر اجراء التجارب البيولوجية.

ع- التسبب عمدا في احداث معاناة شديدة.

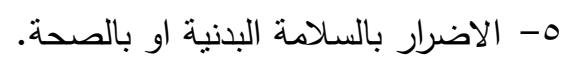

צ- تدمير الممنلكات او الاستيلاء عليها على نطاق واسع من دون مبرر يتعلق بالضرورة العسكرية، وبطريقة

$$
\text { غير مشروعة وتعسفية. }
$$

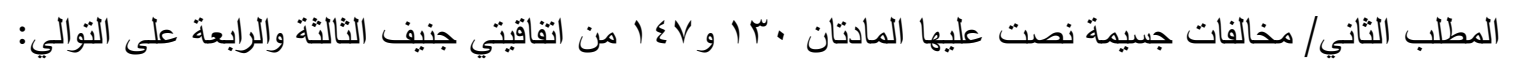
ا- ارغام اسرى الحرب او المدنيين المحمين على الخدمة في القوات المسلحة لدولة معادية.

ץ- تعدد حرمان اسرى الحرب او الاشخاص المحمين من حقهم في الحصول على محاكمة عادلة وقانونية

$$
\text { وفق الاحكام الواردة في الاتفاقيات. }
$$

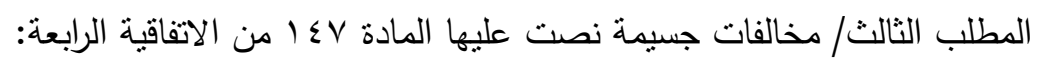

$$
\text { 1- الترحيل او النقل غير المشروع. }
$$

r- الحجز غير المشروع للاشخاص المحمين.

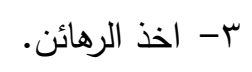

الخاتمة: 


\section{المقدمة:}

تمنل اتفاقيات جنيف لعام 9 19 وبروتوكوليها الاضافيين لعام 19VV عصب الحماية للافراد الذين لا يشاركون في العمليات العدائية او الذين كفوا عن المشاركة فيها. وتكاد تكون معظم دول العالم اطراف في هذها

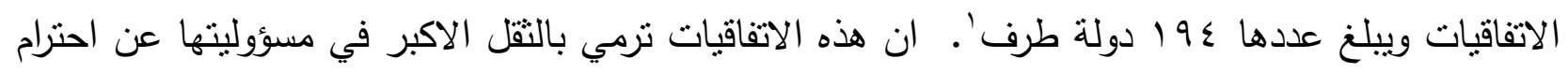

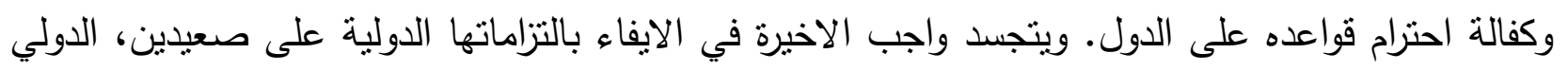

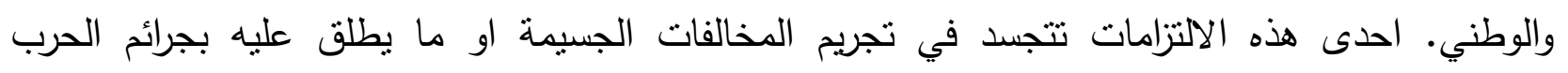

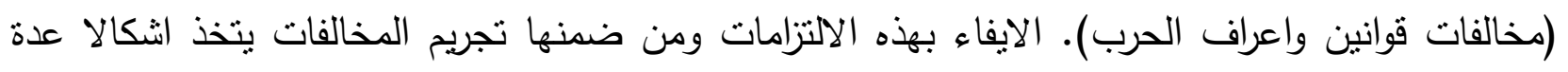

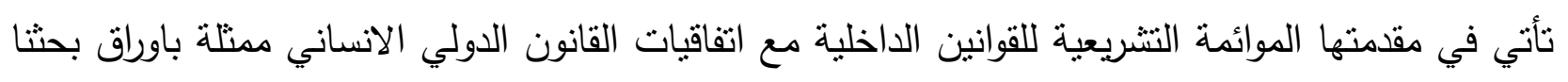

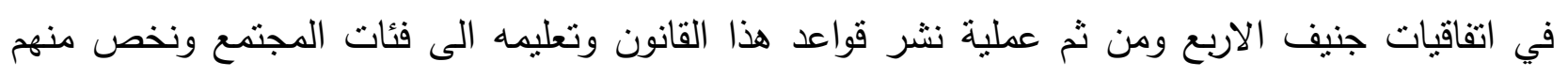
بالذكر ، صانعو السياسة، طلاب القانون والاعلام وفئة العسكريين.

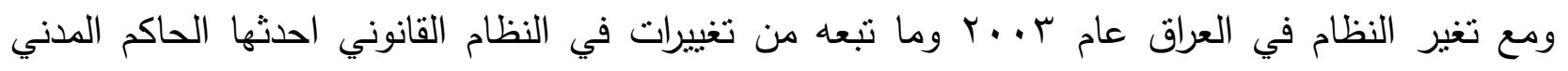

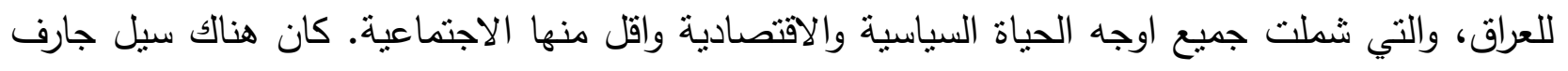

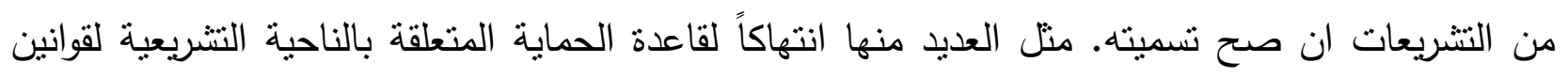

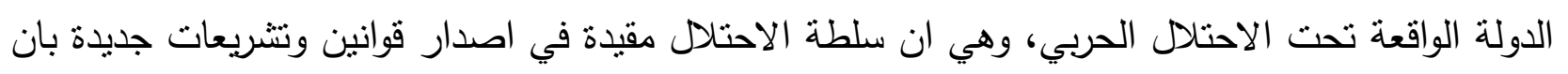

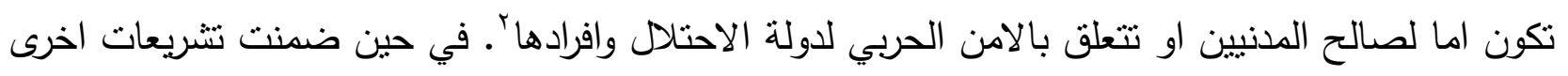

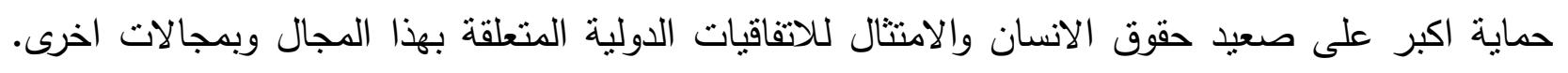

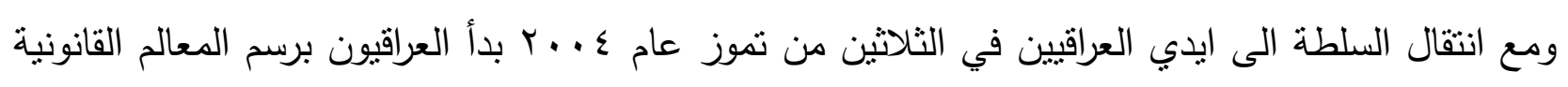

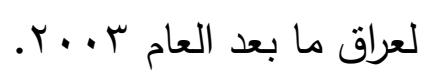

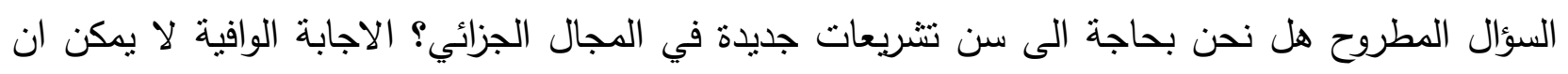

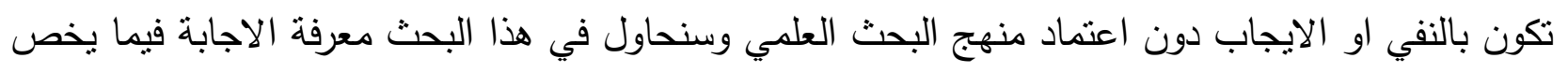
موضوعاً بعينه وهو تجريم المخالفات الجسيمة في اتفاقيات جنيف في القانون العراقي آملين في خطوة مثقدمة

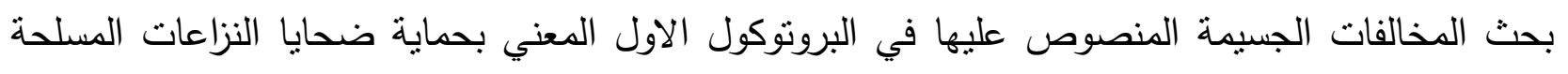

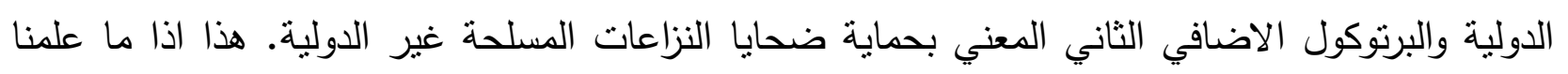
بان العراق صادق على الوثيقة الاولى بّدون الثانية. 
ويشكل الايفاء بالتزاماتتا الدولية على الصعيد الوطني والدولي خطوة متقدمة وحاسمة في احترام، حماية،

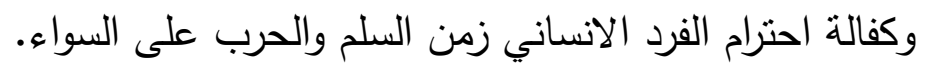

\section{المبحث الاول: نظرة عامة على القانون الدولي الانساني وعلاقته بالقانون الجنائي.}

يعرف القانون الدولي الانساني؛ على انه ذلك الفرع الخاص من القانون الدولي الذي ينظم حالات النزاع

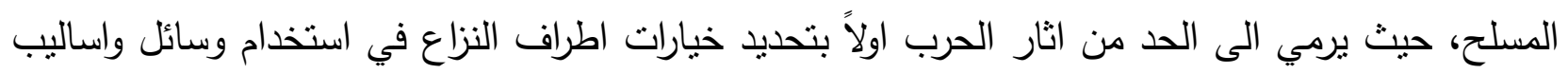
للعمليات الحربية، وثانياً في الزام الدحاربين بتجنيب الاشخاص الذين لا يشاركون او كفوا عن المشاركة في العمليات الحربية آثار الاعمال العدائية؛.من التعريف السابق يتنين لنا ان نطاق هذا القانون يتحدد بمجالين

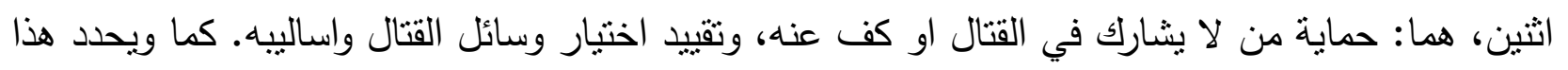

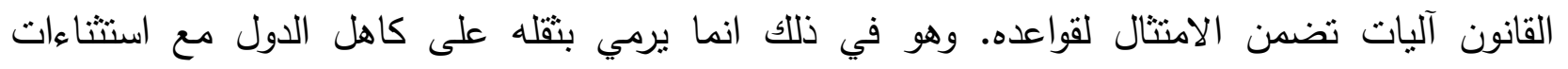

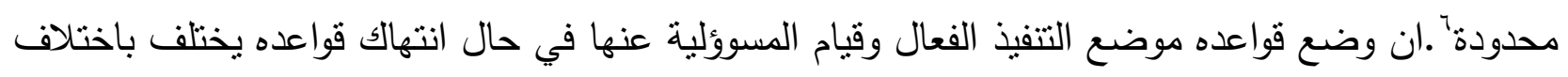

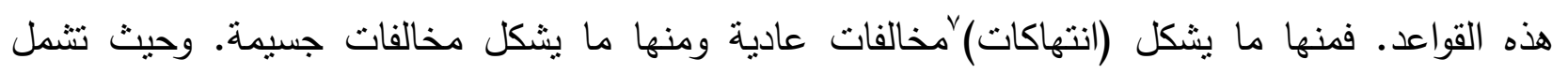
المخالفات العادية كل الافعال المنافية لاتفاقيات جنيف وبروتوكوليها الاضافيين والتي لم يرد ذكرها ضمن التهن

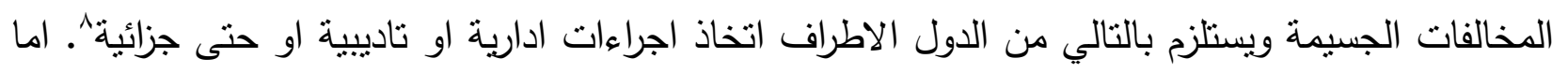

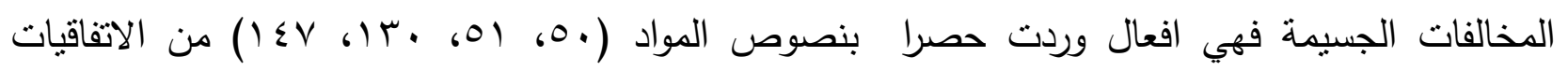
الاربع". هذا وتلتزم الدول باتخاذ اجراءات نتريعية لضمان فرض عقوبات جزائية تجاهها ومن ثم الالتزام

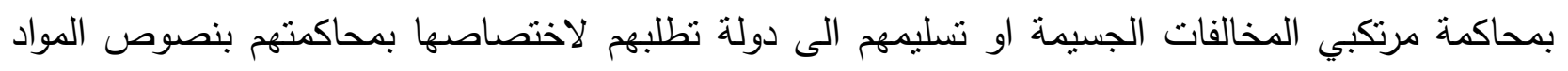

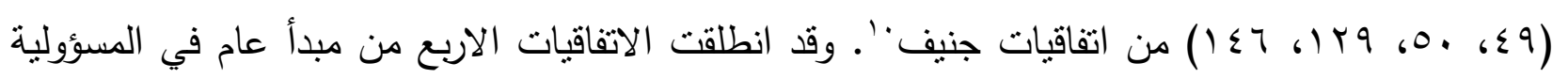

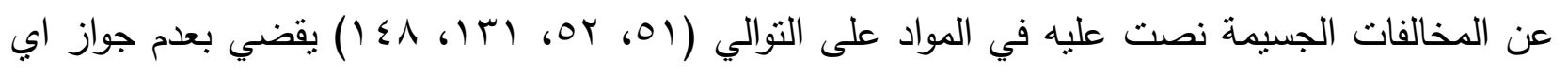

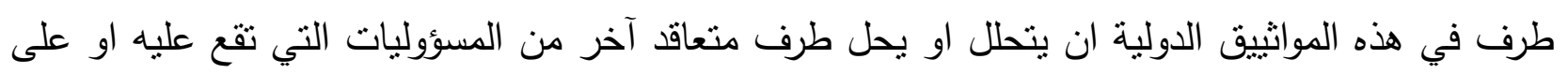

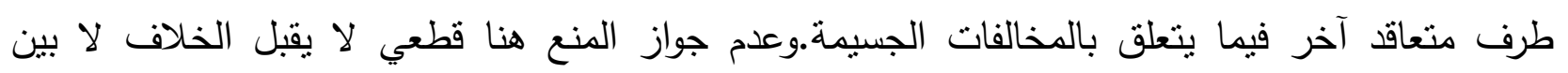

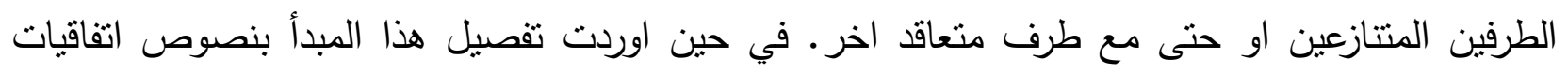

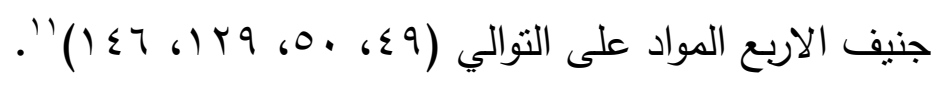

وتتجلى العلاقة الوثيقة بين القانون الدولي الانساني والقانون الجنائي في العديد من المسائل الجوهرية الخاصة بالقانون الجنائي، فالاخير هو من يكفل فاعلية قمع المخالفات الجسيمة على الصعيد الوطني. ولاعمال هذه الهاني الفاعلية يتعين النطرق الى بعض اهم المسائل الجوهرية ومبندئين بالعمود الفقري للقانون الجنائي الا وهو

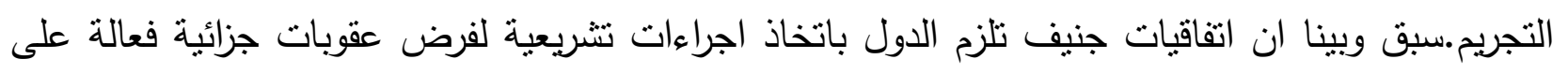




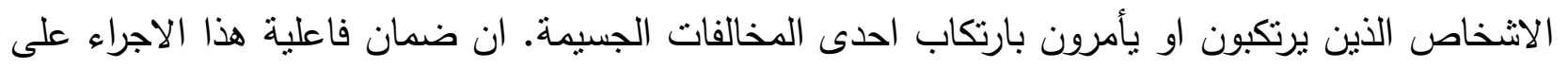

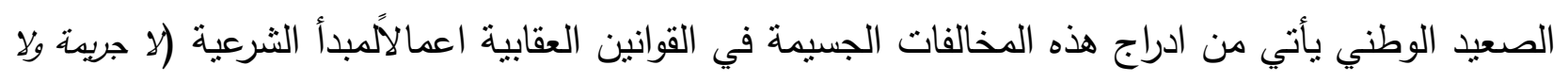

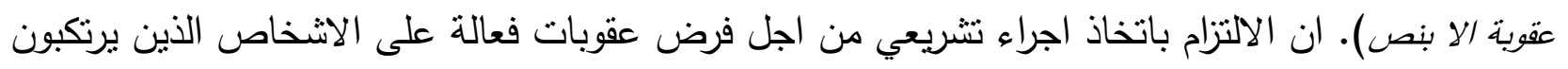

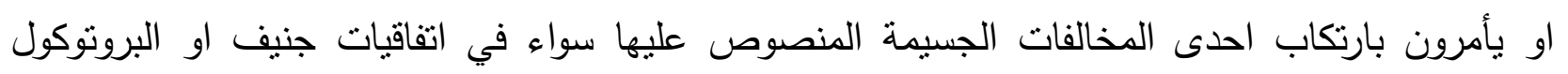
الاول هو التزام صريح ورد في الفقرة الاولى من المواد المذكورة اعلاه وان اثثرت حوله العديد من النقاشات

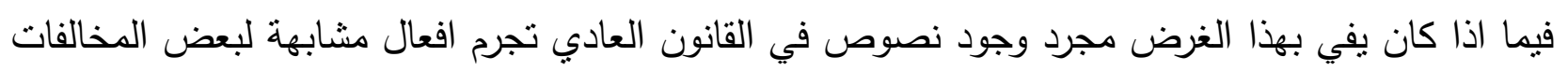

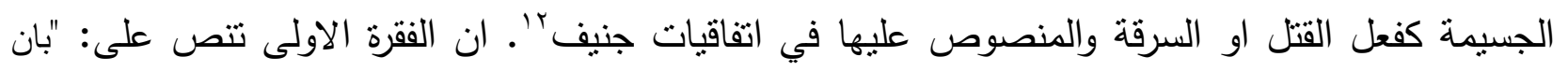
تتخذ أي اجراء تثريعي يلزم لفرض عقوبات جزائية فعالة على الاشخاص الذين يقترفون او يامرون باقتراف احدى المخالفات

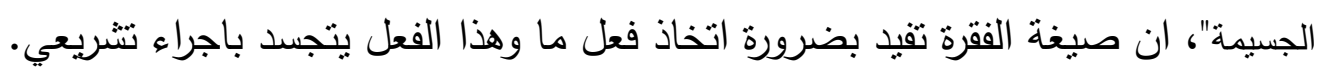

السؤال المطروح هل يكفي وجود تجريم في القانون الجنائي العادي لنفس الافعال الموصوفة بمخالفات جسيمة اذا ما كانت العقوبات المفروضة على هذه الافعال فعالة ومؤثرة في حال اخذنا بنظر الاعتبار ما ينص علئ عليه

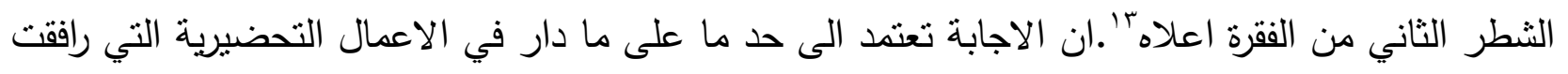

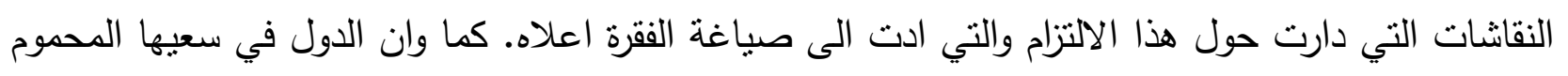

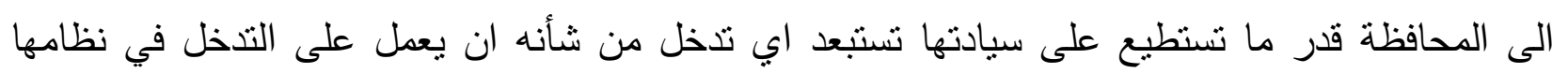

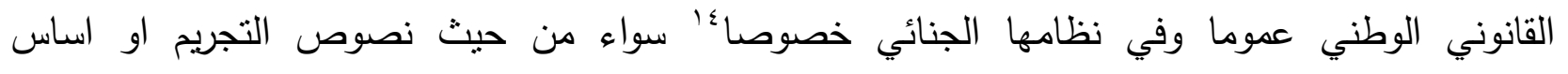
الاختصاص سوالذي سناتي اليه لاحقا-. وهي في نقاشاتها جسدت مخاوفها من تسمية المخالفات الجسيمة

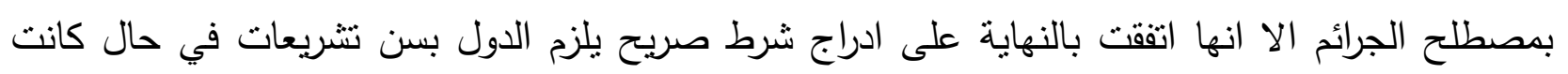

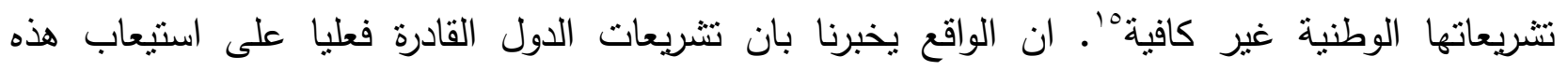

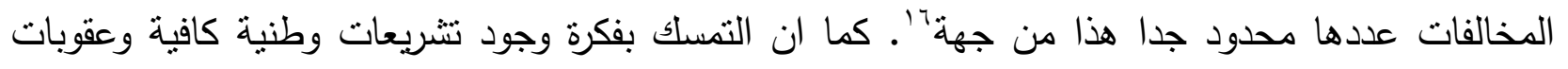
فعالة لوحدهما دون اعمال الثطر الاول من الالتزام بسن تشريعات يتعارض مع مبدأ حسن النية في تفسير

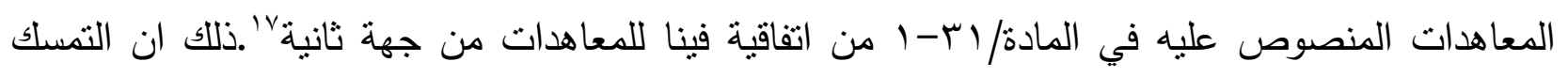
بالثطر الثاني وهو وجود عقوبات فعالة دون النظر الى هدف وغاية معاهدات جنيف فيه شيء من قصر

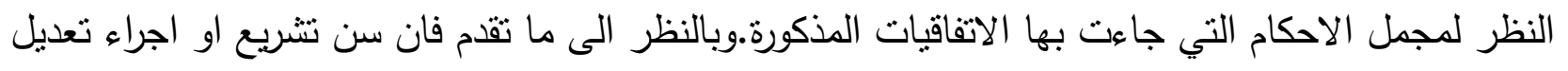

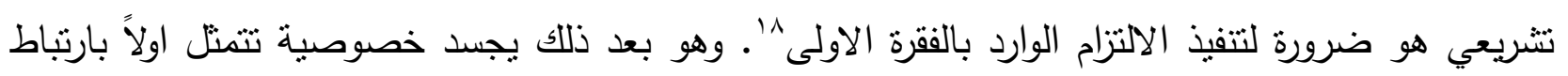

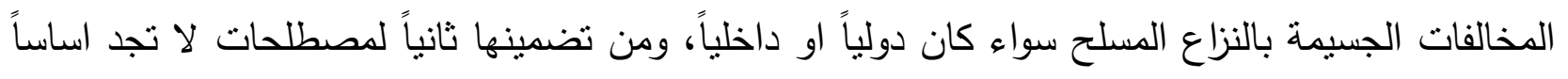

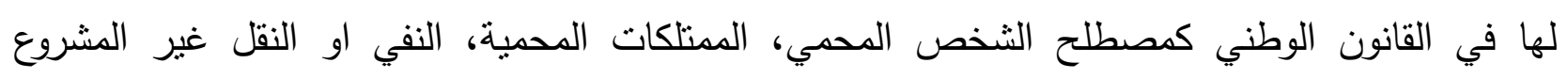

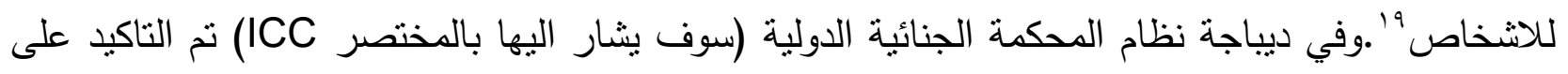


خصوصية الجرائم الدولية وواجب الدول في مقاضاة مرتكبيها من خلال اتخاذ تدابير على الصعيد الوطني بالقول: (وإذ تؤكد أن أخطر الجرائم التي تثثير قلق المجتمع الدولي بأسره يجب ألا تمر دون عقاب مأب وأنه يجب ضمان مقاضاة مرتكبيها على نحو فعال من خلال تدابير تتخذ على الصعيد الوطني وكذلك من خلال تعزيز

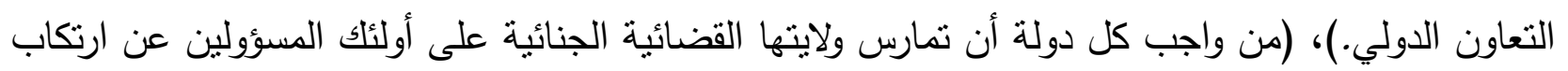
جرائم دولية).

هذا وتمتك الجرائم الدولية انتهاكات للالتزامات تجاه كافة الافراد بrgaOmnes)، حيث عرفتها محكمة العدل

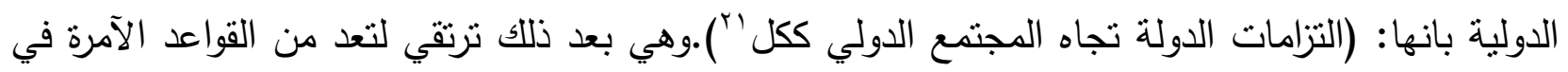

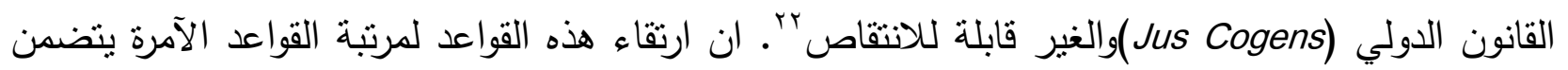

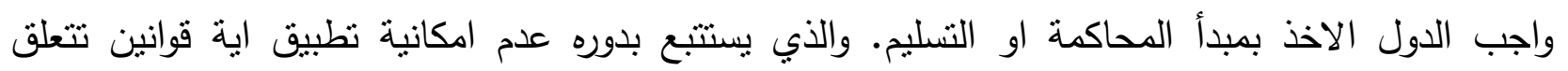

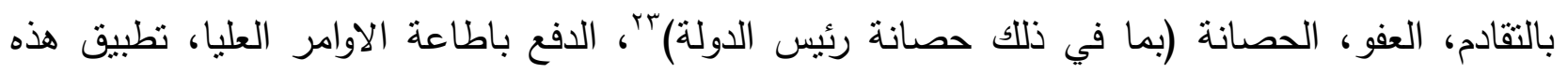
الالتزامات سواء زمن السلم او الحرب، وعدم الانتقاص منها تحت اي ظرف (بضهن (بضمنها حالات الطوارئ)،

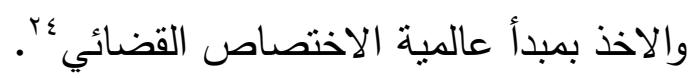

وباعتبار ان المخالفات الجسيمة المنصوص عليها في اتفاقيات جنيف هي جرائم حرب بم بمعنى ثانٍ تشكل

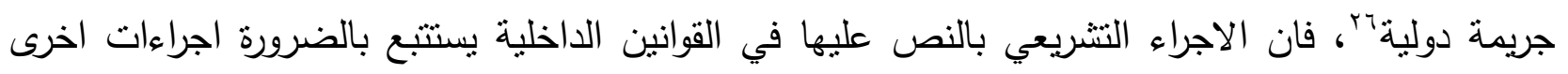

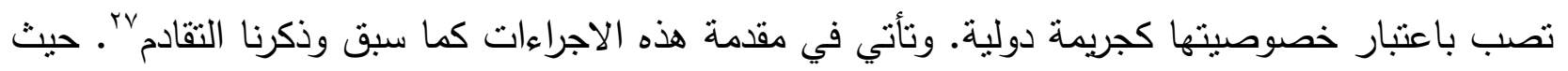

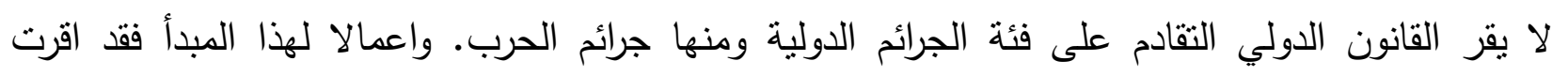

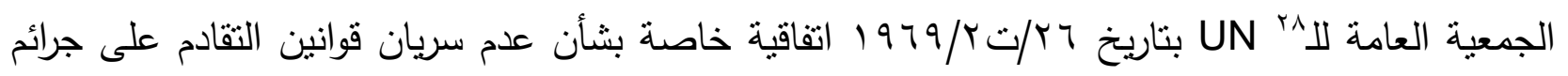

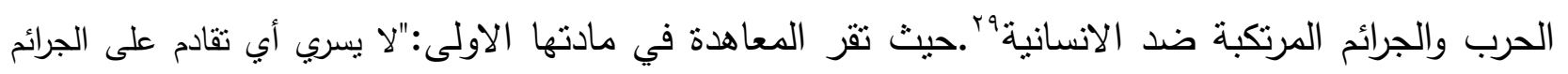

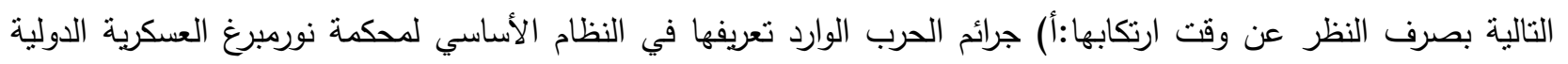

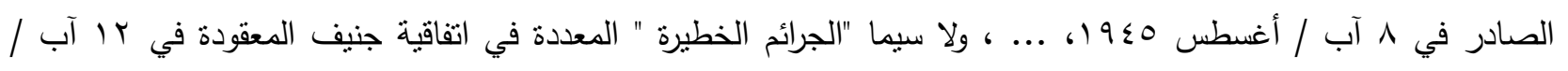

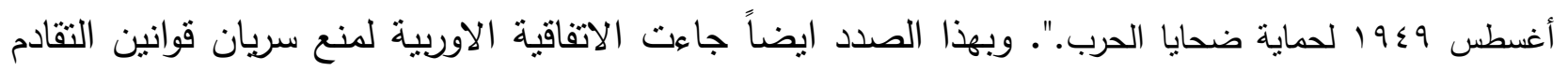

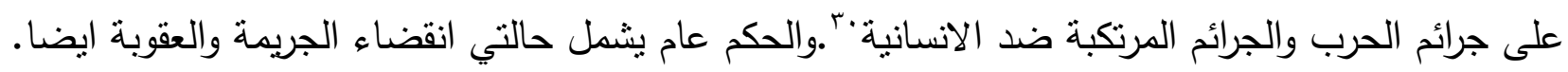
ومن الجدير بالذكر ان هذه القاعدة كرستها ممارسات دول عدة على صعيد القضاء والتشريع الوطني لتصبح

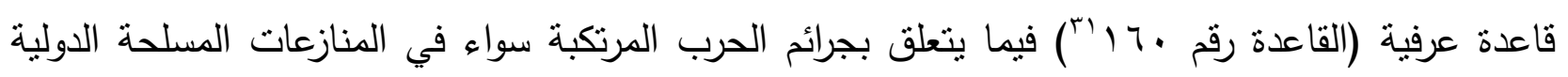

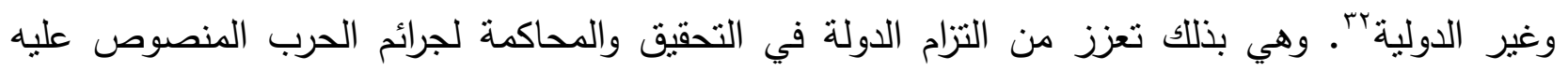

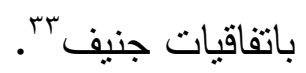


كما وتقرر مبدأ المسوؤلية الجزائية الفردية عن جرائم الحرب بعديد القواعد الاتفاقيةء والعرفية في القانون

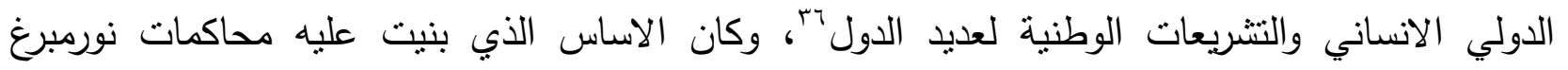

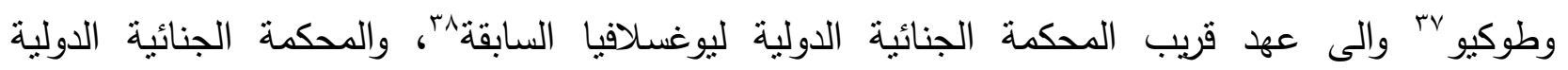

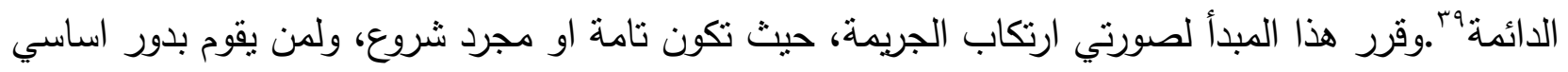

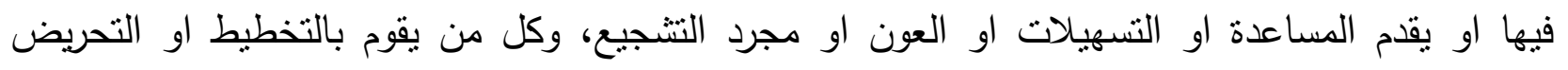
ايضاء‘؛ هذا وتستتبع المسؤولية الجزائية الفردية ليس فقط من يرتكب الفعل بل من بأمر بارتكابها من القادة.

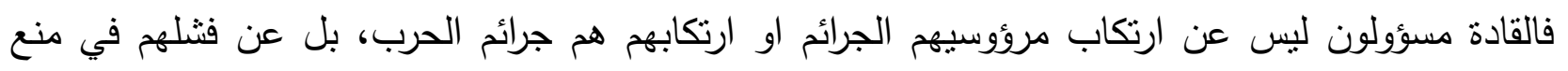

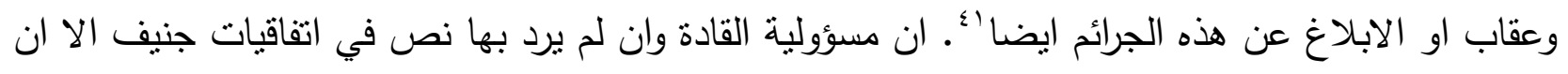

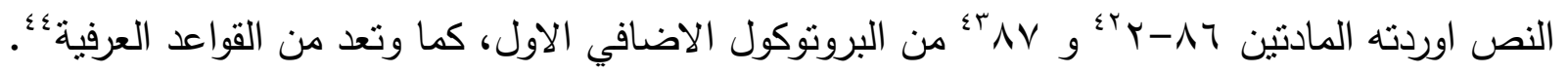
كما وتبدو العلاقة بين القانونين وثثقة الصلة فيما يخص المخالفات الجسيمة تحديداً وهو نطاق بحثنا فان

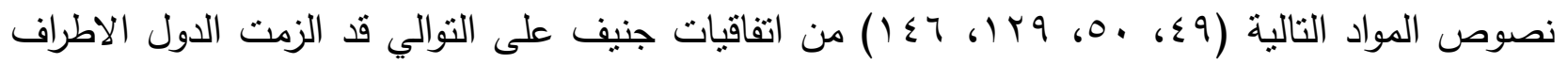

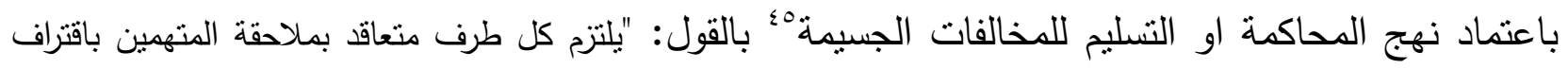
مثل هذه المخالفات الجسيمة أو بالأمر باقترافها، وبتقديمه إلى محاكمه، أياً كانت جنسيتهم. وله أيضاً، إذا فضل ذلإنك، وطبقاً

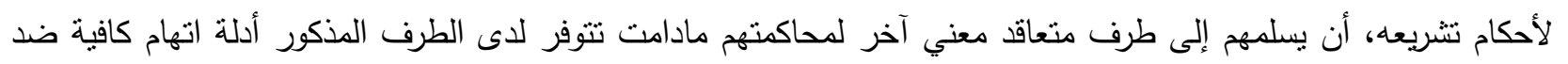

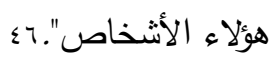

هذا وان خيار المحاكمة الذي اعتمدته اتفاقيات جنيف استتد فيه اساس الاختصاص من ضمن ما استتد اليه الى اختصاص هو اقرب الى الاختصاص العالمي V؛ وان لم تفصح عنه اتفاقيات جنيف بشكل صريح. فكما

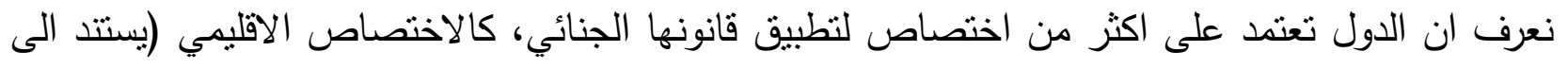

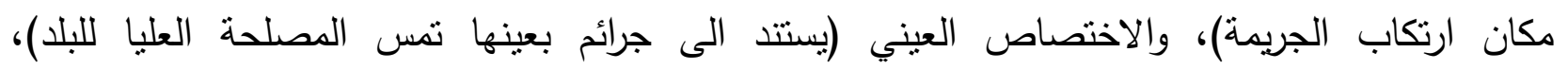

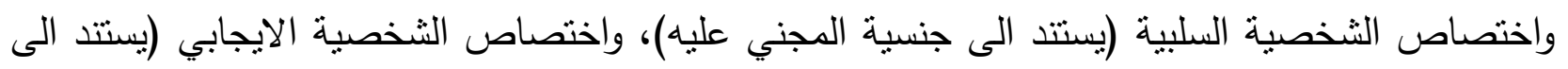

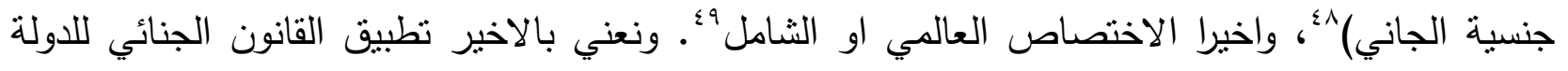

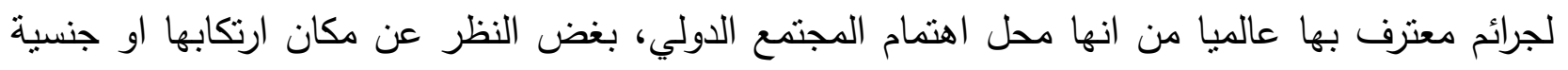

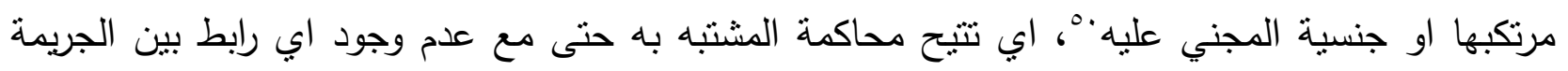

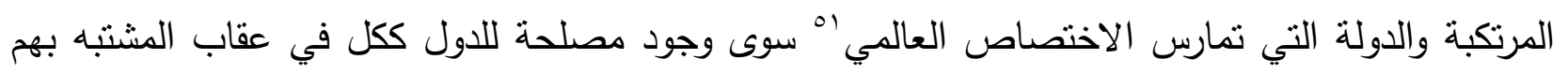

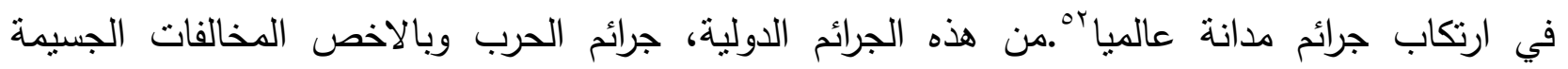

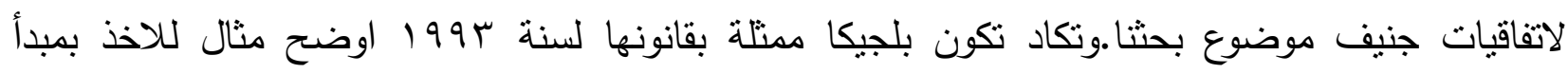

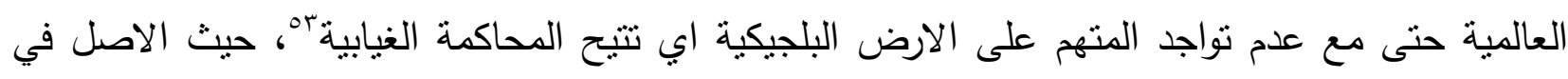


غالبية تطبيقات الدول لمبدأ العالمية هو في نواجد المتهم على ارض الدولة على اعتبار كونها نائبة عن

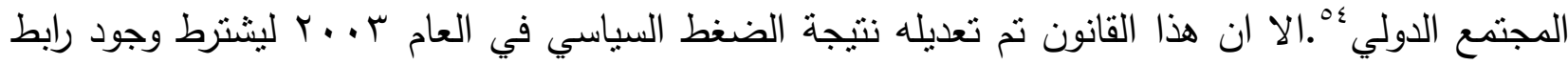
يتعلق اما بالثخصية الايجابية او السلبيةهْ. ان مناقشة مدى اخذ اتفاقيات جنيف بالاختصاص العالمي

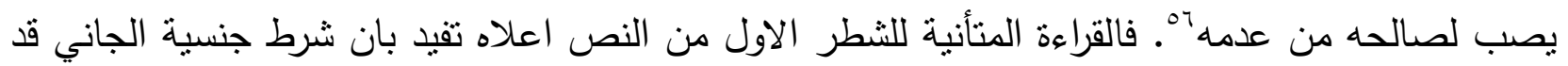

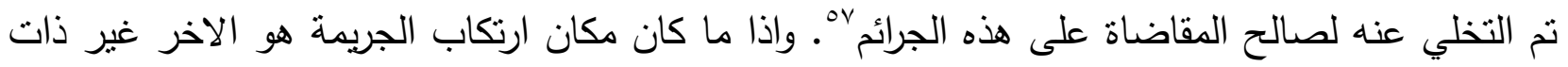
علاقة على اعتبار ان الدولة مرخصة اصلا لعقاب الافعال التي تشكل جرائم وترتكب على اراضيها دون اعتبار لجنسية المشتبه به استتادا لمبدأ الاقليميةهُه وانطلاقا من صلاحية الدولة لممارسة اختصاصها

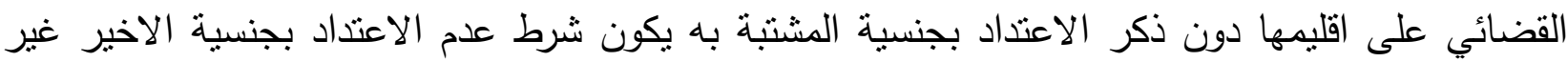

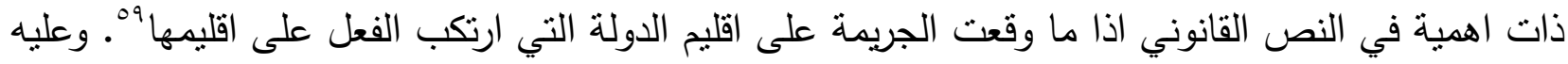

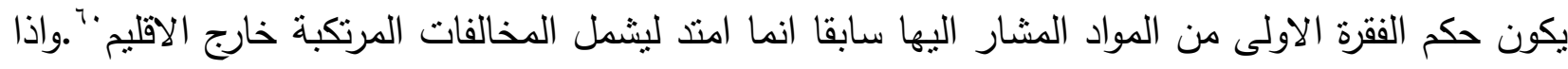
ما كانت جنسية المتهم غير ذات اهمية في حال ارتكاب الفعل خارج اقليم الدولة التي تقاضيه فان عدم

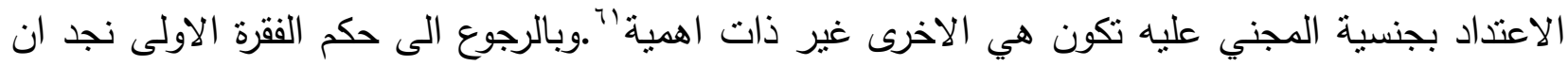
الالتزام بالمحاكمة لا يقتصر على الدول اطراف النزاع وانما هو حكم عام يمتد ليشمل كل الدول الاطراف في

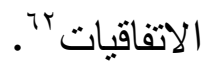

وفيما يتعلق بممارسة الدول لمبدأ العالمية بخصوص الجريمة الدولية نجدها تأخذ أحد اتجاهين:اما ان تتص عليه تتريعياً بسن قانون وطني (الاختصاص التشريعي العالمي)، او ان تعدد الى الاستتاد اليه عند اجراء

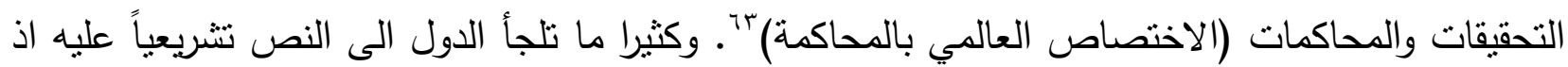
انه يمنل بنفس الوقت الاساس الذي تقوم عليه التحقيقات والمحاكمات، الا ان ذلك لا يمنع دولا اخرى من

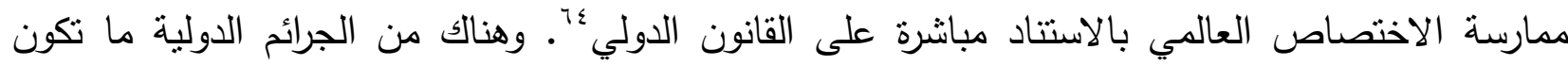
الدولة ملزمة بالاخذ بالاختصاص العالمي عند اجرائها للتحقيقات والمحاكمات او ما يكون مجرد خيار مناح

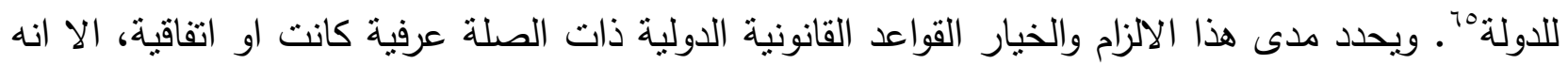

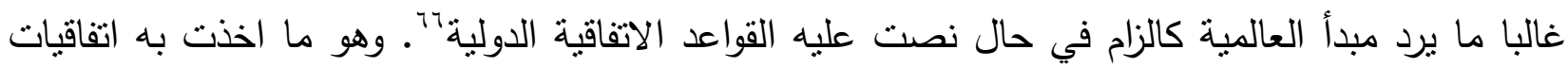

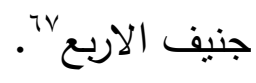

\section{المبحث الثاني: الموائمات التشريعية للمخالفات الجسيمة في النظم القانونية لدول العالم.}

تتص المادتين Tr و TV من اتفاقية فينا لقانون المعاهدات ^^ على حكمين: الاول بسمو القانون الدولي على القانون الداخلي والثاني على نرك مسألة كيفية ادماج احكام المعاهدات الدولية التي تبرمها الدولة للنظام 
القانوني لكل دولة. والدول فيما يخص المسألة الاخيرة لا تتبع نظام قانوني واحد مما يستتبع عدم اتباعها نهجاً

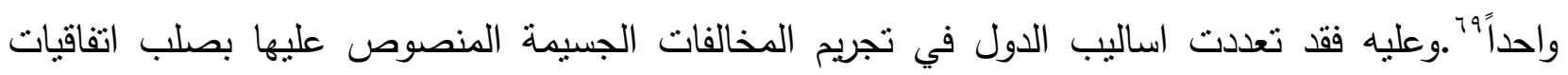
جنيف وهو ما سنتاوله في المطلب الاول من هذا المبحث ولكون اللجنة الدولية للصليب الاحمر هي الراعي

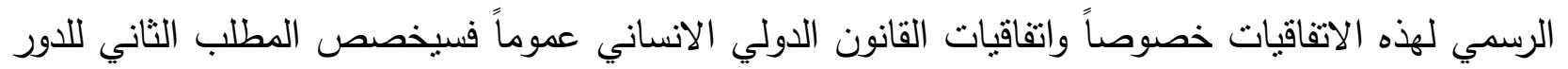
الذي تقوم به بصدد ادماج المخالفات الجسيمة في القوانين الوطنية.

\section{المطلب الاول/ اساليب الدول في تجريم المخالفات الجسيمة.}

جهد الفقه " واللجنة الدولية للصليب الاحمر "في اتباع تصنيف موحد الا ان الامر صعب ادراكه بسبب اختلاف كل من النظم القانونية لكل دولة اولاً وانظمة العدالة الجنائية الوطنية ثانياً. وبهذا الصدد نؤيد الرأي الأي الذاهب الى ان هذه الاساليب في مجملها تصب في نموذجين رئيسين هما اسلوب الاحالة الى احكام القانون

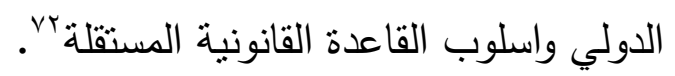

\section{اولاً: اسلوب الاحالة الى قواعد القانون الدولي الانساني.}

يفيد هذا الاسلوب بسن تتريع وطني من عدد محدود من المواد تجرم فيها المخالفات الجسيمة وتحدد فيها العقوبات المفروضة في حال ارتكابها، ويحيل في احكامه الى نصوص المعاهدات الدولية ذات الصلة اون

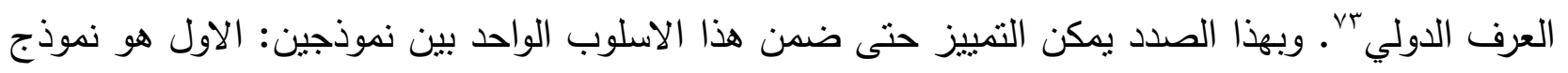

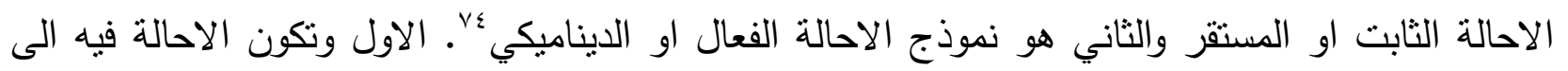

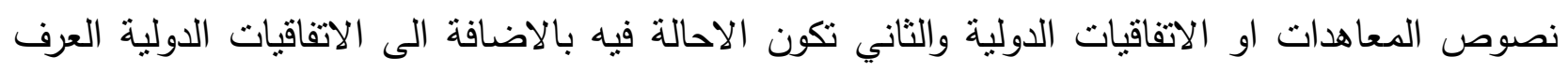

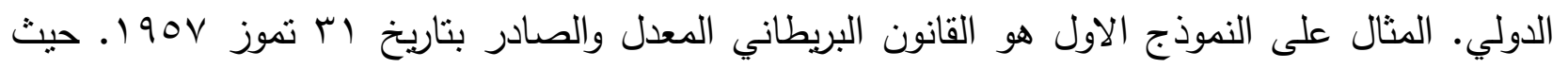

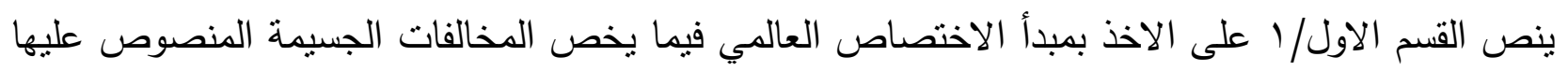
في اتفاقيات جنيف الاربع، ومحدداً نطاق من العقوبات المفروضة بهامش عريض. فئي حال ارتكاب القتل العمد فان العقوبة هي السجن مدى الحياة وفي حال ارتكاب المخالفات الجسيمة الاخرى فان العقوبة هي العي

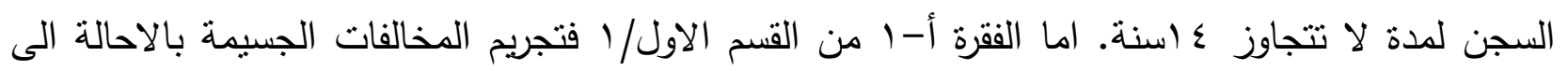

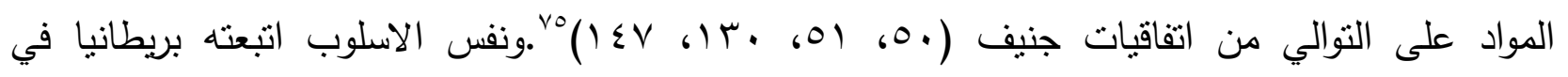

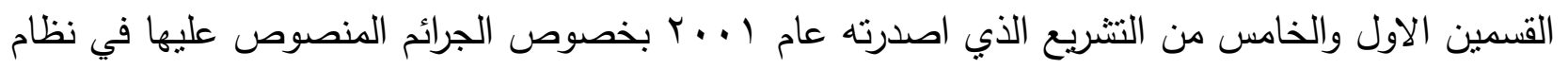
روما الاساس لانشاء المحكمة الجنائية الدولية، حيث تجرم جرائم الحرب والجريمة ضد الانسانية وجريمة

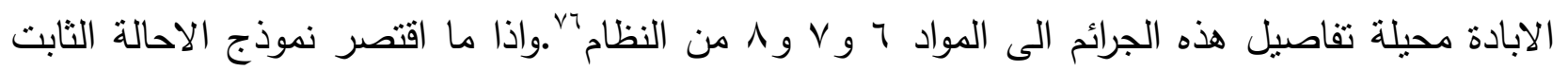


على الاحالة الى الاتفاقيات الدولية فان نموذج الاحالة الفعال او الديناميكي يحيل الى كل من القانون الدولي

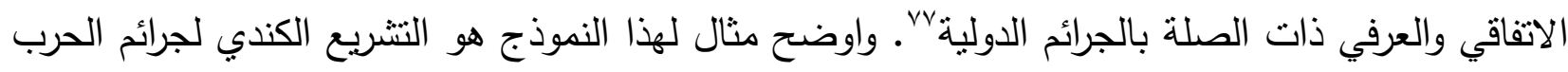

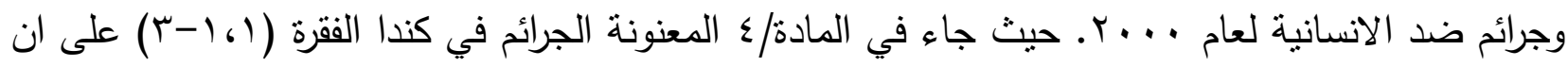

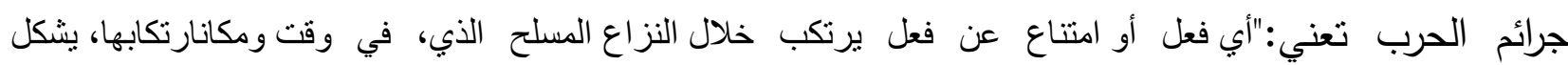

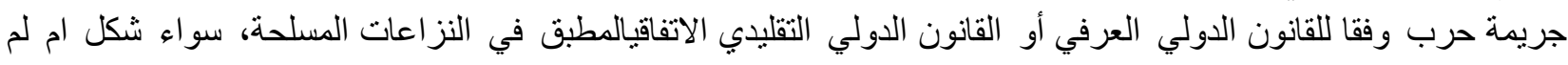

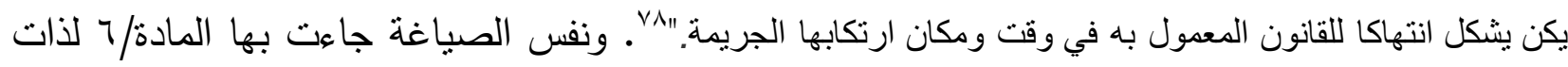

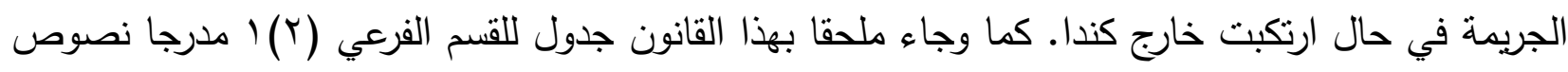

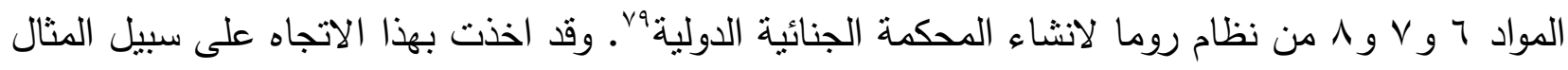

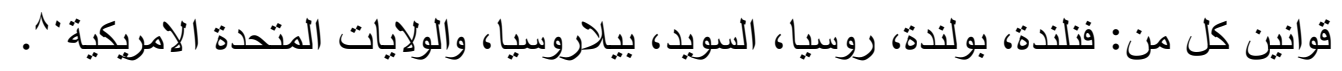
هذا ولكلا نموذجي هذا الاسلوب مميزات ومآخذ يمكن اجمالها عموما في الآتي:

المميزات: يتميز هذا الاسلوب بانه اقتصادي وبسيط، فكل ما يعمله هذا الاسلوب هو الاشارة الى النصوص

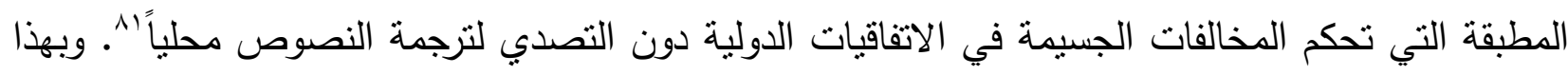
الصدد لا تعود هناك من حاجة الى سن تشريع جديد سواء عند تعديل احكام المعاهدة او انضمام دولة

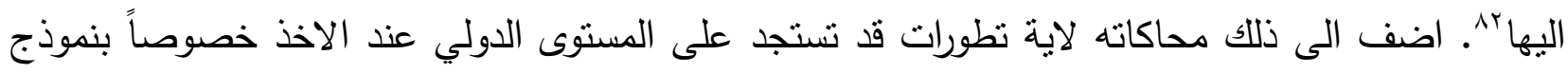
الاحالة الفعال.

المآخذ: تدور المآخذ حول انتهاك مبدأ الثرعية عند الاخذ بكلا المنهجين وان كانت احتمالية الانتهاك اكبر عند الاخذ بالاحالة الفعال ذلك انه يشير ليس فقط الى احكام الاتفاقيات الدولية وانما الى العرف الدولي التي

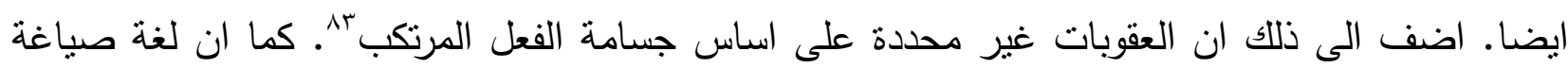
النصوص الدولية قد تثير هي الاخرى مشكلة فاللغة المعتمدة للاخيرة تختلف عن تلك المألوفة في نظام العدالة

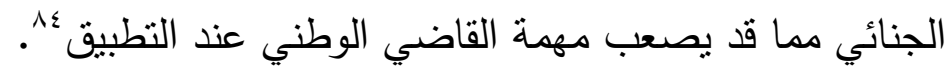
ثانياً: اسلوب القاعدة القانونية المستقلة.

يجد تجريم الانتهاكات الجسيمة حسب هذا الاسلوب اساسه في التشريع الوطني، اي اننا نكون امام قاعدة

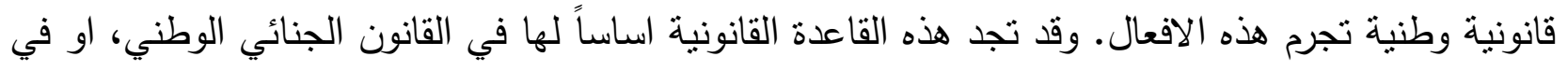

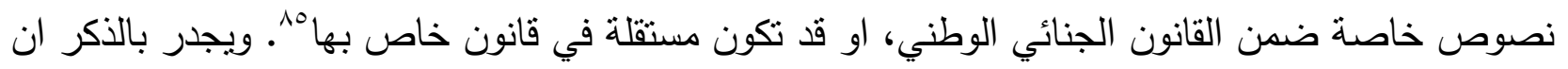


ان الاخير قد يتضمن بالاضافة الى تجريمه وعقابه للمخالفات الجسيمة على جرائم الحرب او الجرائم الدولية بشكل عام.

يفيد النموذج الاول والقاضي بان القاعدة القانونية المستقلة تجد اساسها في التشريع الجنائي الوطني العادي بكفاية القانون الجنائي الوطني لتجريم وعقاب اي فعل يدخل ضمن المخالفات الجسيمة. بمعنى ثانٍ لا حاجة لنصوص جنائية جديدة مع وجود نصوص محلية تمانل الافعال المجرمة في نصوص اتفاقيات جنيف. وعلى لئى

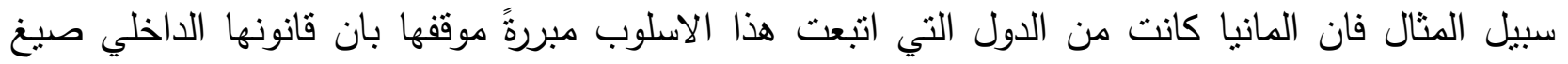

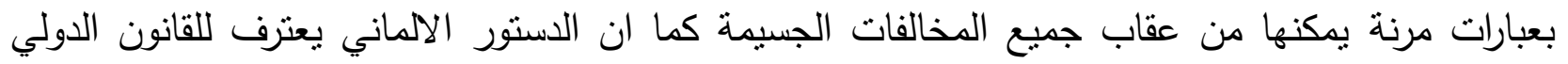

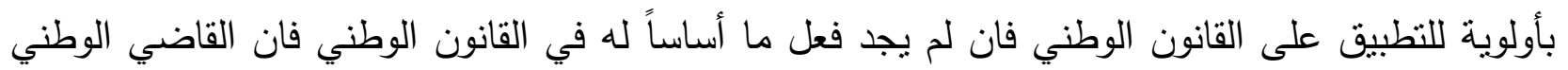

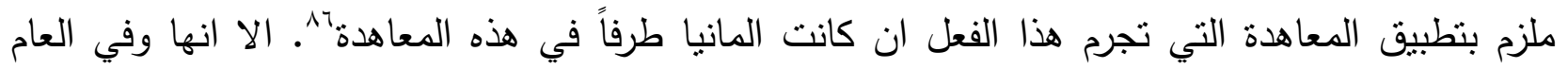

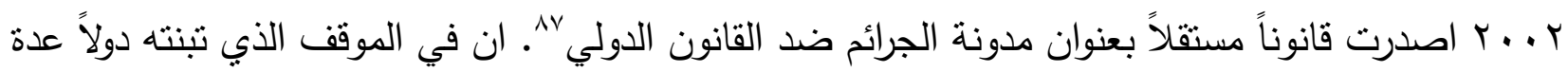

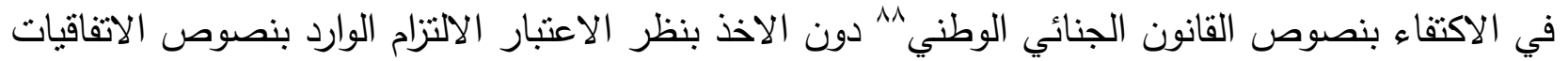

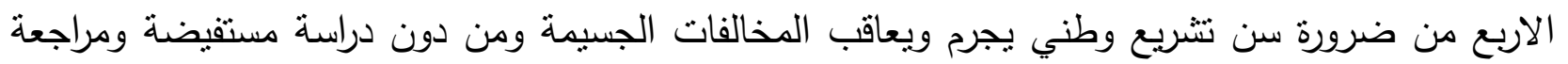

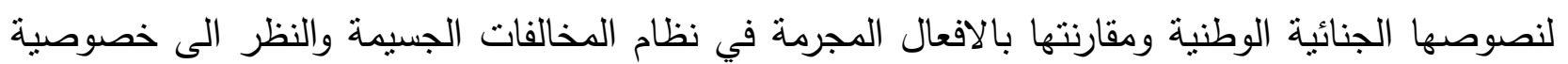
هذه المخالفات بارتباطها بالنزاعات المسلحة الدولية حيث ان الافعال المجرمة وفق القانون الجنائي الوطني قد بـان نص عليها بالاساس لتجرم وقت السلم لا الحربه^و وورود مصطلحات لا نجد لها نظيراً في القانون الوطني

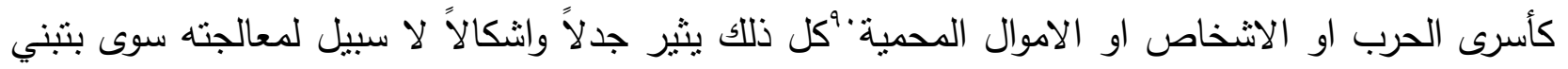
تشريع ينص على تجريم المخالفات الجسيمة.ومن الملاحظ بأنه وعلى الرغم من مميزات هذا الاسلوب بكونه سهل التطبيق من قبل الاجهزة القضائية الوطنية وان الافعال المجرمة فيه مستقرة في نظامها القانوني

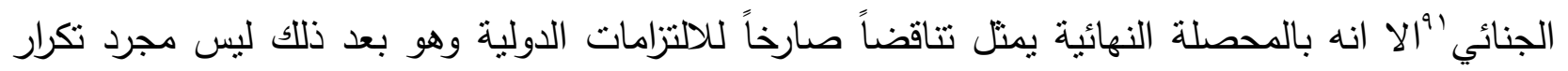
لافعال مجرمة في القانون الجنائي الوطني كما سنرى في الجزء التالي من هذا البحث عند نتاول ماهية

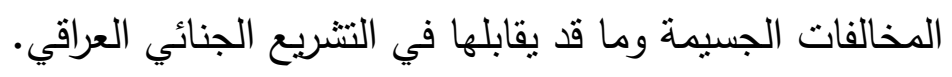

ان اتجاه الدول بالاكتفاء بتشريعاتها الجنائية الوطنية ادى الى ان يصدر المؤتمر الخامس والعشرون للصليب

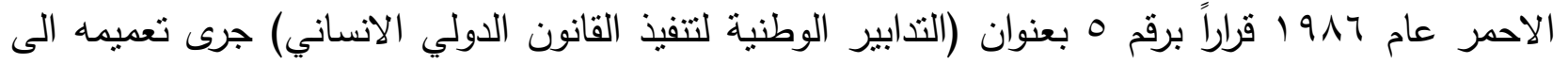

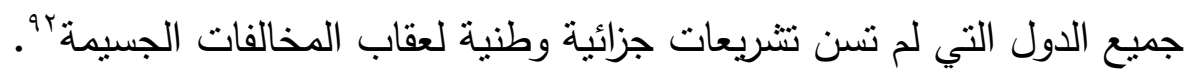

ويندرج تحت النموذجين الثاني والثالث صياغة نصوص خاصة بالمخالفات الجسيمة في قانون العقوبات او قانون العقوبات العسكري او قد تأخذ شكل قانون مستقل بذاته. وقد كان من بين عب دولة تمت دراستها بَّان 
V IV دولة فضلت خيار الادماج على سن تشريع مستقل (والحديث هنا عن الجرائم الدولية بشكل عام) واربعة دول فقط شرعت قانون مستقل؟؟. هذا وان عملية سن نصوص او تشريع خاص تتخذ احد طريقين: الطريق الاول وتقوم فيه الدولة بنقل قائمة الجرائم كاملة (المخالفات الجسيمة) الى القانون الجنائي الوطني بنفس لفن عبارات الصياغة التي وردت في الاتفاقيات الدولية مع ايراد عقوبات لهاه جريمة او وفق كل فئة من فئات الجرائم. اما الطريق الثاني فتعدد فيه الدولة الى اعادة التعريف او الصياغة

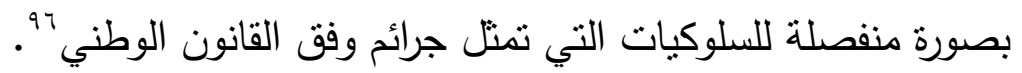

ان الجرائم بشكل عام والمخالفات الجسيمة بشكل خاص كما ترتكب من قبل المدنيين ترتكب من قبل

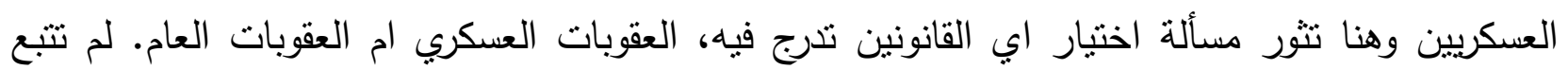

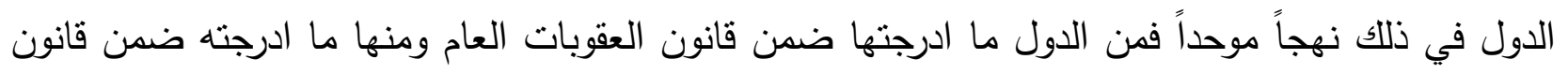

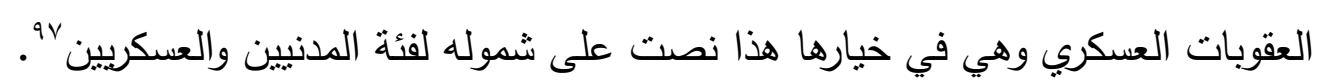

وكما لاسلوب الاحالة مميزات ومآخذ فان اتباع اسلوب القاعدة القانونية سواء بتضمين القانون الجنائي نصوصا تجرم المخالفات الجسيمة او بسن تتريع مستقل مميزات ومآخذ تكاد تتخلص في الاتي: المميزات: ان في تعريف وفصل الجرائم الدولية (المخالفات الجسيمة) عن الجرائم العادية يؤكد على طبيعتها

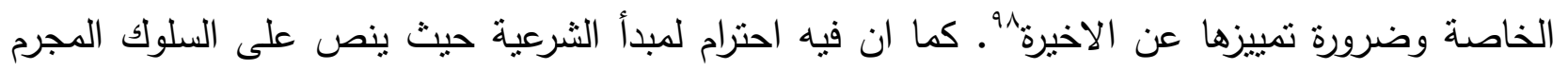
والعقوبة بنفس الوقت. ويعدد هذا الخيار الى تسهيل مهمة الاشخاص المكلفين بانفاذ القانون فلا تعود من

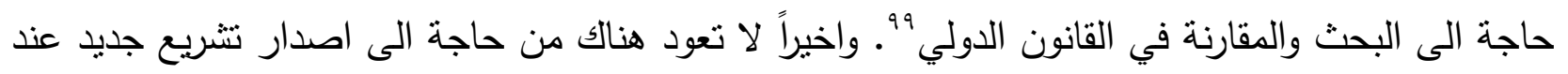

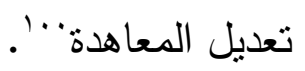

المآخذ: رغم مميزات هذان النموذجان الا انهما بنفس الوقت يثيران مسألة بغاية الاهمية في حال فضلت الدول

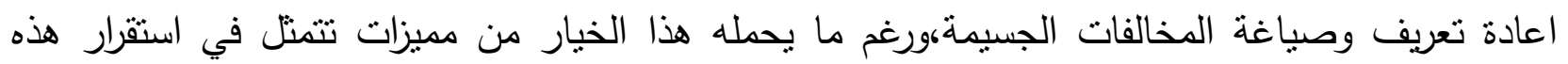

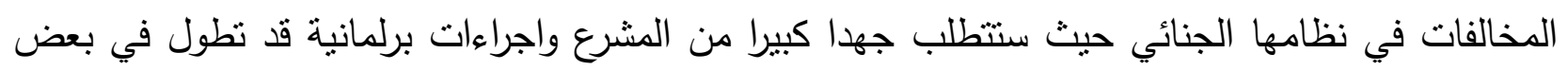
الاحيان وقد تستوجب تعديلات تشريعية في بعض القوانين ذات العلاقة كقانون العقوبات العام والعقوبات

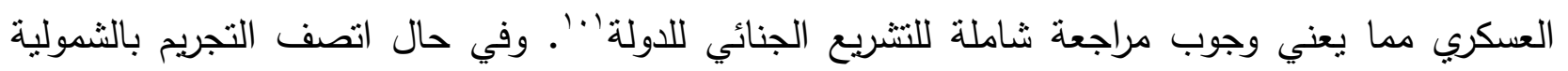

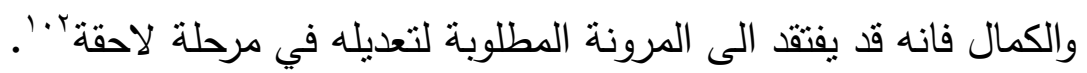

ان اعتماد نموذج او اسلوب معين لادراج المخالفات الجسيمة في اي نظام قانون وطني يعتمد والى حد كبير

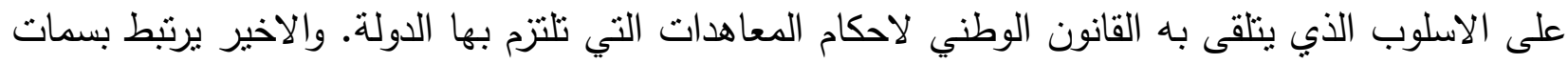


النظام القانوني لكل بلد وبامكانية التطبيق المباشر لاحكام المعاهدات من عدمه هذا اولاً، الدول التي تتبع نظام القانون المدني او القانون العامَّ'، وبمدى التطور القانوني للنظام القانوني بشكل عام والقانون الجنائي بشكل خاص الذي وصل اليه البلد ثانياً. فمن الدول ما لا تفضل خيار تشريع منفصل عن القانون الجنائي

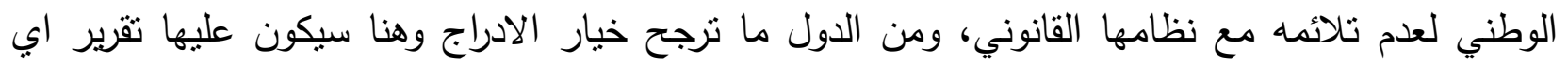
النموجين تعتمد الصياغة ام القائمة المفصلة. كما ويتعين عليها بعد ذللك تقرير اي القانونين تدرج فيه لونيه

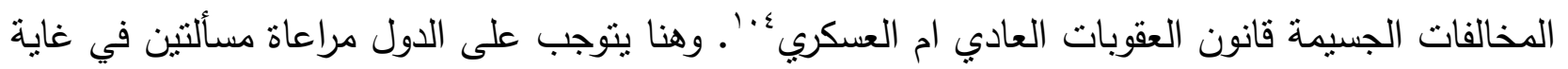
الاهمية: الاولى تتعلق بامكانية ارتكاب هذه المخالفات الجسيمة من قبل المدنيين والعسكريين على السواء، والثانية تخص مبدأ العالمية كالتزام مفروض على الدول الاخذ به عند ارتكاب الجريمة الدولية وخصوصاً في

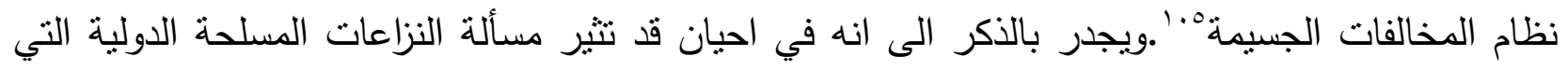

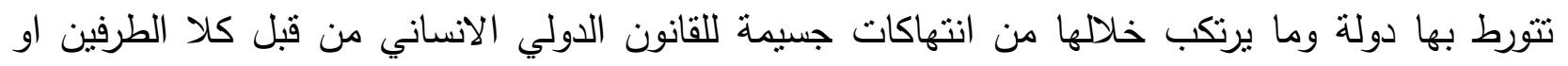
احدهما حافزاً للدولة يدفعها لادراج نظام المخالفات الجسيمة ولاعنماد نموذج معين من احد الاساليب المذكورة

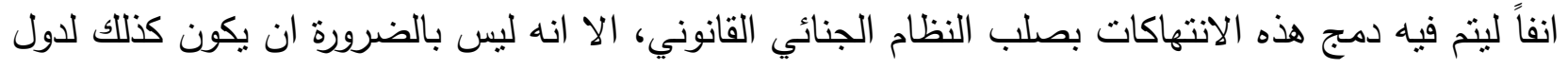

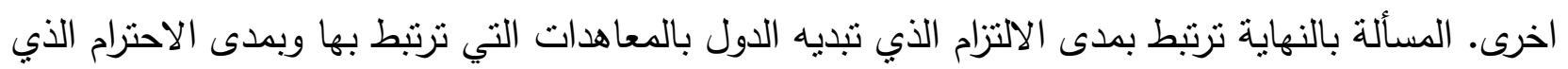
تبديه تجاه تعاقداتها دولياً ووطنياً.

\section{المطلب الثاني/دور اللجنة الدولية للصليب الاحمر في الموائمة التشريعية للمخالفات الجسيمة في التشريعات الوطنية.}

ان الحديث عن المؤائمة التشريعية لنظام المخالفات الجسيمة في القوانين الوطنية بستدعي الحديث بالضرورة عن اللجنة الدولية للصليب الاحمر كراعي لاتفاقيات جنيف وبروتوكوليها الاضافيين ايضا. وفي خطوة محسوبة كانت نتيجة لتهاون الدول في التزاماتها الوطنية المنصوص عليها بالاتفاقيات انثأت اللجنة الدولية للصليب الاحمر قسم الخدمات الاستثارية من اجل متابعة ومد يد العون للاول بتقديم المشورة القانونية وتبادل

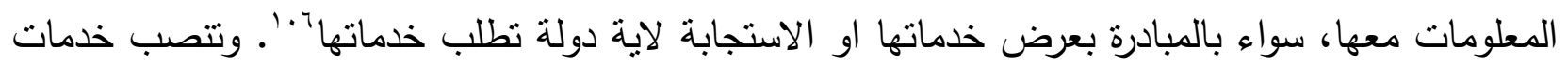

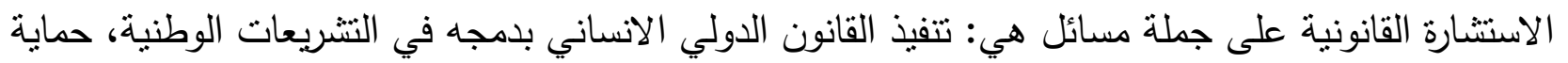

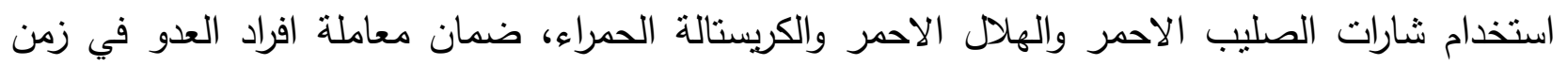

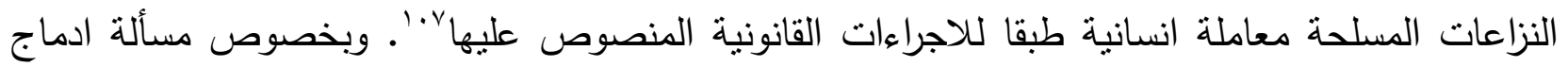
القانون الدولي الانساني وطنياً ونظراً لما تتمتع به اللجنة الدولية من موارد بشرية ومالية فقد وضعت ولتهاعة وحدة

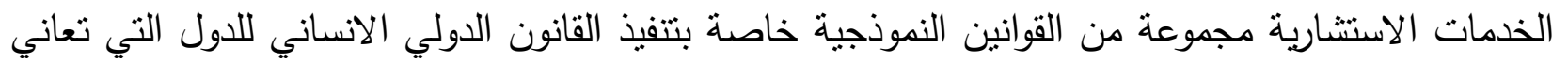


من نقص او غياب في مواردها المالية وخبراتها القانونية^’'. وفي مجال التنفيذ على الصعيد الوطني شجعت

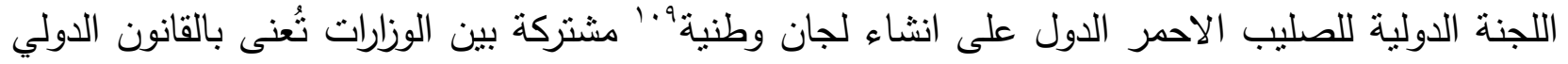

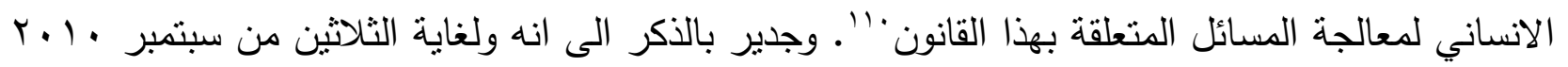

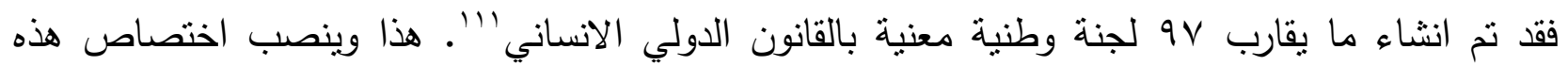
اللجان التي يجب ان تكون مرتبطة بالسلطة التنفيذية على عدد من المهام منها على وجه الخصوص لا لا

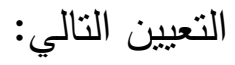

$$
\text { ا ـ ادراج احكام معاهدات القانون الدولي الانساني في القانون الوطني. }
$$
r. اعداد كافة التدابير التشريعية او القانونية او الادارية اللازمة للتطبيق الفعال ومن ثم احترام قواعد

$$
\text { القانون الانساني. }
$$

r. اعتماد التشريعات الملائمة التي تتص على قمع المخالفات الجسيمة للقانون وتتظيم شارات الصليب

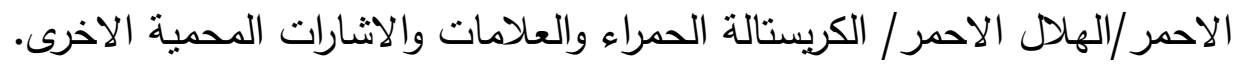
ع. اعتماد لوائح لتحديد وضمان وضع الاثخاص المحميين بموجب احكام القانون الدولي الانساني وكفالة احترام الفرد والضمانات الاساسية في اوقات النزاع المسلح. ه. تدريب وتعيين موظفيين مؤهلين في مجال القانون الانساني، لاسيما مستشارين قانونيين للقوات المسلحة. 7. تحديد اماكن المواقع المحمية بموجب القانون الدولي الانساني ووضع علامات عليهاج" . هذا ولكل دولة الحرية في اضافة مهام اخرى لهذه اللجان الوطنية، اخذاً بنظر الاعتبار ان عملية تتفيذ القانون الدولي الانساني لا تقتصر على مجرد سن التشريعات وانما هي عملية مستمرة تشمل رصد وتطبيق القانون

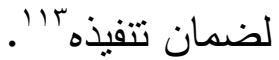

وفي معرض حديثنا عن اللجنة الدولية للصليب الاحمر واللجان الوطنية لتنفيذ القانون الدولي الانساني لا يفوتتا ان نتحدث عن الجمعيات الوطنية ممثلة بالهلال الاحمر او الصليب الاحمر ودورها في الموائمة التشريعات لقواعد القانون الدولي الانساني من عدة نواحي، أهمها: (توعية السلطات الوطنية بالحاجة الى الى تتريعات لتنفيذ القانون، وضع مشاريع قوانين وطنية او التعليق على اخرى قائمة او جديدة تصوغها السلطات الوطنية، التشجيع على ادراج واعتماد قوانين لتنفيذ القانون \&ُ" ل). 
المبحث الثالث:المعالجة التشريعية للمخالفات الجسيمة في قانون العقويات وقانون العقويات العسكري العراقي.

ونعني بالمخالفات الجسيمة اي من الافعال المدرجة ادناه اذا ما ارتكبت وكان لها علاقة بنزاع مسلح دولي

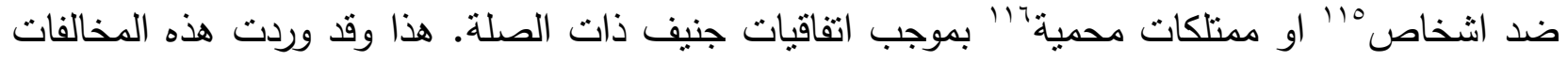
على سبيل الحصر ، كما وانها استتاداً لاحكام الاتفاقيات من المواد التي تتطلب اعتماد تدابير تشريعية لتتفيذها

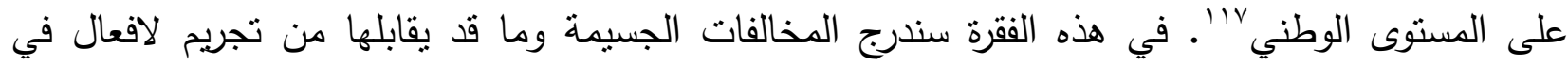
التشريع الجنائي العراقي تعد من وجهة نظر السلطة التشريعية مستوفية للالتزام القاضي بسن تشريع يجرم المخالفات الجسيمة لكونها لم تتخذ اي اجراء منذ التصديق على الاتفاقيات الاربع.

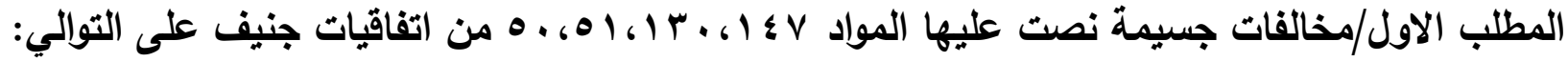

1- القتل العمد: ويأتي هذا الفعل في مقدمة الافعال التي جرمتها الاتفاقيات الاربع لمساسه بحق جوهري

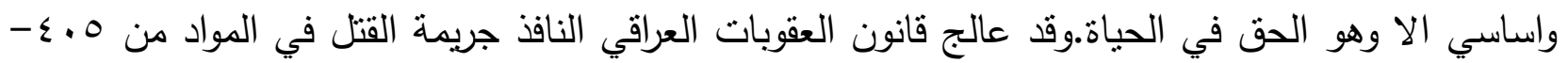

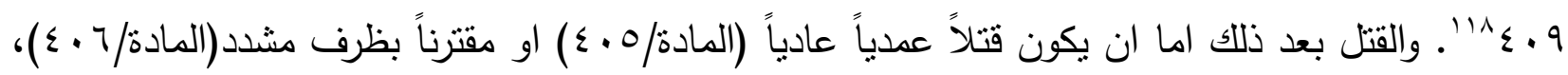

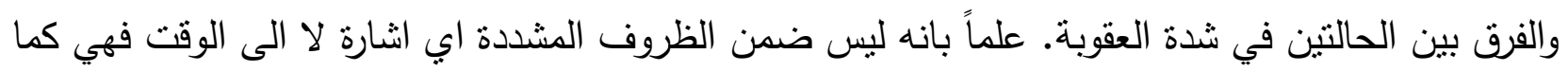

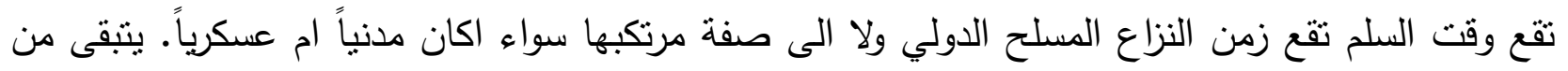
القتل العدد حالتين: الاولى القتل بدافع الثفقة والثانية مساعدة انسان على الانتحار ـ. والحالتين يحتمل وقوعهما في ميادين القتال واثثاء النزاع المسلح الدولي. لم يعالج قانون العقوبات العراقي النافذ القتل بدافع الثفقة وبالتالي فهو قد يقع ضمن القتل العدد حسب القواعد العامة.اما مساعدة انسان على الانتحار فقد عالجته

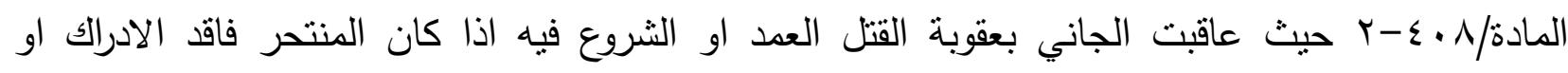
الارادة. وعليه فمن الممكن عد الحالة الاخيرة ضمن المخالفات الجسيمة. اما قانون العقوبات العسكري النافذ

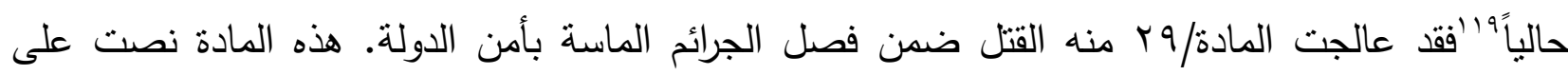

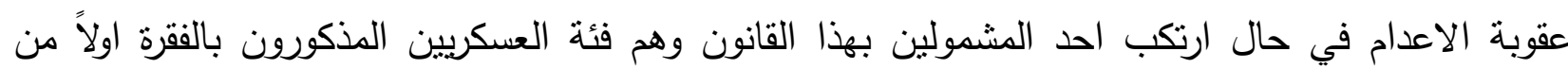

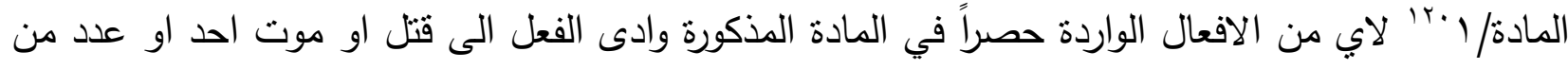

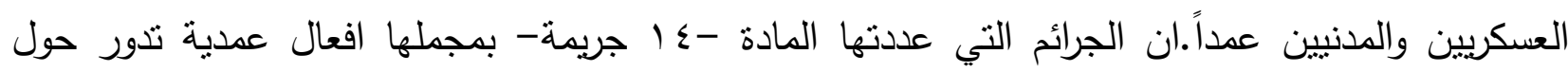
معاونة العدو او الاضرار بالجيش الوطني او القوات الحليفة له. الاضافة التي حققتها المادة هي انها نصت

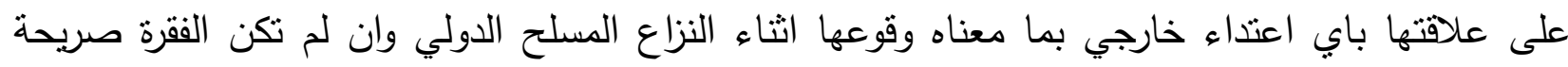
وموفقة. كما ان العموم الذي ادرج بنهاية مقدمة المادة الدذكورة في عدم تحديدها للمجني عليهم من عسكريين 
ومدنيين كان مستحسناً من اجل توسيع نطاقها الى مدني وعسكري القوة المعادية فالمطلق يجري على اطلاقه. وبشكل اكثر تحديداً جاء الفصل التاسع بعنوان الجرائم المرتكبة على النفس او المال في اثثاء النفير العام حيث نصت المادة/ (T-V على حالة استعمال القوة والتي تؤدي الى موت المجني عليه. وهنا ايضاً دونما تحديد للمجني عليه سواء كان من مواطني الدولة او مواطني دولة حليفة او معادية. واخيراً بطرح السؤال

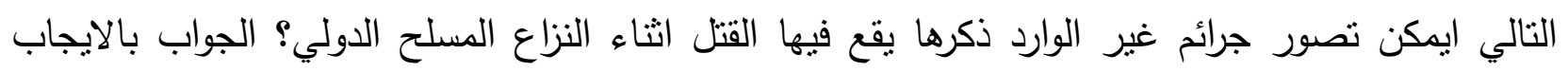
والمثال عليها: قتل المدنيين والاشخاص العاجزين عن القتال الذين هم تحت سلطة طرف في النزاع الغير مبرر بموجب قواعد ادارة العمليات، والاخير يمكن ان ينتج عن هجوم مباشر على مدني او من هجوم

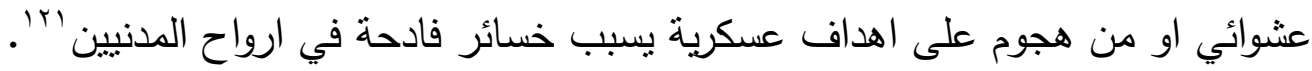
r- التعذيب او المعاملة اللاانسانية: يعرف التعذيب على انه الحاق "ألم شديد أو معاناة شديدة، جسدياً أو عقلياً" بغرض "الحصول على معلومات أو اعترافات، أو انزال عقوبة، أو الترويع، أو الاكراه، أو لأي

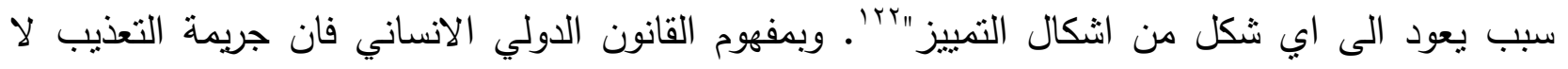

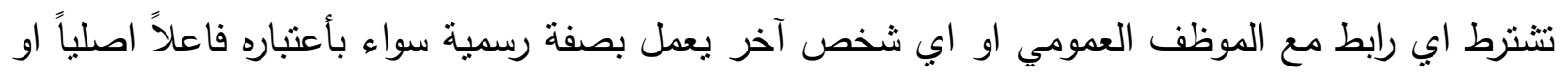

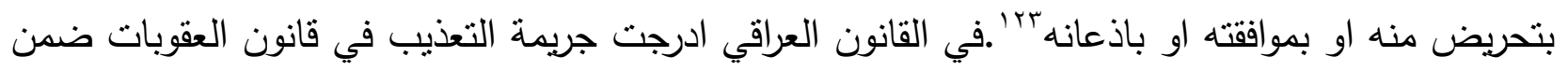

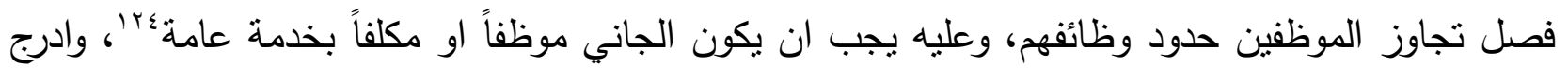

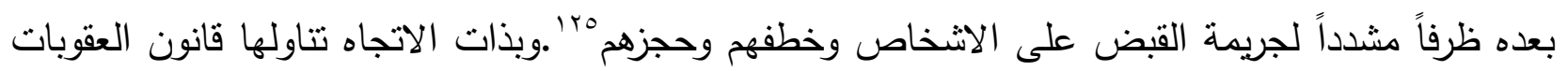
العسكري النافذ حيث نص عليها ضمن فصل تجاوز حدود الوظيفة اي ضمن نطاق منتسبي القوات المسلحة

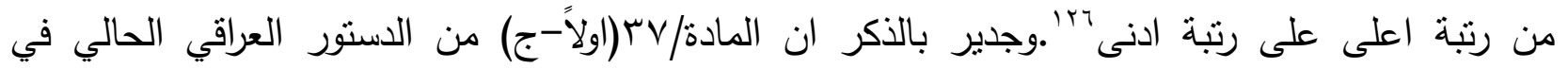

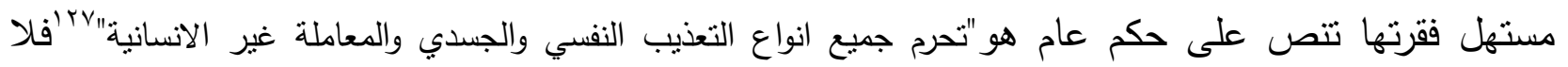

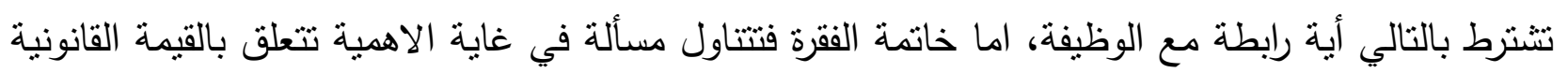
للاعتراف المنتزع بالتعذيب في اهداره وعدم الاعتداد به "ولا عبرة باي اعتراف انتزاع بالاكراه او التهديد او التعذيب". الثطر الاول لم يتم تقنينه لحد كتابة هذا البحث بتحرير جريمة التعذيب من رابط الوظيفة او الصفة الرسمية

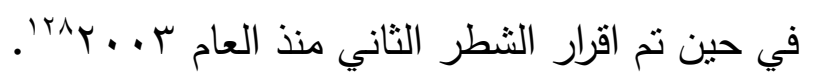

اما المعاملة اللاانسانية فتعرف على انها الحاق "ألم شديد أو معاناة شديدة، جسدياً أو عقلياً"ها والفعل بعد ذللك مطلق من حيث انتفاء شرط وجود غرض محدد لهذه المعاملة كما هو الحال في التعذيب. ومثالها: سوء

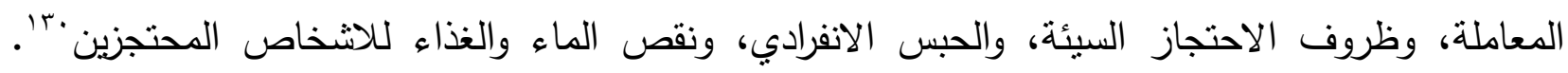

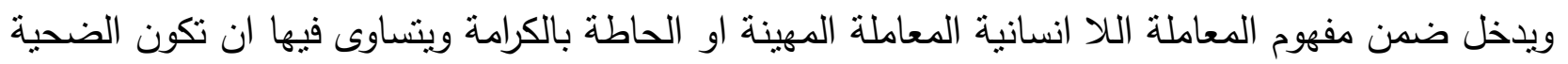


شخصاً مدركا وواعياً او شخصاً فاقداً لادراكه ووعيه او ميناً، ومثالها: اجبار المحتجز على القيام بأمر ما رغم

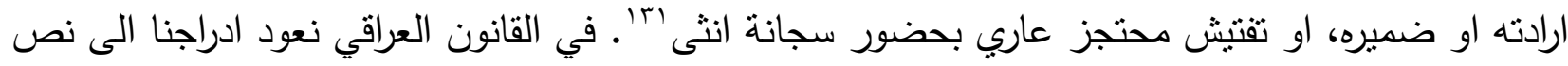
المادة/rTr من قانون العقوبات العراقي بالقول: "كل موظف او مكلف بخدمة عامة استعمل القسوة مع احد من الناس اعتماداً على وظيفته فاخل باعتباره او شرفه او احدث الماً ببدنه". رغم انتفاء شرط الغرض الا انها ابقت على رابط الموظف او المكلف بخدمة عامة. السؤال الذي يطرح نفسه بشدة هل القسوة تتدرج ضمن المعاملة اللا انسانية

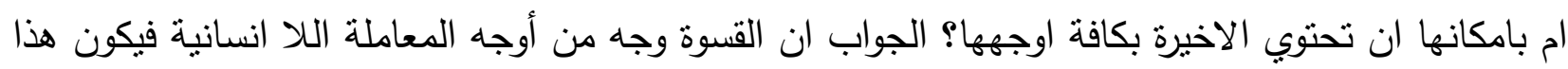
النص قاصراً عن استيعاب كل افعال المعاملة اللا انسانية.

r-حظر اجراء التجارب البيولوجية:كرد فعل على التجارب الطبية التي طالت الالاف من المحتجزين اثثاء الحرب العالمية الثانية ادرجت كأحدى المخالفات الجسيمة. وحظر اجراء التجارب الطبية أو العلمية

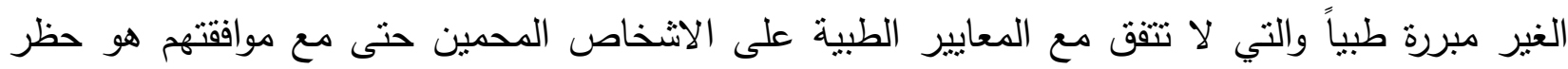

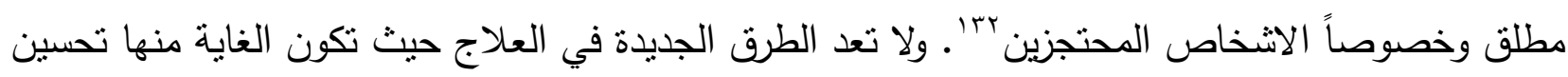

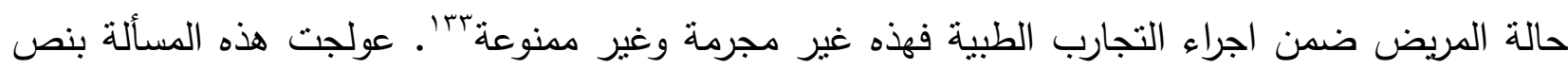

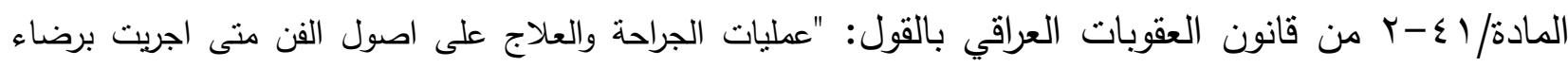

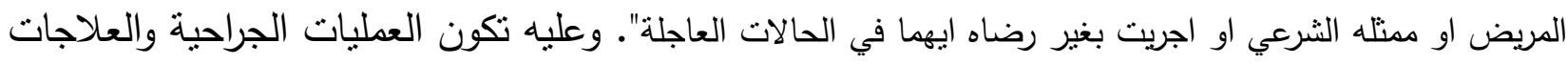
الطبية غير المنطبقة على اصول الفن، أو التي تجرى بغير رضى المريض او ممثله الثرعي، وغير العاجلة

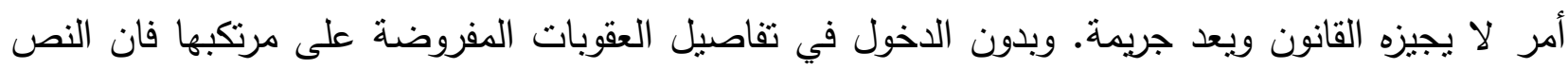
قاصر عن استيعاب التجارب الطبية وان قيل في احيان بتمانل الاثر الناتج عن كلاهما الا ان معناهما الفني غير متطابق مما يقتي معالجة هذا الامر تشريعياً. ـ - التسبب عمدا في احاث معاناة شديدة: ه- الاضرار بالسلامة البدنية او بالصحة:

المخالفتين الرابعة والخامسة قصد بها واضعو الاتفاقيات الاربع الى تجريم افعال لا نبلغ من الجسامة درجة التعذيب او المعاملة اللا انسانية ولكن من شأنها ان تؤثز على اللياقة البدنية او صحة الجرحى او المرضى الهی

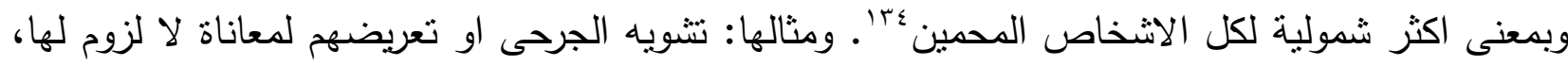

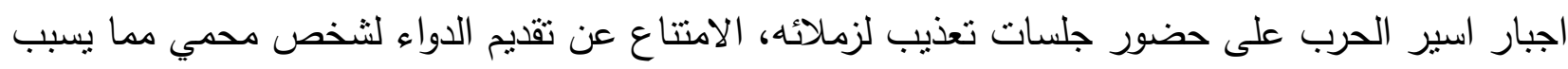

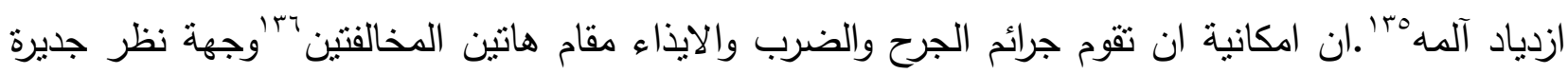

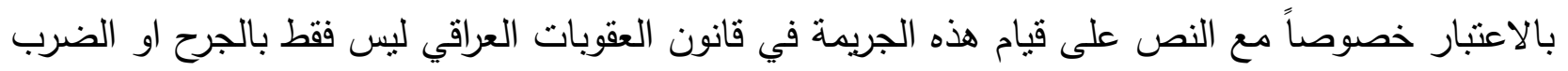


وانما بالعنف او اعطاء مادة ضارة او بارتكاب اي فعل آخر مخالف للقانون المواد(ץ (ـ-0 1؟). الا ان اتجاه اتفاقيات جنيف في الاخذ ليس بتعداد افعالٍ كالجرح او الضرب او سواهواه وانما في تجريمها لافعال

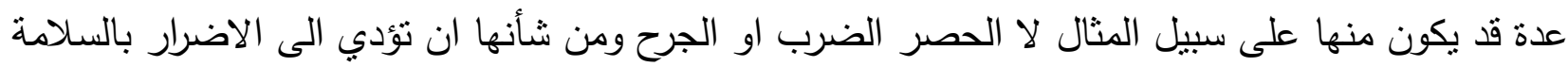

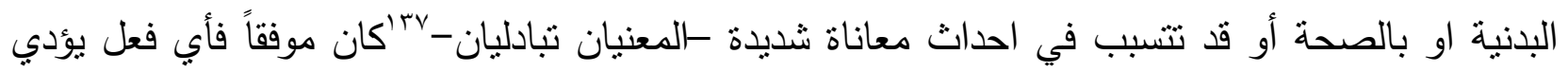
الى الاضرار بالسلامة البدنية او الصحة يفي بغرض التجريم دون الخوض في تعداد الافعال هذا من ناحية.

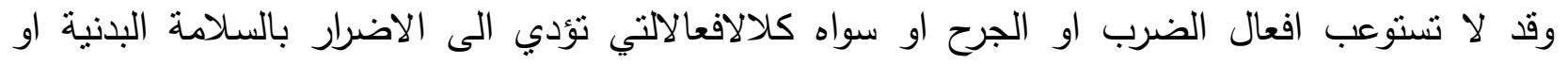
بالصحة او تتسبب في احداث معاناة شديدة من ناحية اخرى وليتسبب بالنهاية في تضييق نطاق التجريم.

צ- تدمير الممتلكات او الاستيلاء عليها على نطاق واسع من دون مبرر يتعلق بالضرورة العسكرية،

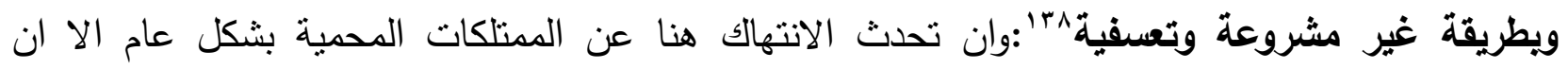
التعليقات اثارت على وجه الخصوص الى المستشفيات المدنية ومتعلقاتها، سيارات الاسعاف، والطائرات

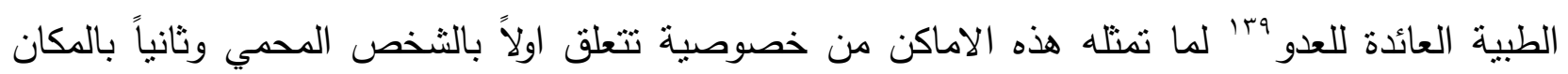

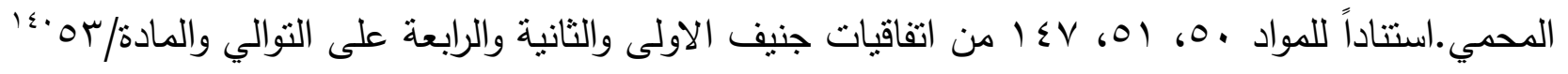

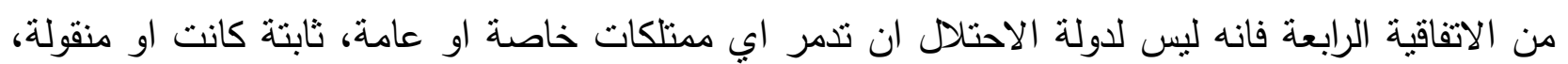

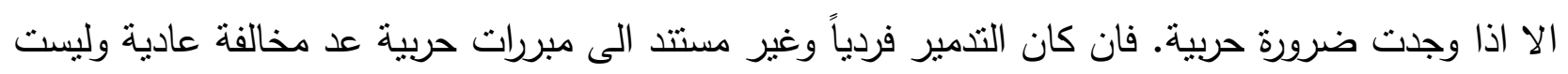

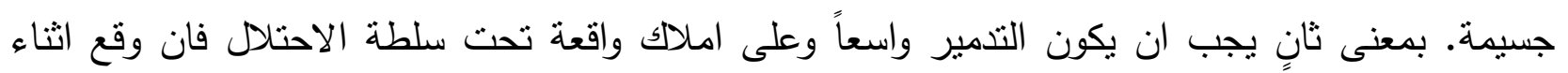

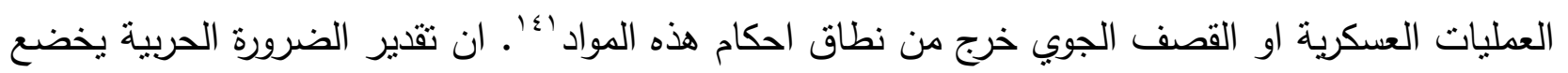

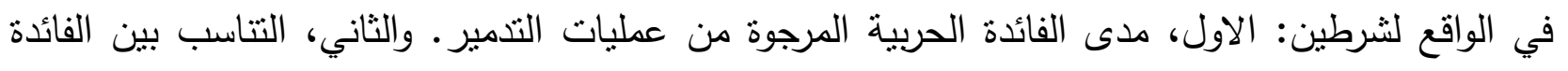

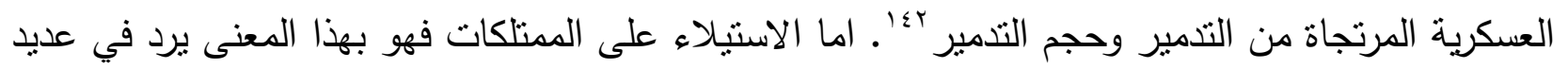

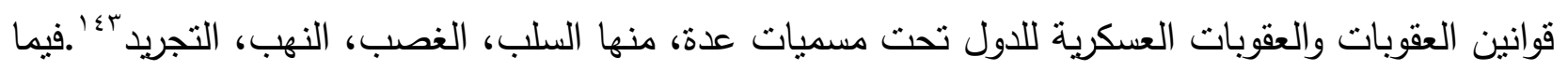
يتعلق بالتذمير والذي هو لفظ اعم وانشمل من الاتلاف او التخريب الذي نص عليه قانون العقوبات العسكري العراقي النافذ حالياً في المادة/(آ تحت بند الفصل التاسع (الجرائم المرتكبة على المال او النفس في الثاء

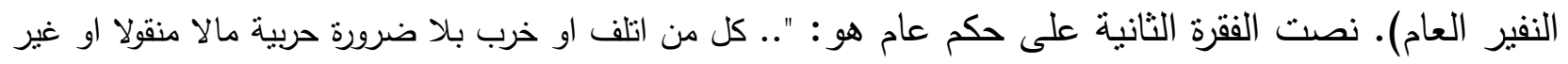

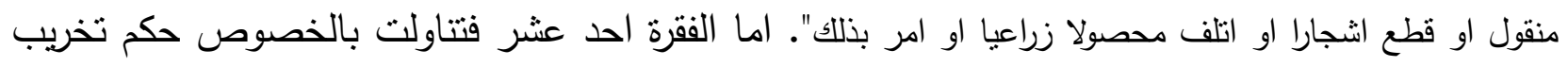

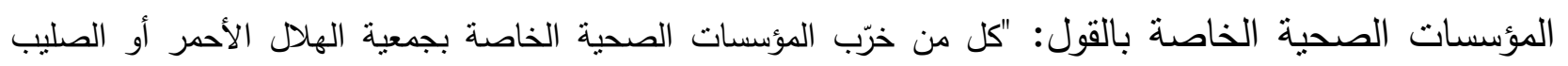

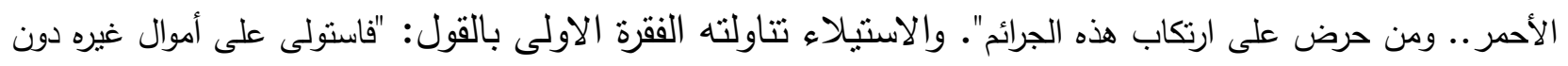

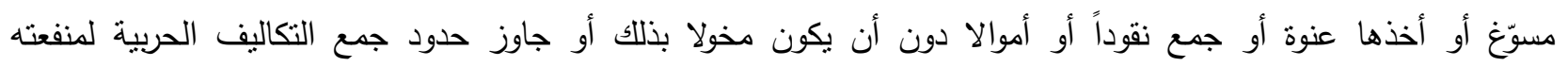

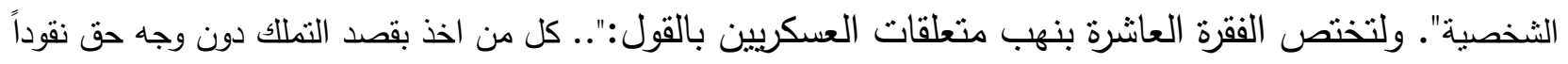


او اثياء من القتلى في ميادين التنال او الجرحى في اثناء السير او في المستثفى او في اثثاء القتال او اخذ اموال الاسير

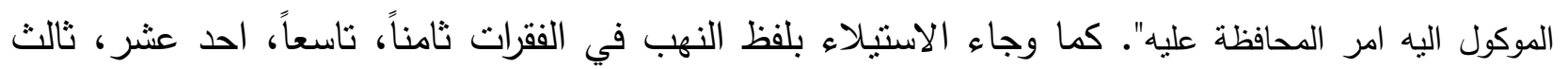
عشر . اما قانون العقوبات الحالي فعد ظرف الحرب ووقوع السرقة على الجرحى حتى من الاعداء ظرفاً مشدداً

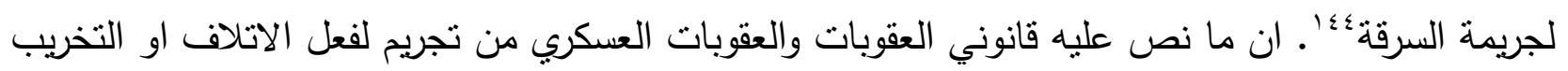

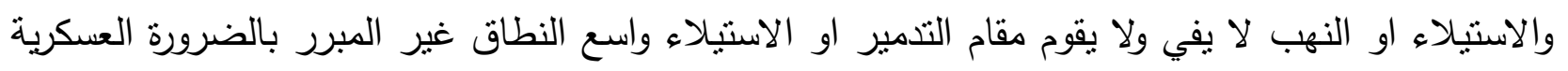

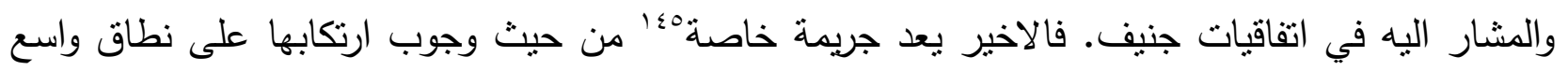

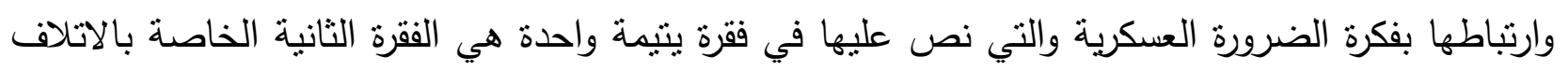
او التخريب الا انها لا تفي باي شكل من الاشكال بمتطلبات تجريم هذه المخالفة الجسيمة.

المطلب الثاني/ مخالفات جسيمة نصت عليها المادتان • ب ا و \& I من اتفاقيتي جنيف الثالثة والرابعة على التوالي: على

1-ارغام اسرى الحرب او المدنيين المحمين على الخدمة في القوات المسلحة لدولة معادية:تختص

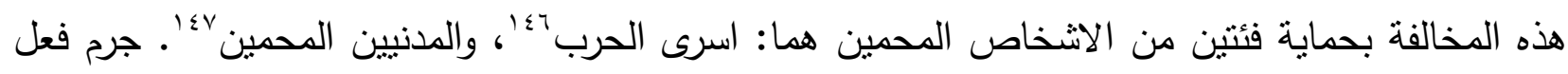
اكراه مواطني الطرف الاخر على الاتشتراك في عمليات الحرب ضد بلدهم بلأحدة الحرب البرية الملحقة

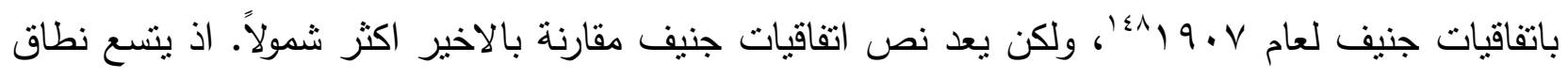
المادة ليشمل حالات الاكراه على الخدمة في القوات المسلحة المعادية، من الخدمة كجندي الى الخدمة كعميل

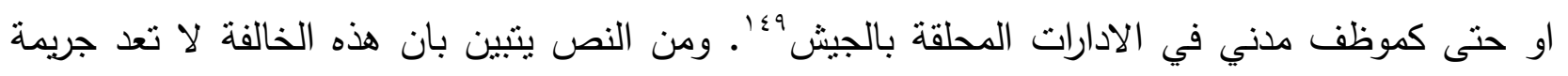

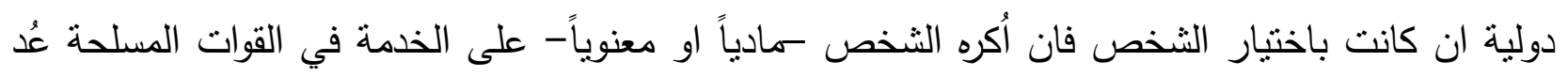

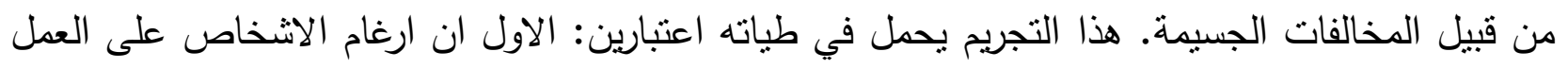

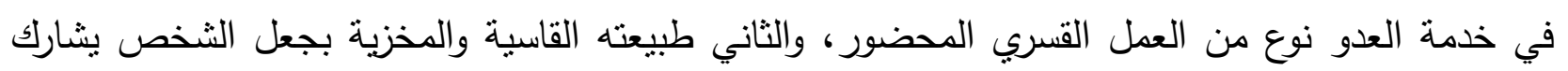
قسراً بالعمليات العسكرية ضد بلده سواء دفع له اجر ام لم يدفع مُ . ومن الجدير بالذكر ان لقوات الاحتلال

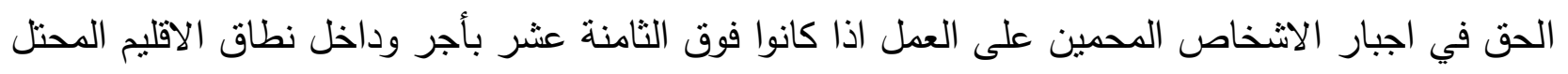

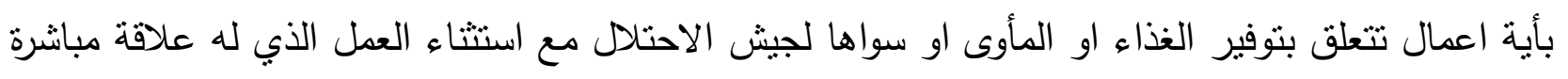

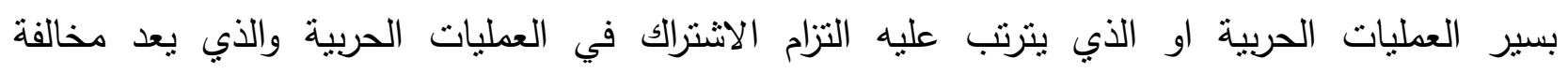

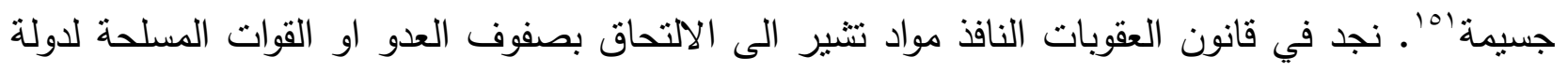

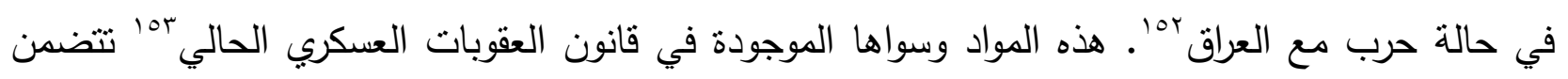
الالتحاق طوعاً وليس كرهاً مما يخرجها من نطاق تجريم هذه المخالفة الجسيمة. 
ץ-تعمد حرمان اسرى الحرب او الاثخاص المحمين من حقهم في الحصول على محاكمة عادلة وقانونية وفق الاحكام الواردة في الاتفاقيات: لاسرى الحرب فصل كامل في الاتفاقية الثالثة بتتاول العقوبات

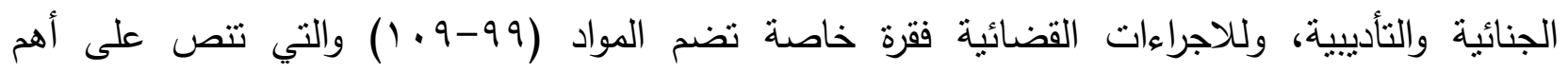

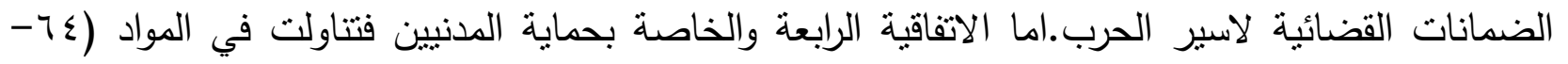

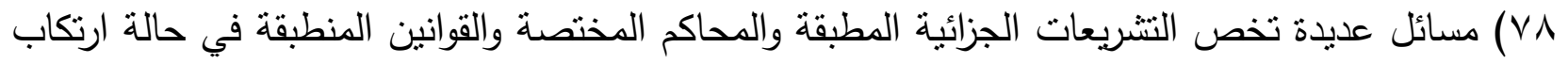

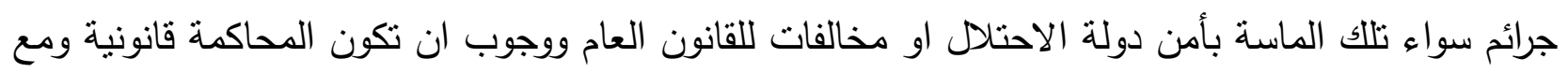

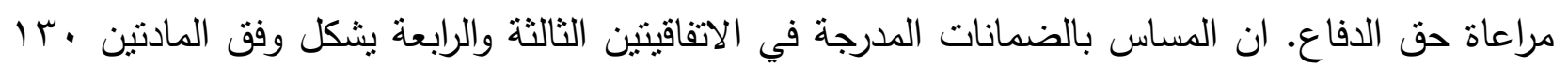

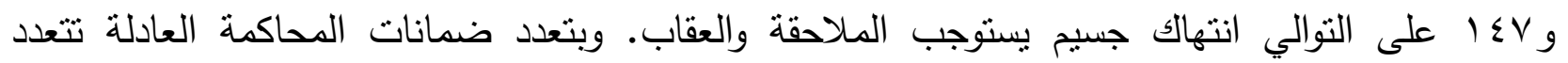
بالضرورة الافعال التي تتضوي تحت جناحها لنتكل اكثر من مخالفة جسيمة في حال لم تراعى. ويلاحظ ان

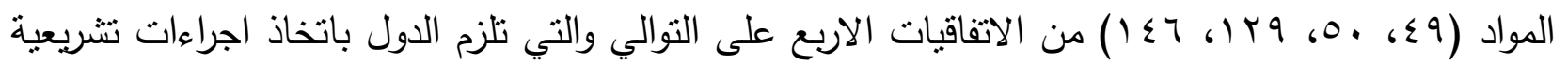

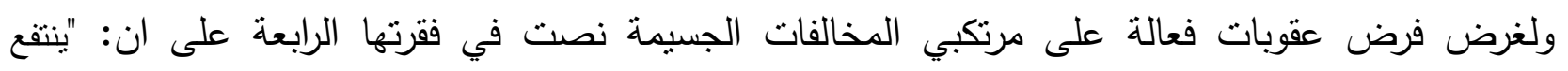

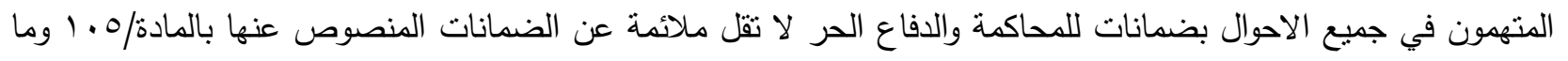

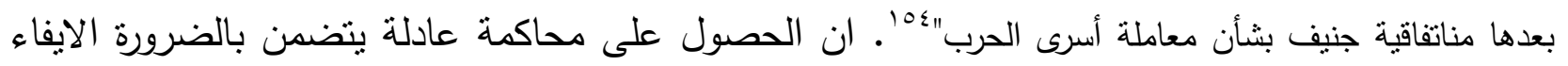

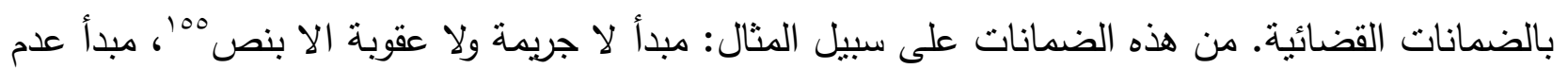
جواز المحاكمة على ذات الجرم مرنين 107، حق المتهم في ان يحاكم امام محكمة مستقلة غير متحيزة ومشكلة

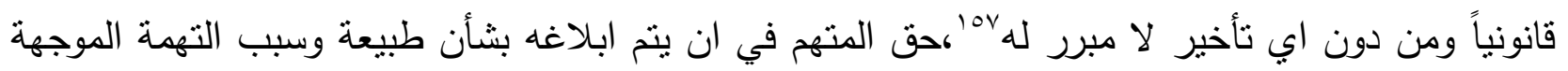

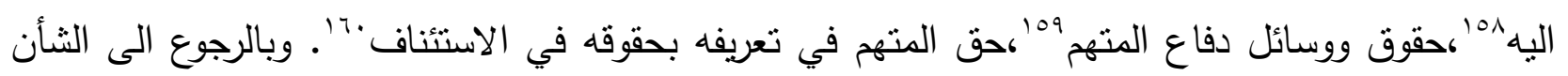

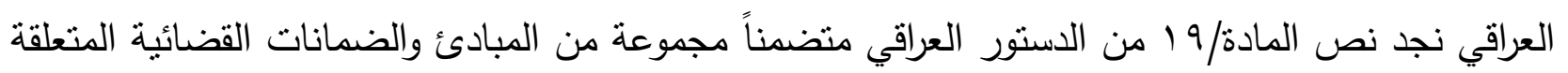
بالتقاضي بشكل عام والمبادئ الجنائية بشكل خاص. من هذه المبادئ: استقلاص القضاء، مبدأ الثرأ الشرعية، مبدأ عدم رجعية القانون الجنائي، عدم جواز المحاكمة عن ذات الجريمة مرتين، كفالة وقدسية حق الدفاع.ان البحث في قانون العقوبات العراقي لايجاد جرم يقابل هذه المخالفات الجسيمة قد يؤدي بنا الى جرم مغاير لا لا يقابل باي حال هذه المخالفات وفي الامر تجاوز لمبدأ عدم جواز القياس في القواعد الايجابية لقانون

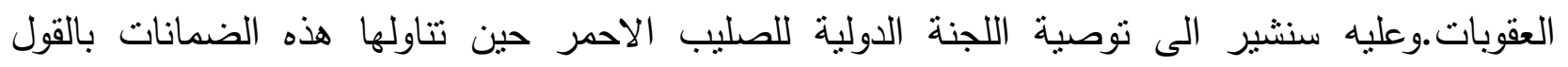

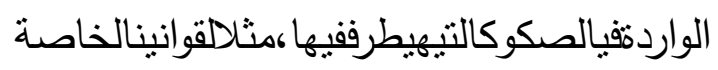

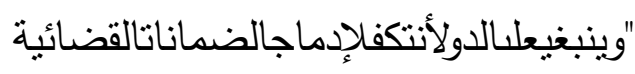

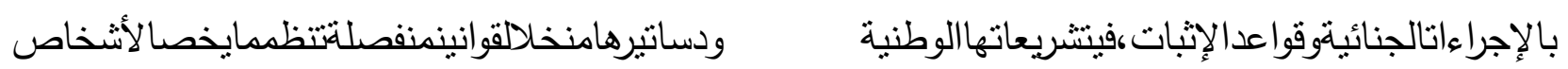

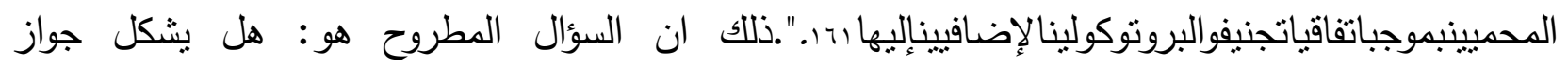
المحاكمة عن ذات الجريمة جريمة بحد ذاته؟ وان شكل جريمة ما هي العقوبة المفروضة عليه. والامر ذاته 
يطرح على كل المبادئ المشار اليها أعلاه. ولذلك نعم تحرص الدساتير على النص عليها كمبادئ دستورية

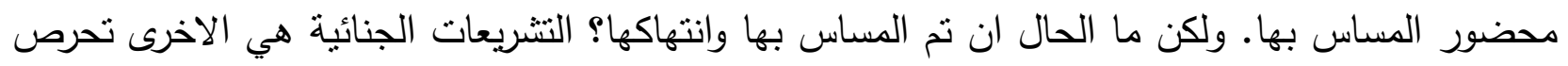
على ايرادها. ويطرح السؤال ذاته هل تعد جرائم؟ وهل نم النص على خصوصية ضحاياها من الاثخاص المحمين، وهلتم تعريف الاشخاص المحمين؟ اختصاراً لما تقدم عمدنا الى ادراج توصية اللجنة الدولية

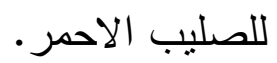

\section{المطلب الثالث/ مخالفات جسيمة نصت عليها المادة V \& ا من الاتفاقية الرابعة:}

1-الترحيل او النقل غير المشروع:تشير هذه المخالفة الى الانتهاك الواقع للمادتين 0؛ و 9؛ من

الاتفاقية الرابعة والمتعلقة بعدم جواز نقل الاشخاص المحميين الى دولة ليست طرفاً في الاتفاقية او نفيهم الى الى

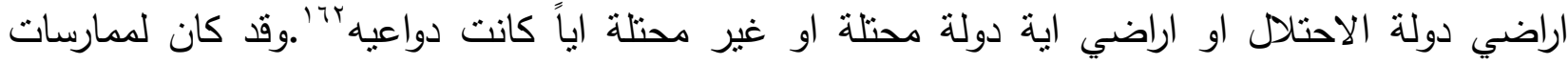

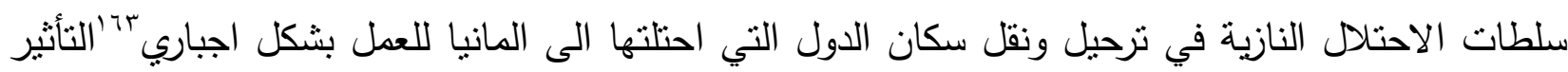
الاكبر في عد هذا الفعل من المخالفات الجسيمة التي توجب تجريمها كجريمة حرب حيث بررت المانيا عملها

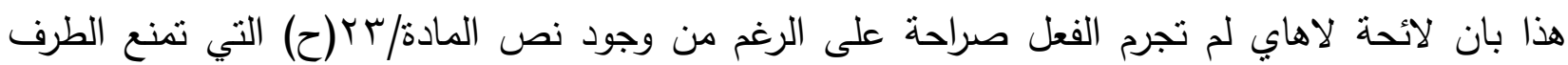

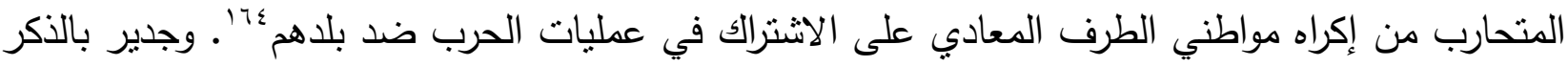
ان الترحيل (النفي) غير مشروع باعتباره ينصب على ترحيل الاشخاص المحمين خارج الاقليم المحتل. اما

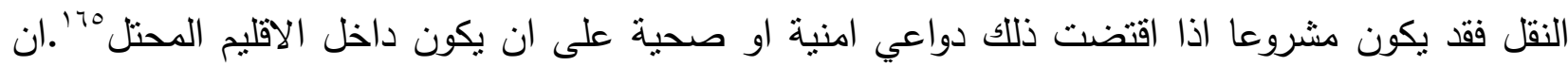

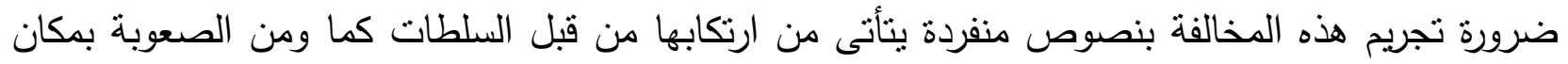
اعتماد القياس في محاولة لايجاد نص تجريمي يشابه فعل الترحيل او النقل للاشخاص المحميين كما في فعل

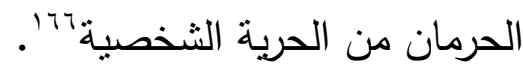

ץ- الحجز غير المشروع للاشخاص المحمين:يعرف الحجز على انه(حرمان الفرد من حريته الثخصية ما لم يكن ذللك لادانته في جريمة)"Yl'. هذا وتجيز اتفاقية جنيف الرابعة حجز الاثخاص سواء بحبسهم او

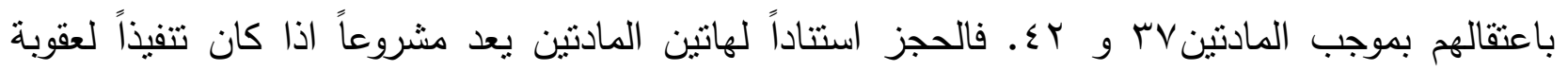
الحبس وعندها يتخذ طابع الحكم القضائي او قد يتخذ كاجراء احترازي اداري في حال استدعت دواعى امنية متعلقة بامن الدولة التي يوجد الاشخاص المحميون تحت سلطتها^^1. فان وقع فعل الحجز في سوى الحالتين المذكورتين عد مخالفة جسيمة استوجبت المحاكمة والعقاب على مرتكبه. هذا وتجرم غالبية قوانين العقوبات في دول العالم فعل الحجز غير المشروع وتعده جريمة ضد القانون العام. والقانون العراقي لا يخرج عن هذا

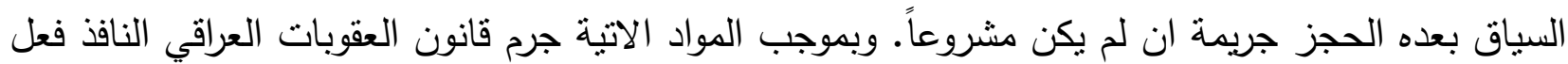


الحجز غير المشروع. اولاً يعد الحجز غير مشروع بموجب المادة/rrr حين يقبض موظف او مكلف بخدمة

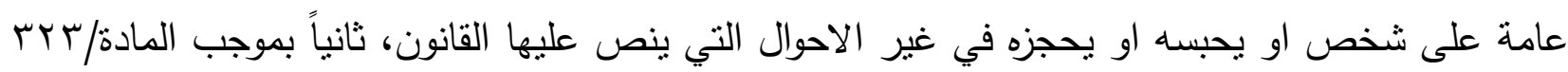

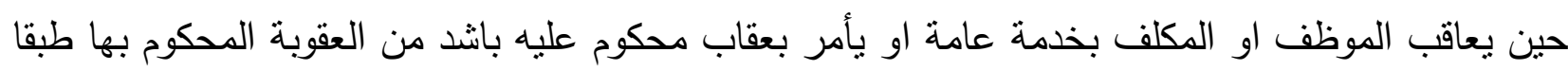

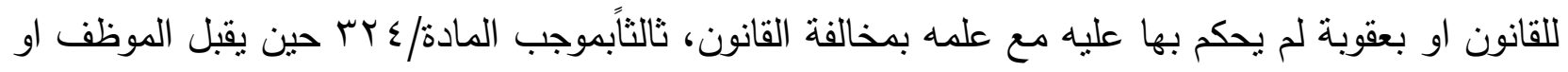

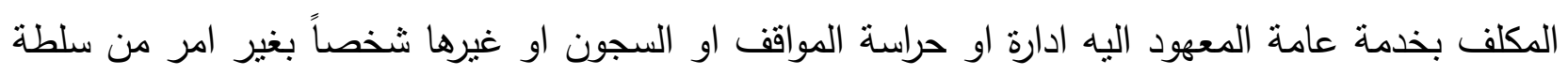
مختصة او يمتتع عن تتفيذ امر صادر باطلاق سراحه او استبقائه الى ما بعد الاجل المحدد لتوقيفه او حجزه مرئ

ب- اخذ الرهائن:كان شائعاً في حروب القرن التاسع عشر وحتى منتصف القرن العشرين ممارسة اخذ

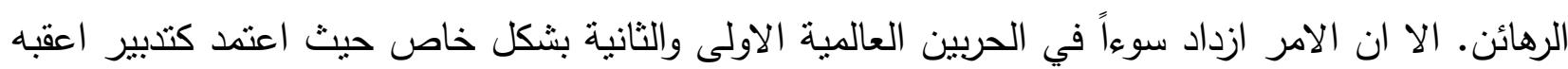

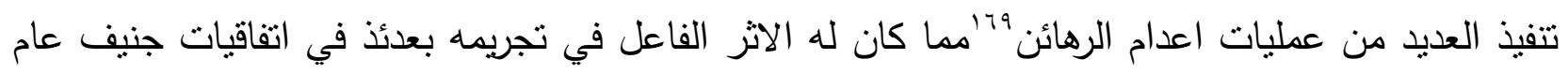

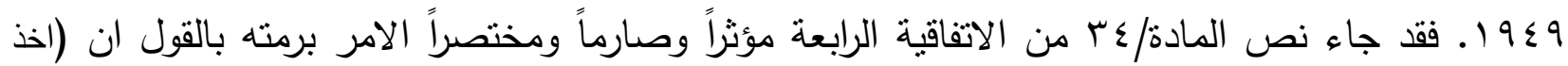
الرهائن محظور) وليدرج ضمن المادة/ I I كاحدى المخالفات الجسيمة.هذا وتعرف الاتفاقية الدولية لمناهضة

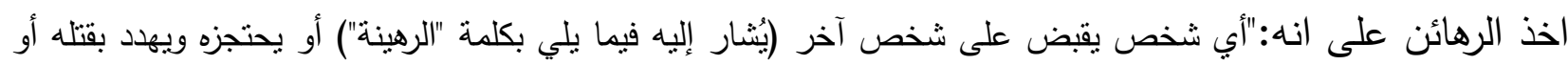

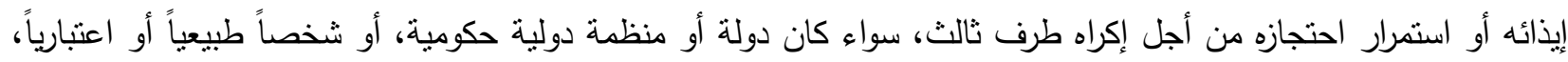

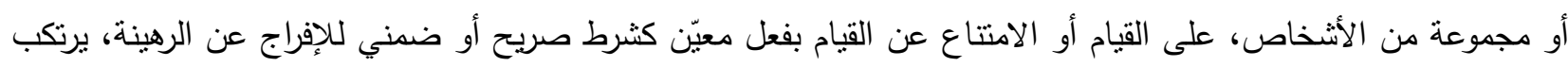

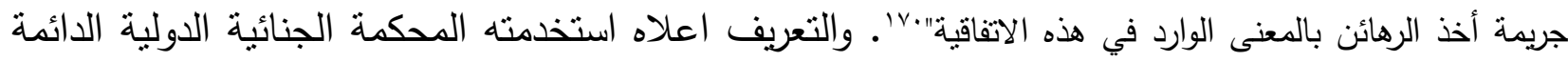

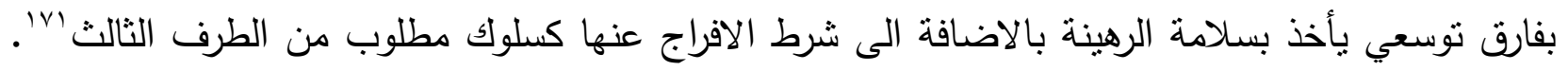

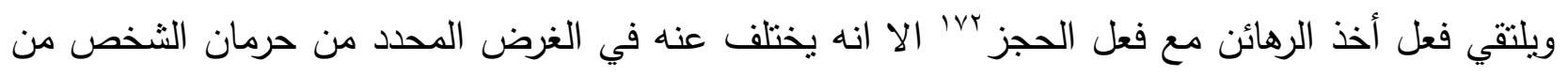
حريته "rr . وهكذا نلاحظ خصوصية هذا الفعل وتميزه عن حرمان الثخص من حريته في انه غالباً ما يرافق

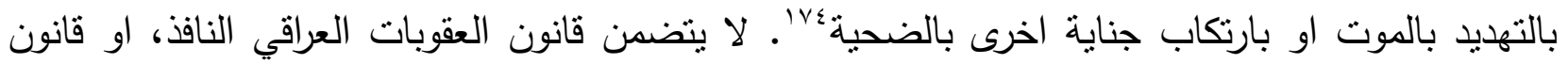

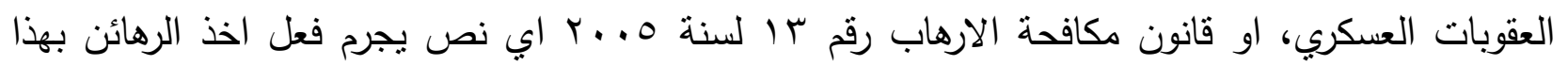

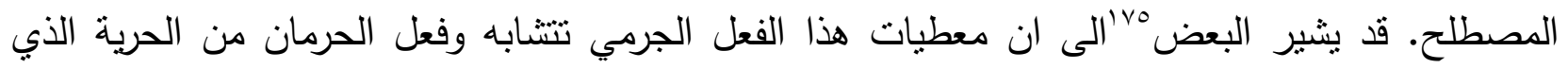
سبق وان نتاولناهآنفاً ويرد عليه بان فعل الحرمان من الحرية لا برتبط باي شرط وان فعل اخذ الرهائن غالباً

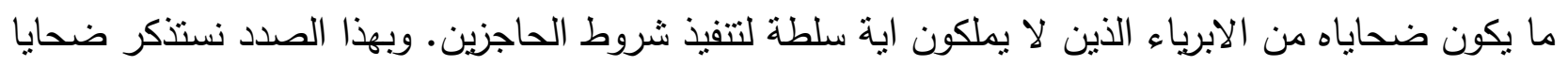

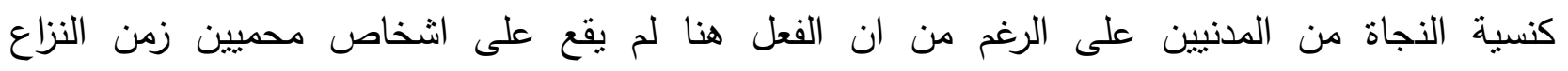
المسلح.وعليه يكون الاكتفاء بنصوص تجرم فعل الحجز غير المشروع للايفاء بمنطلبات تجريم فعل اخذ 
الرهائن رأي غير مصيب فقعل الحجز غير المشروع لا يستوعب فعل اخذ الرهائن مما يقتضي التتويهوتجريم فعل أخذ الرهائن كفعل جرمي مستقل بحد ذاته.

\section{الخاتمة:}

ان مناقثة وجود التزام على الدولة باتخاذ اجراء تشريعيلفرض عقوبات فعالة على الاشخاص الذين يقترفون او

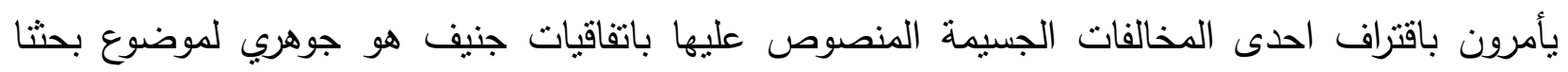

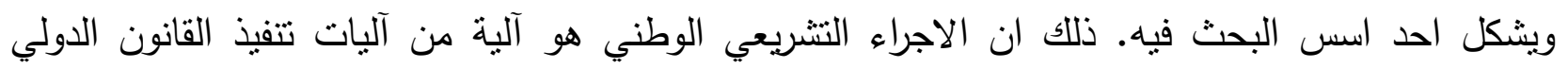

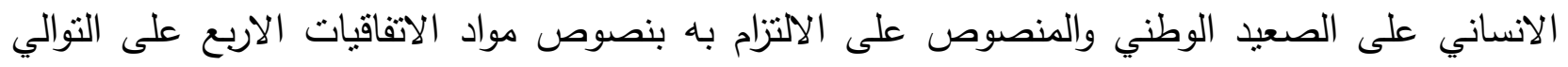

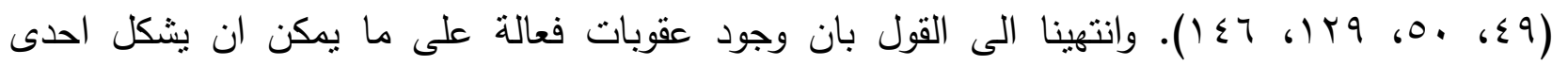
المخالفات الجسيمة دون النظر الى هدف وغاية معاهدات جنيف فيه شيء من قصر النظر لهجمل الاحكام التي جاءت بها الاتفاقيات المذكورة. فالالتزام بسن تشريع او تعديل آخر قائم ضروري لتنفيذ الالتزام الوارد بالفقرة الاولى من المواد المتقدمة اعلاه.

كما وتتكل العلاقة الوثيقة بين القانون الدولي الانساني والقانون الجنائي باعتبار الاخير الاداة الوطنية لتنفيذ

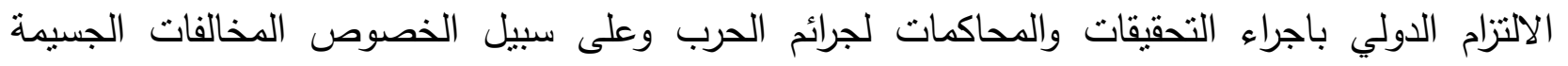
لاتفاقيات جنيف وبرونوكوليها الاضافيين الاساس الثاني مع ما يشكله الاخذ بنظام الاختصاص العالمي من آلية تتفيذية فعالة لعقاب المخالفات الجسيمة بالاضافة الى كونه التزاماً دولياً تعاقدياً.

ولتميز وخصوصية الجريمة الدولية عن سواها من الجرائم العادية يقتي من الدولة الاخذ بما يقابلها من

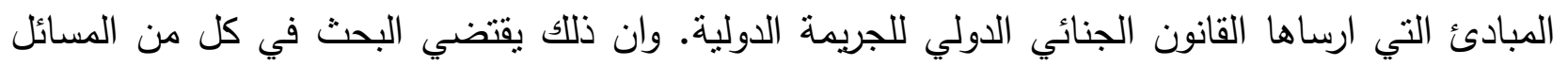
التي تطرقنا اليها لبيان مدى اتساق القانون الوطني مع المعايير التي تقررت على الصعيد الدولي الاتفاقي والعرفي للجريمة الدولية.

ان الالتزام بسن تشريع او تعديل آخر قائم للايفاء بالتزاماتتا الدولية قادنا الى النظر في مدى النقص والفراغ

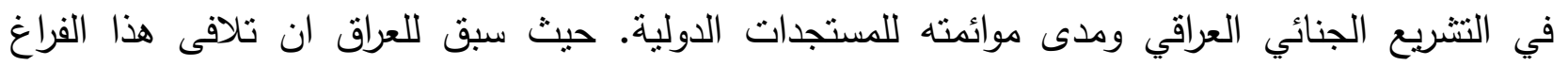
القانوني في قانون المحكمة الجنائية الخاصة بمحاكمة رموز النظام السابق وهي تظل بعد ذللك محكمة خاصة

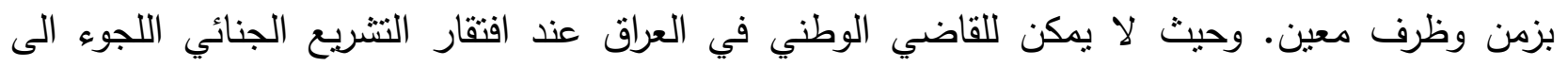
الاتفاقيات الدولية كما يفعل القاضي الالماني، هذا اذا ما علمنا بان المانيا من الدول التي تعتبر القانون

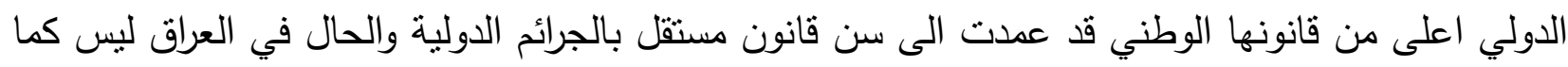


المانيا والاخير بحد ذاته مجال يقتضي البحث والغوص فيه عميقاً، وما موقق المانيا الا تجسيداً للاهمية المتتامية للجريمة الدولية على المستويين الدولي والوطني.

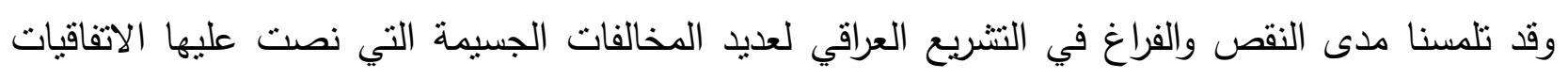

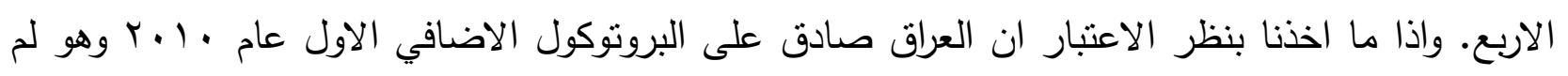

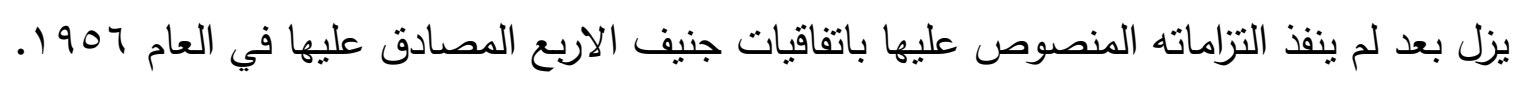

ومن هذه النقطة الحساسة والفاصلة ننظر بعين القلق الى مدى التزام العراق بتتفيذ التزاماته الدولية المتعلقة بسن نتريع لنظام المخالفات الجسيمة او تلك الخاصة بالاخذ بالاختصاص العالمي لنظام المخالفات الجسيمة.

\section{التوصيات:}

ا. المصادقة على الاتفاقيات الدولية ذات الصلة بالقانون الدولي الانساني، وما خطوة العراق في العام • . • ب بالمصادقة على البروتوكول الاضافي الاول لاتفاقيات جنيف الخاص بالمنازعات المسلحة الدولية

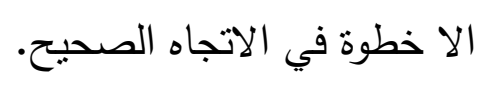
r.ان المصادقة لوحدها لا تكفي اذ يجب بالمقابل تتفيذ الالتزامات الدولية المنصوص عليها بصلب الاهب نصوص الاتفاقيات الدولية المصادق عليها. r.ان التتفيذ الوطني الفعال (بسن قوانين تجرم المخالفات الجسيمة او تعديل اخرى قائمة) كآلية من آليات

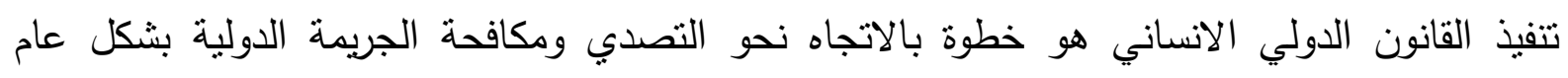

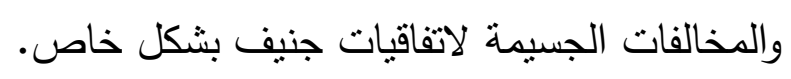
ع ـ الاخذ بنظام العالمية كونه احد اساليب مكافحة الجريمة الدولية عامة ونظام المخالفات الجسيمة خاصة. ه. ضرورة العمل على الحد من الحصانة بالمصادقة على الاتفاقيات الدولية الخاصة بهذا المجال التهال.

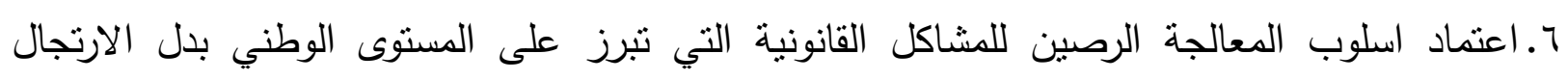
والبحث عن حلول مؤقتة لمشاكل ليس هناك ما يمنع من تكرار ارتكابها سوى بتجريمها.

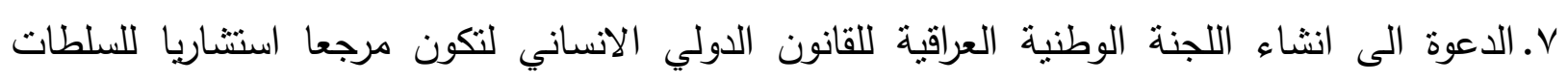

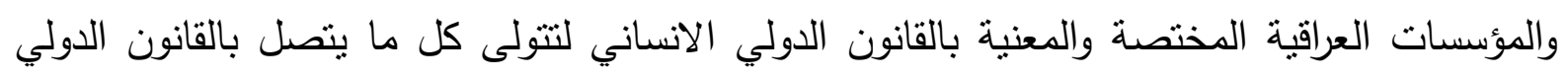

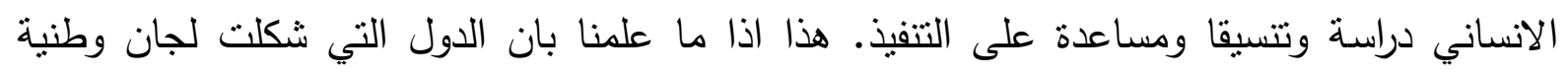




$$
\text { واخيرا اكرر ما سبق واوردته في مجال آخر بان التعليم والثعور بالانسانية هو من بحيى الثعوب. }
$$




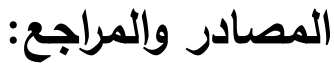

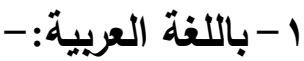

اولاً: الكتب.

\begin{abstract}
1. ابو النصر، د. عبد الرحمن.تفاقية جنبف الرابعة لحماية الدنبيين لعامه ؟9 (وتطبيقها في الاراضي الفلسطينية المحتلة.طا.

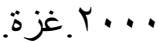

r. جون-ماري هنكرتس، دوز و الد-باك. القانون الدولي الانساني العرفي. الدجلد الاول: القو اعد. اللجنة الدولية للصليب الاحمر
\end{abstract}

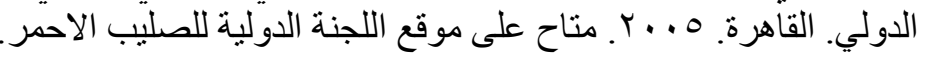

(accessed on http://www.icrc.org/eng/resources/documents/misc/customary-law-translations.htm

July17,2011)

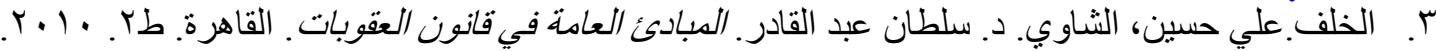

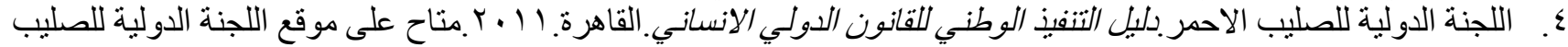

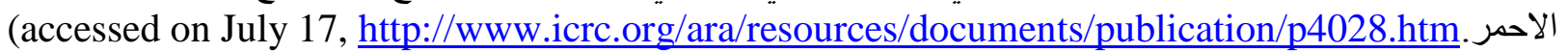

2011).

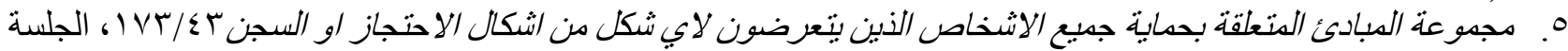

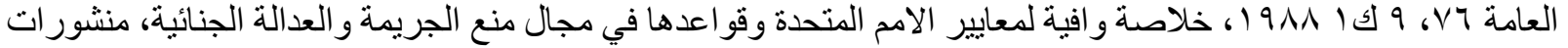

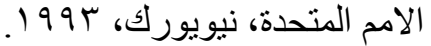

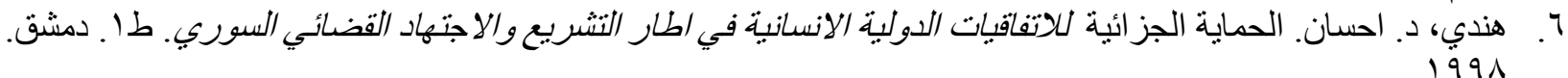

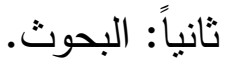

$$
\begin{aligned}
& \text { ا. ابو الوفا، د. احمد. الفئات المشمولة بحماية القانون الدولي الانساني. القانون الدولي الانساني. دليل التطبيق على الصعيد }
\end{aligned}
$$

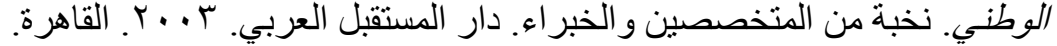

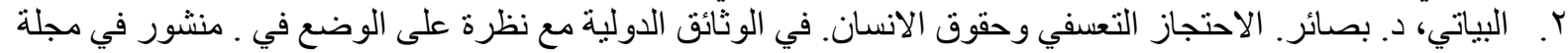

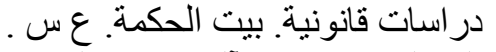

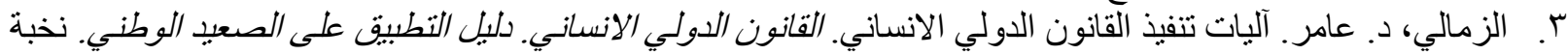

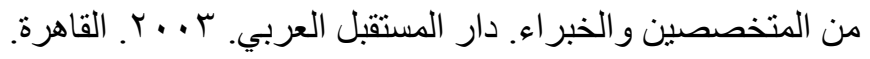

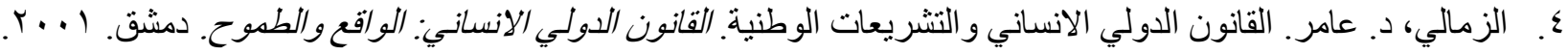

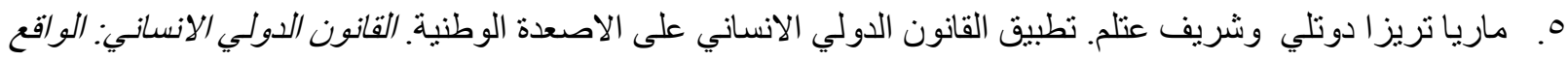

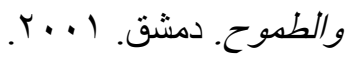

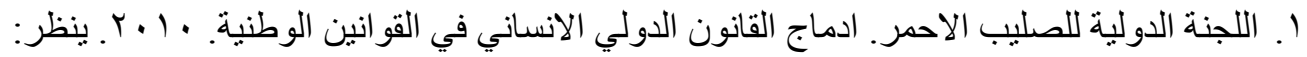
http://www.icrc.org/ara/war-and-law/ihl-domestic-law/overview-domestic-law.htm(accessed on Oct.1, 2011). 
http://www.icrc.org/ara/resources/documents/legal-fact-sheet/implementation-ihl-factsheet-2010$\underline{10-27 . h t m}$

$$
\begin{aligned}
& \text { r. اللجنة الدولية للصليب الاحمر . الخدمات الاستشارية المقدمة من اللجنة الدولية في مجال القانون الدولي }
\end{aligned}
$$

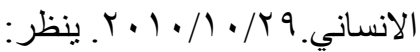

http://www.icrc.org/ara/what-we-do/building-respect-ihl/advisory-service/overview-advisoryservices.htm(accessed on Oct.1, 2011).

$$
\text { رابعاً: القوانين. }
$$

http://www.iraq-ild.org/LoadLawBook.aspx?SP=ALL\&SC=120120012516407 (accessed on August 20, 2011).

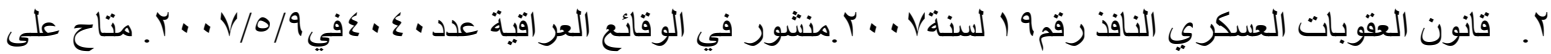

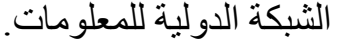

http://www.iraq-ild.org/LoadLawBook.aspx?SP=SUB\&SC=070120089400316\&PageNum=1 (August 2011).

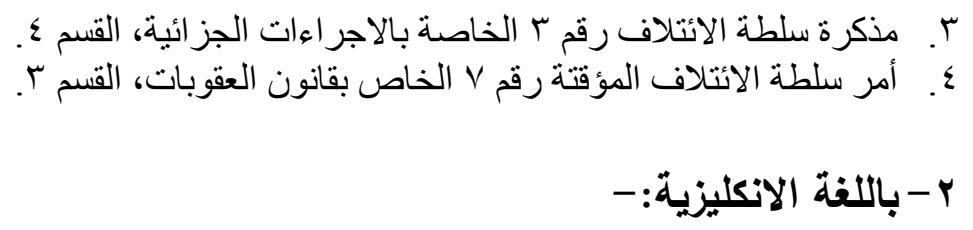

1. Commentry of GCI, GCII, GCIII, GCIV. available athttp://www.icrc.org/ihl.nsf/COM/365570061? OpenDocument (accessed on August 2011).

2. Gasser. Hans-Peter, International Humanitarian Law - An introduction, in: HAUG (Hans). Humanity for all, The International Red Cross and Red Crescent Moment.Henry Dunant Institute. 1993.

3. Glaser. Stefen. Droit International Conventionnel.Bruxelle,1970.

4. Lombois. Droit PenalInterational. 2 Mme. Edition. Dalloz.1971.

1. Amnesty International (AI). 2001. Universal Jurisdiction: The Duty of States to Enact or Implement Legislation. September 2001. Amnesty International. Index: IOR 53/018/2001. P. 3. available at http://www.amnesty.org/en/library/asset/IOR53/018/2001/en/1bab09b7-d8ef11dd-ad8c-f3d4445c118e/ior530182001en.pdf (accessed on July 27, 2001).

2. CherifBassiouni. International Crimes Jus Cogens and ObligatioErgaOmnes. Law and Contemporary Problems. Vol.59. no. 4. Autumn. 1996. Duk University school of Law. P.256. 
available at http://www.sos-attentats.org/publications/bassiouni.jus.cogens.pdf (accessed on July 30, 2011).

3. Christopher C. Joyner. Arresting Impunity: The Case for Universal Jurisdiction in Bringing War Criminals to Accountability. Law And Contemporary Problems. Vol. 59: No. 4. Autumn 1996. P.168,169. available at http://www.law.duke.edu/shell/cite.pl?59+Law+\&+Contemp.+Probs.+153+(Fall+1996) (accessed on August 4, 2011).

4. Claus Kress. War Crimes Committed in NIAC and the Emergency System of International Criminal Justice. Israel Yearbook on Human Rights. Vol. 30. 2000. P. 169. available at http://books.google.com/books?id=2g7G48JOhvQC\&pg=PA169\&lpg=PA169\&dq=DINSTEI

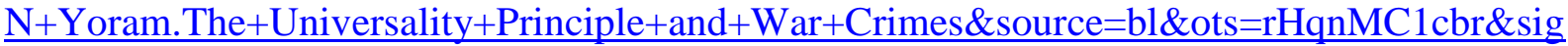
=BZSrVZHuqdyrE2eT9dWNxZKoa7k\&hl=en\&ei=IsEvTrPsMI_RsgbAh-

QL\&sa=X\&oi=book_result\&ct=result\&resnum $=1 \& v e d=0 C B Q Q 6 A E w A A \# v=$ onepage\&q\&f =false (accessed on July 30, 2011).

5. George Duncan's. Massacres and Atrocities of World War II. http://members.iinet.net.au/ gduncan/massacres.html (accessed on Sep.30, 2011).

http://www.amnesty.org/en/library/asset/IOR53/018/2001/en/1bab09b7-d8ef-11dd-ad8cf3d4445c118e/ior530182001en.pdf (accessed on July 27, 2001).

6. Human Right Watch. Universal Jurisdiction in Europe. June 2006. availableathttp://www.hrw.org/fr/node/11297/section/8\#_ftn145 (accessed on August 1, 2011).

7. John H. Fried. Transfer of Civilian Manpower from Occupied Territory.American Journal of International Law(AJIL). Vol. 40, No. 2, Apr., 1946.

8. Knut Dormann\& Robin Geib. The Implementation of Grave Breaches into domestic Legal Orders. Journal of International Criminal Justice( JICJ). Vol. 7, no. 4, September 2009.

9. Marko Divac Oberg. The absorption of grave breaches into war crimes law. International Journal of the Red Cross(IRRC). Vol. 91.No.873.March 2009.p.163. available at http://www.icrc.org/eng/assets/files/other/irrc-873-divac-oberg.pdf (accessed on August 19, 2011).

10. Roemer Lemaître. Belgium rules the world: Universal Jurisdiction over Human Rights Atrocities. jurafalconis. jg 37. 2000-2001. nr 2. p. 255-282. available at http://www.law.kuleuven.be/jura/art/37n2/lemaitre.htm\#N_53_(accessed on August 1, 2011).

11. Roger O'Keefe. The Grave Breaches Regime and The Universal Jurisdiction. JICJ. Vol. 7. 2009.

$$
\begin{aligned}
& \text { ا ـ قرار الجمعية العامة للامم المتحدة رقم (A/RES/64/117) في } 7 \text { ا كانون الاول 9. . . ؟. متاح على الثبكة الدولية } \\
& \text { للمعلومات. }
\end{aligned}
$$

http://daccess-ddsny.un.org/doc/UNDOC/GEN/N09/468/83/PDF/N0946883.pdf?OpenElement(accessed on August 9, 2011). http://www.cambridge.org/resources/0521135818/9864_9864_SecretaryGeneral+Report+Universal+Jurisdiction.pdf (accessed on August 9, 2011). 
2.International Committee of the Red Cross(ICRC). Final Records of the Diplomatic Conference. Vol. II-B. Berne. http://www.loc.gov/rr/frd/Military_Law/pdf/Dipl-Conf-1949-Final_Vol-2B.pdf (accessed on July 27, 2011).

3.International Committee of the Red Cross(ICRC).2003. Advisory Service on IHL. Information Kit.National Enforcement of the IHL .2003.available at http://www.icrc.org/eng/resources/documents/misc/5xdj4g.htm (accessed on August 3,2011).

4.International Committee of the Red Cross(ICRC). 2010. Table Of NationalCommittees and Other National Bodies OnInternationalHumanitarian Law. available at http://www.icrc.org/eng/assets/files/other/national-committes-icrc-30-09-2010.pdf (accessed on Sep.1,2011).

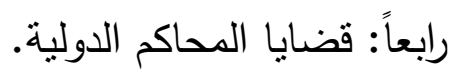

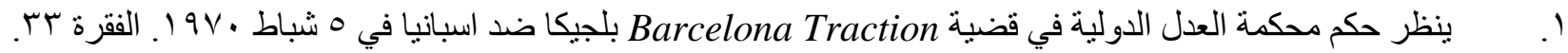
available at http://www.icj-cij.org/docket/files/50/5387.pdf (accessed on July 30, 2011).

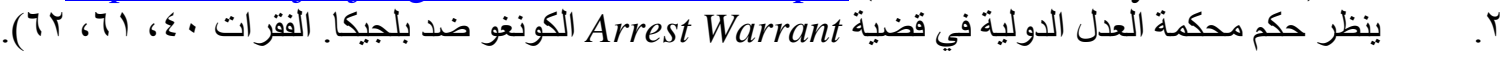
http://www.icj-cij.org/docket/files/121/8126.pdf (accessed on August 1, 2011).

$$
\text { خامساً: القوانين والاتفاقيات الدولية. }
$$

http://www.icrc.org/eng/assets/files/other/ihl_and_other_related_treaties.pdf (accessed on July6,2011). r. الكتيبات العسكرية لعديد الدول على موقع اللجنة الدولية للصليب الاحمر وحسب الترتيب الابجدي. http://www.icrc.org/customary-ihl/eng/docsLight/src_IIMiMa\#b ; http://www.icrc.org/customaryihl/eng/docs/v2_cha_chapter43_rule151 (accessed on July 17, 2011).

$$
\text { r. ميثاق المحكمة العسكرية الدولية في نورمبرغ، المادة/ه من ميثاق المحكة العسكرية الدولية في طوكيو. ينظر : }
$$
http://avalon.law.yale.edu/imt/imtconst.asp (accessed on July 16, 2011).

$$
\text { ع. النظام الاساس لمحكمة يو غسلافيا السابقة. ينظر: }
$$

http://www.icty.org/sections/LegalLibrary/StatuteoftheTribunal (accessed on July 17, 2011).

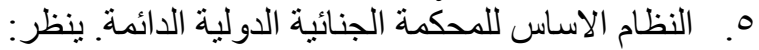

http://www.icc-cpi.int/Menus/ICC/Legal+Texts+and+Tools/Official+Journal/Rome+Statute.htm (accessed on July17,2011).

6. The Geneva Conventions Act 1957 (as amended). available at http://www.icrc.org/ihlnat.nsf/6fa4d35e5e3025394125673e00508143/18fd6374473918c3c1256b6d003097ca!OpenDo cument

7. International Criminal Court Act 2001. available at http://www.icrc.org/ihlnat.nsf/6fa4d35e5e3025394125673e00508143/940fb595ea042785c1256aea003bf593!OpenDoc $\underline{\text { ument }}$

8. Crimes Against Humanity and War Crimes Act, SC 2000, c 24. available at http://www.canlii.org/eliisa/highlight.do?text=crime+against+humanity+and+war+crimes+act\& language $=$ en $\&$ searchTitle $=$ Search + all + CanLII+Databases $\&$ path=/en $/ \mathrm{ca} /$ laws $/$ stat $/ \mathrm{sc}-2000-\mathrm{c}-$ 24/latest/sc-2000-c-24.html (August 2011)

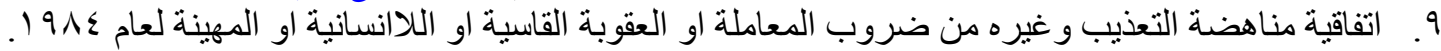

http://www1.umn.edu/humanrts/arab/b039.html (August 2011)

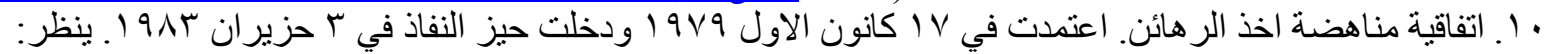


http://www.un.org/ar/sc/ctc/laws.html (accessed on Sep.30, 2011).

'ينظر وثثقة تنين الدول وتاريخ تصديقها على اتفاقيات القانون الدولي الانساني على موقع اللجنة الدولية للصليب الاحمر وحتى http://www.icrc.org/eng/assets/files/other/ihl_and_other_related_treaties.pdf (accessed on July6,2011).

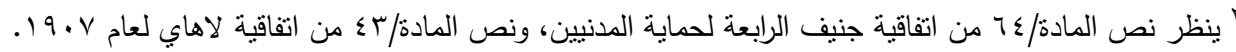

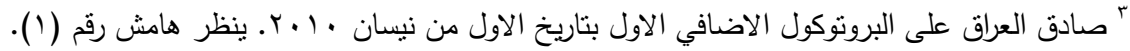

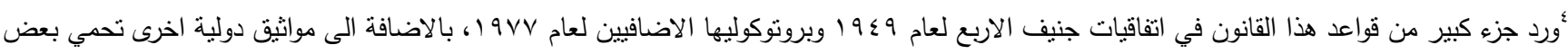
الفئات من الاثخاص او الاعيان، او تحظر استخدام اسلحة بعينها.ينظر مواثيق القانون الدولي الانساني على الموقع الرسمي للجنة الدولية للصليب الاحمر.

$$
\text { قاعدة الاتفاقياتوقاعدة بيانات قواعد القانون الدولي الانساني العرفي على التوالي: }
$$

http://www.icrc.org/ihl (accessed on July 10, 2011).

http://www.icrc.org/customary-ihl/eng/docs/home (accessed on July 10, 2011).

${ }^{5}$ Gasser, Hans-Peter, International Humanitarian Law - An introduction, in: HAUG (Hans), Humanity for all, The International Red Cross and Red Crescent Moment. Henry Dunant Institute, 1993, p. «१).

"هذه الاستثناءات المحدودة تتمثل في القضاء الجنائي الدولي ممثلا بمحاكمه الخاصة التي انثأها مجلس الامن او الدائمة المنثأة باتفاقية روما.

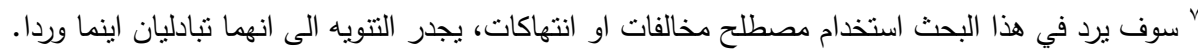

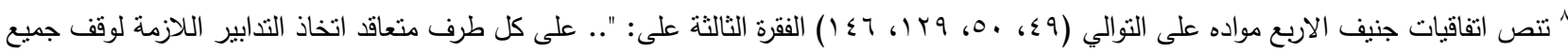
الافعال التي تتعارض مع احكام هذه الاتفاقية بخلاف المخالفات الجسيمة المبينة في المادة النالية. ...". 9 سنأتي الى بيان هذه المخالفات بالتفصيل لاحقا.

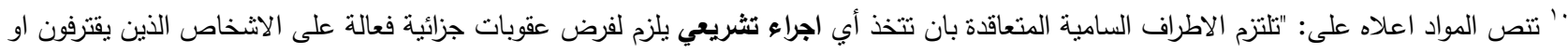

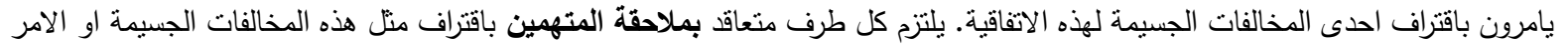

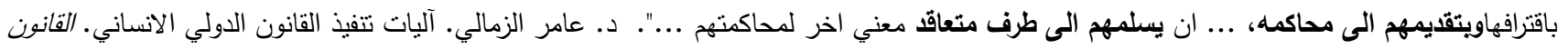

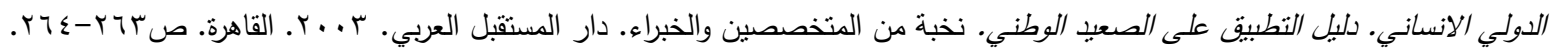
" الموص المواد اعلاه.

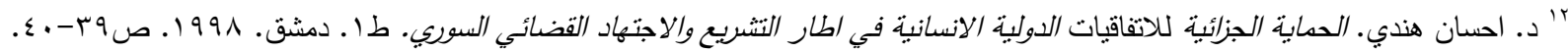

${ }^{13}$ Knut Dormann\& Robin Geib. The Implementation of Grave Breaches into domestic Legal Orders. Journal of International Criminal Justice(jicj). Vol. 7, no. 4, September 2009. P.707.

14 Id. P. 708.

${ }^{15}$ Final Records of the Diplomatic Conference, Vol. II-B. Berne. at 356 (UK); at 357 (France).; at 357; at 362.http://www.loc.gov/rr/frd/Military_Law/pdf/Dipl-Conf-1949-Final_Vol-2-B.pdf (accessed on July 27, 2011).

${ }^{16}$ International Committee of the Red Cross(ICRC).2003. Advisory Service on IHL. Information Kit.National Enforcement of the IHL .2003.P.4-5.available at http://www.icrc.org/eng/resources/documents/misc/5xdj4g.htm (accessed on August 3,2011).

${ }^{17}$ Knut Dormann\& Robin Geib. Op. Cit., P. 709.

${ }^{18}$ Ibid; Amnesty International (Al). 2001. Universal Jurisdiction: The Duty of States to Enact or Implement Legislation. September 2001. Amnesty International. Index: IOR 53/018/2001. P. 3. available at 
http://www.amnesty.org/en/library/asset/IOR53/018/2001/en/1bab09b7-d8ef-11dd-ad8c-

f3d4445c118e/ior530182001en.pdf (accessed on July 27, 2001).

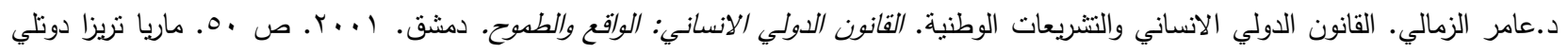

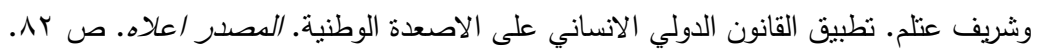

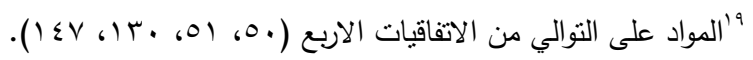

20 Claus Kress. War Crimes Committed in NIAC and the Emergency System of International Criminal Justice. Israel Yearbook on Human Rights. Vol. $30.42000 . \quad$ P. 169 . available at http://books.google.com/books?id=2g7G48JOhvQC\&pg=PA169\&Ipg=PA169\&dq=DINSTEIN+Yoram.The+Universality+Pr inciple+and+War+Crimes\&source=bl\&ots=rHqnMC1cbr\&sig=BZSrVZHuqdyrE2eT9dWNxZKoa7k\&hl=en\&ei=IsEvTrPsMI_ RsgbAh-QL\&sa=X\&oi=book_result\&ct=result\&resnum=1\&ved=0CBQQ6AEwAA\#v=onepage\&q\&f=false (accessed on July $30,2011)$.

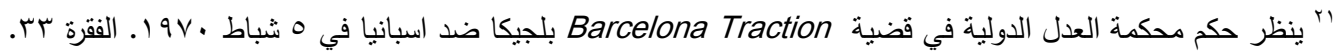
available at http://www.icj-cij.org/docket/files/50/5387.pdf (accessed on July 30, 2011).

${ }^{22}$ Claus Kress. Op. Cit., P. 169; CherifBassiouni. International Crimes Jus Cogens and ObligatioErgaOmnes. Law and Contemporary Problems. Vol.59. no. 4. Autumn. 1996. Duk University school of Law. P.256. available at http://www.sos-attentats.org/publications/bassiouni.jus.cogens.pdf (accessed on July 30, 2011).

rr خضع مبدأ عدم الاعنداد بالحصانة الى تعديل بموجب القانون الدولي،ففي قضية Arrest Warrant محضت مكمة العدل الدولية بان رئيس الوزراء بتمتع بحصانة وظيفية من الخضوع للاختصاصالقضائي امام المحاكم الاجنبية طالما كان في الوظيفة مهما كانت الجريمة الدولية المرتكبة. ينظر : http://www.icj-cij.org/docket/files/121/8126.pdf (accessed on August 1, 2011), (para.40, 61, 62).

${ }^{24}$ CherifBassiouni. Op. Cit., P.265; Christopher C. Joyner. Arresting Impunity: The Case for Universal Jurisdiction in Bringing War Criminals to Accountability. Law And Contemporary Problems. Vol. 59: No. 4. Autumn 1996. P.168,169. available at http://www.law.duke.edu/shell/cite.pl?59+Law+\&+Contemp.+Probs.+153+(Fall+1996) (accessed on August 4, 2011).

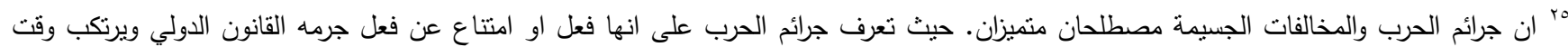

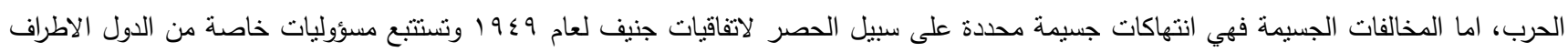

$$
\text { بالتشريع والعقاب في القانون المحلي. وبمرور الزمن تلاشى هذا التمييز • ينظر : }
$$

Marko Divac Oberg. The absorption of grave breaches into war crimes law. IRRC. Vol. 91.No.873.March 2009.p.163. available at http://www.icrc.org/eng/assets/files/other/irrc-873-divac-oberg.pdf (accessed on August 19, 2011). استتاداً للقاعدة العرفية اه إنان الانتهاكات الجسيمة للقانون الدولي الانساني نشكل جرائم حرب. جون-ماري هنكرنس، دوز والد-باك. القانون الدولي الانساني

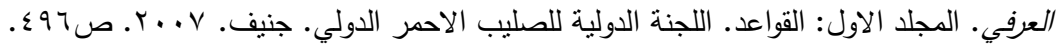

$$
\begin{aligned}
& \text { rrr نص المادة/r-1 (أ، ب) من نظام روما الاساس للمحكمة الجنائية الدولية. }
\end{aligned}
$$

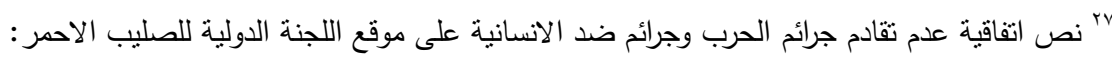

http://www.icrc.org/ara/resources/documents/misc/62sgjl.htm (accessed on July 14, 2011).

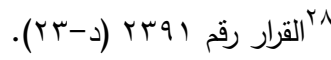

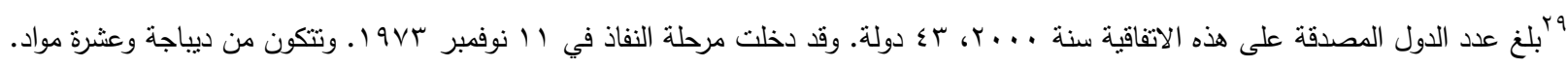


${ }^{30}$ Article. 1. See http://conventions.coe.int/treaty/Commun/QueVoulezVous.asp?NT=082\&CM=1\&CL=ENG (accessed on July 15,2011$)$.

$$
\begin{aligned}
& \text { "rr (لا يطبق قانون التقادم على جرائم الحرب). ينظر : جون-ماري هنكرتس، دوز والد-باك. مصدر سابق. ص هبه. }
\end{aligned}
$$

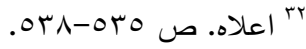

$$
\begin{aligned}
& \text { rr }
\end{aligned}
$$

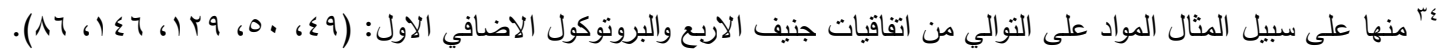

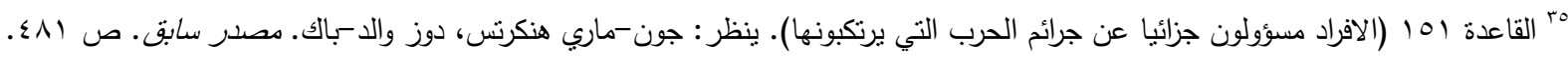

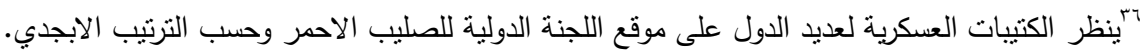

http://www.icrc.org/customary-ihl/eng/docsLight/src_IIMiMa\#b ; http://www.icrc.org/customary-

ihl/eng/docs/v2_cha_chapter43_rule151 (accessed on July 17, 2011).

T المادة/7 من ميثاق المحكمة العسكرية الدولية في نورمبرغ، المادة/ه من ميثاق المحكمة العسكرية الدولية في طوكيو • ينظر : http://avalon.law.yale.edu/imt/imtconst.asp (accessed on July 16, 2011).

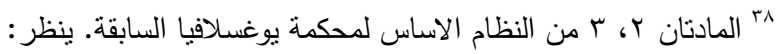

http://www.icty.org/sections/LegalLibrary/StatuteoftheTribunal (accessed on July 17, 2011).

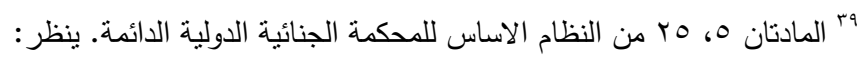

http://www.icc-cpi.int/Menus/ICC/Legal+Texts+and+Tools/Official+Journal/Rome+Statute.htm (accessed on July17,2011).

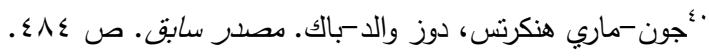

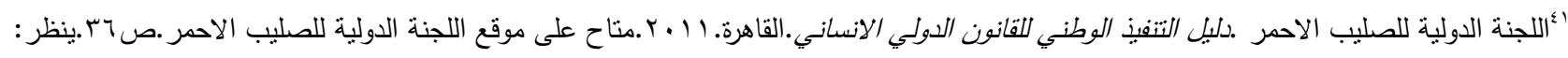
http://www.icrc.org/ara/resources/documents/publication/p4028.htm (accessed on July 17, 2011).

rأ تحت عنوان النقصير نصت الفقرة على: "لا يعفي قيام أي مرؤوس بانتهاك الاتفاقيات او هذا اللدق رؤساءه من المسؤولية الجنائية او التأديبية،اذا علموا او

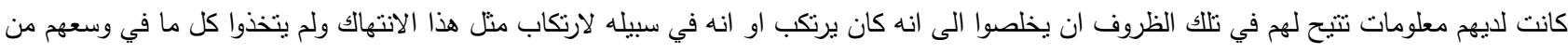

$$
\text { اجراءات مستطاعة لمنع او قمع هذا الانتهاك". }
$$

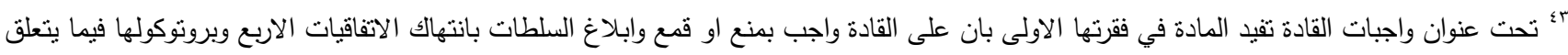

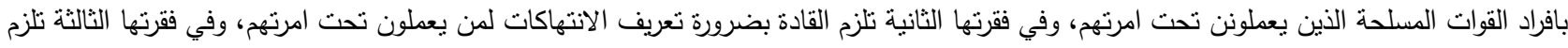

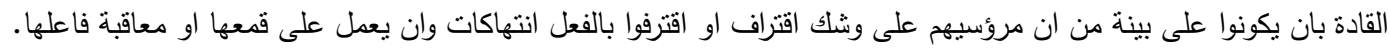

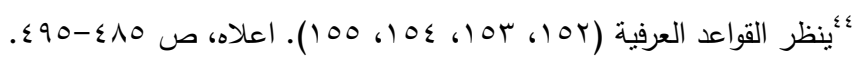

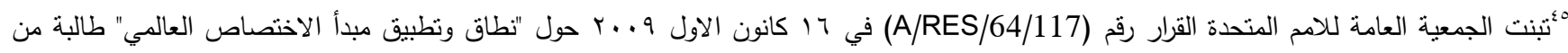
السكرتارية العامة دعوة الدول الى تقديم معلومات حول نطاق تطبيق مبدأ العالمية بضمنها معلومات حول المعاهدات الدولية ذات العلاقة والقواعد القانونية

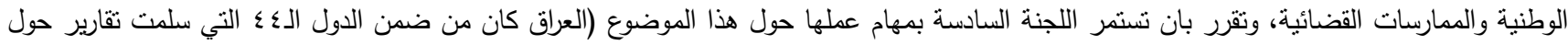

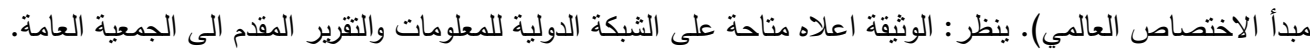
http://daccess-dds-ny.un.org/doc/UNDOC/GEN/N09/468/83/PDF/N0946883.pdf?OpenElement(accessed on

August 9, 2011).http://www.cambridge.org/resources/0521135818/9864_9864_Secretary-

General+Report+Universal+Jurisdiction.pdf (accessed on August 9, 2011).

http://untreaty.un.org/ilc/guide/7_6.htm وتجري بنفس الوقت مناقثات في لجنة القانون الدولي حول الالتزام بالتسليم او المحاكمة. ينظر

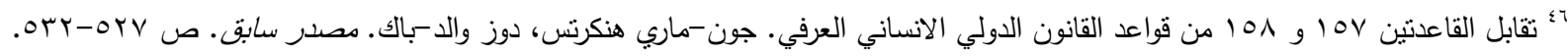




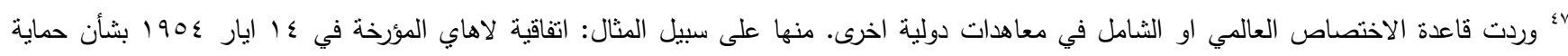

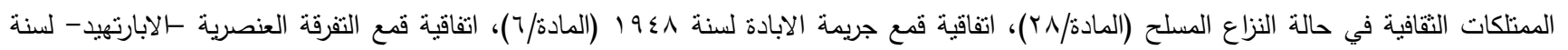

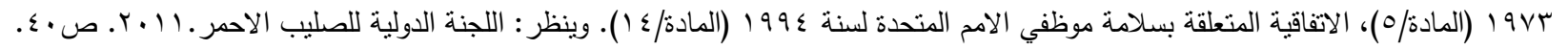

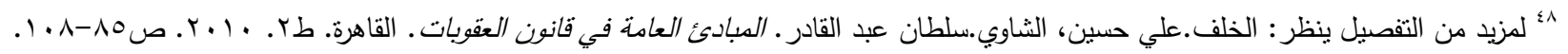

Christopher C. Joyner. Op. Cit., P.164.

$$
\text { 9؛ من دعاة هذا الاختصاص كل من كلاسيير ولومبوا، لاجل ملافاة النتائج غير المقبولة الناتجة عن مبدأ الاقليمية. ينظر : }
$$

Glaser.Stefen.Droit I.Conventionnel.Bruxelle,1970.P.51-52 ;Lombois.Droit Penal I.,2 Mme.Edition. Dalloz.1971.P.19.

${ }^{50}$ Roemer Lemaître. Belgium rules the world: Universal Jurisdiction over Human Rights Atrocities. jurafalconis. jg 37.

2000-2001. nr 2. p. 255-282. available at http://www.law.kuleuven.be/jura/art/37n2/lemaitre.htm\#N_53_(accessed on August 1, 2011).

${ }^{51}$ ICRC. 2003. Information Kit.Op. Cit., P. 6.

${ }^{52}$ Christopher C. Joyner. Op. Cit., P.1 $\vee$..

${ }^{53}$ Roemer Lemaître.Op. Cit., P. 255-282.

${ }^{54}$ Christopher C. Joyner. Op. Cit., P. 165.

$$
\text { وينظر ايضا: اللجنة الدولية للصليب الاحمر • 11 ـ r. مصدر سابق. ص و؟. }
$$

${ }^{55}$ Human Right Watch. Universal Jurisdiction in Europe. June 2006.

availableathttp://www.hrw.org/fr/node/11297/section/8\#_ftn145 (accessed on August 1, 2011).

به قسم الخدمات الاستشارية باللجنة الدولية للصليب الاحمر. قمع انتهاكات القانون الدولي الانساني على الصعيد الوطني. القانون الدولي الانساني. دليل

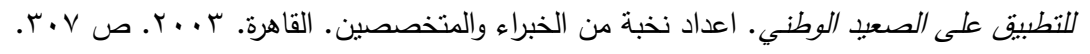

ICRC. 2003. Information Kit.Op. Cit., P. 6.

57 Roger O'Keefe. The Grave Breaches Regime and The Universal Jurisdiction. JICJ. Vol. 7. 2009. P.813.

$58 / d$.

${ }^{59}$ /d; Christopher C. Joyner. Op. Cit., P. 170.

${ }^{60}$ Roger O'Keefe.Op. Cit., P. 813.

${ }^{61} / d$.

${ }^{62}$ Id. P. 814; Christopher C. Joyner. Op. Cit., P.1V•.

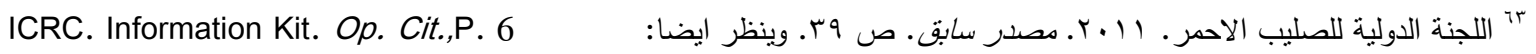
${ }^{64} / d$.

$65 / d$.

${ }^{66} / d$.

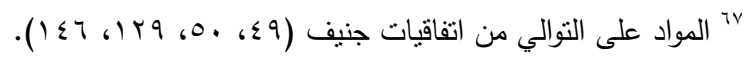

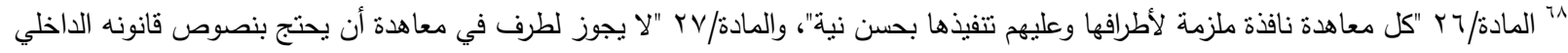
كمبرر لإخفاقه في تتفيذ المعاهدة، لا تخل هذه القاعدة بالمادة $7 ء "$ ـ متاحة على الشبكة الدولية للمعلومات: http://www1.umn.edu/humanrts/arabic/viennaLawTreatyCONV.html (accessed on August 10, 2011).

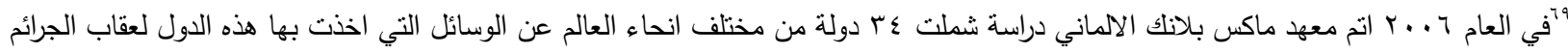
الدولية وبضمنها جرائم الحرب. الدراسة مناحة باللغة الالمانية.

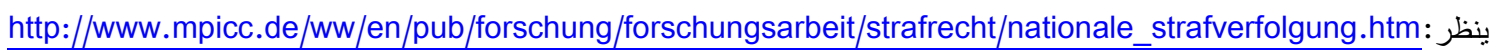




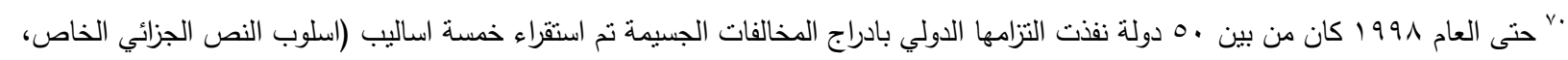

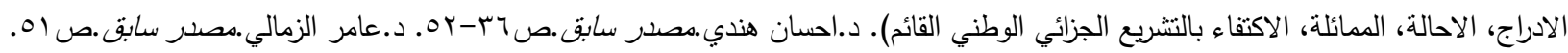
اV يدرج دلبي التنفيذ الوطني للقانون الدولي الانساني اربعة اساليب لادخال المخالفات الجسيمة في القانون الوطني هي: (تطبيق القانون الجنائي الوطني

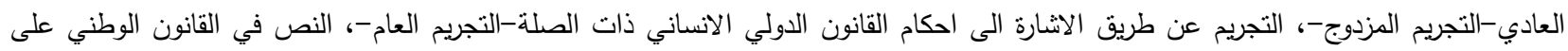
جرائم محددة تتطابق مع تلك المذكورة في المعاهدات الدولية-التجريم الخاصي-، الجمع بين التجريم بحكم عام والتجريم الصريح والمحدد لبعض الجرائم

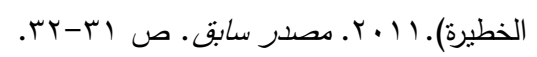

${ }^{72}$ Knut Dormann\& Robin Geib. Op. Cit., P. 710.

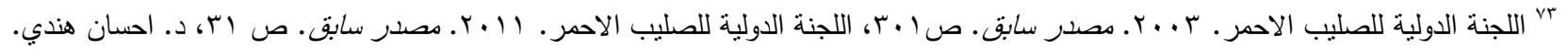

${ }^{74}$ Knut Dormann\& Robin Geib. Op. Cit., P. 711. مصدر سابق. صریم.

${ }^{75}$ The Geneva Conventions Act 1957 (as amended). available at http://www.icrc.org/ihlnat.nsf/6fa4d35e5e3025394125673e00508143/18fd6374473918c3c1256b6d003097ca!OpenDocument ${ }^{76}$ International Criminal Court Act 2001. available at http://www.icrc.org/ihlnat.nsf/6fa4d35e5e3025394125673e00508143/940fb595ea042785c1256aea003bf593!OpenDocument ${ }^{77}$ Knut Dormann\& Robin Geib. Op. Cit., P. 711.

لعديما بان الاشارة الى العرف الدولي وردت لجريمتي الابادة وجريمة ضد الانسانية ايضا. ينظر النشريع الكندي المشار اليه في ادناه. ${ }^{79}$ Crimes Against Humanity and War Crimes Act, SC 2000, c 24. available at http://www.canlii.org/eliisa/highlight.do?text=crime+against+humanity+and+war+crimes+act\&language=en\&searchTit le=Search+all+CanLII+Databases\&path=/en/ca/laws/stat/sc-2000-c-24/latest/sc-2000-c-24.html (August 2011)

${ }^{80}$ Knut Dormann\& Robin Geib. Op. Cit., P. 712.

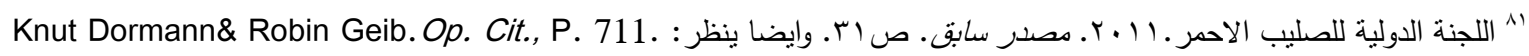
.0 el $^{\mathrm{r}}$ . .

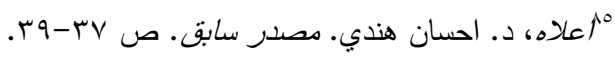

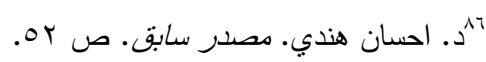

${ }^{87}$ See http://www.icrc.org/ihlnat.nsf/6fa4d35e5e3025394125673e00508143/09889d9f415e031341256c770033e2d9!OpenDocument

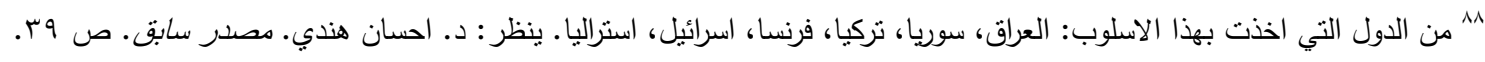
Knut Dormann\& Robin Geib.Op. Cit., P. 713.

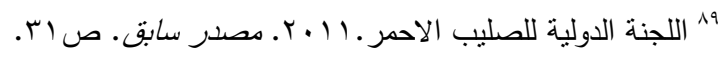

${ }^{90}$ Knut Dormann\& Robin Geib. Op. Cit., P. 713.

${ }^{91}$ /d. P. 714 .

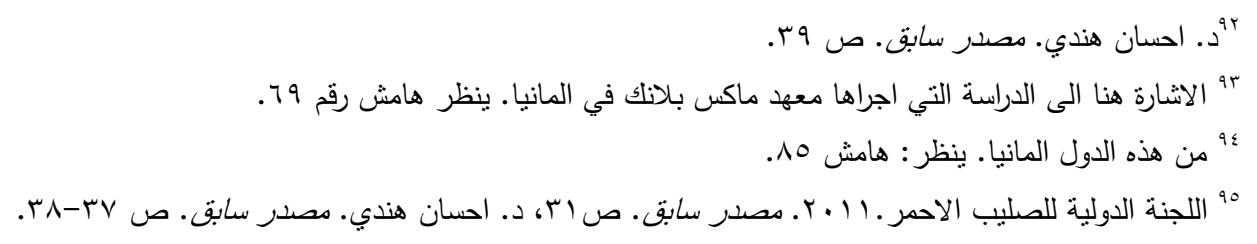




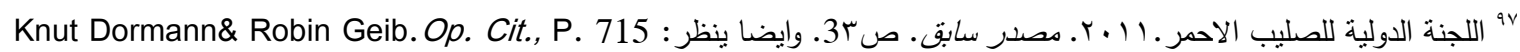
${ }^{98} / d$.

$$
\begin{aligned}
& 99 \text { اللجنة الدولية للصليب الاحمر ـ11 • r. مصدر سابق. ص اب. }
\end{aligned}
$$

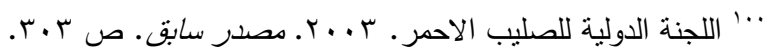

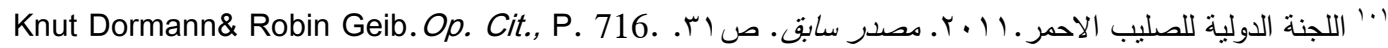

(i.r.r

ז.1 الدول التي تتبع نظام القانون المدني، ومنها العراق، تتهج اسلوب القاعدة القانونية المستقلة سواء شرعت قانون خاص او نصوص خاصة ضمن القانون الجنائي الوطني. اما الدول التي نتبع نظام القانون العام، ومنها على سبيل المثال انكلترة، نتبع اسلوب الاحالة الى قواعد القانون الدولي الانساني.

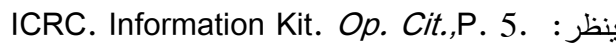

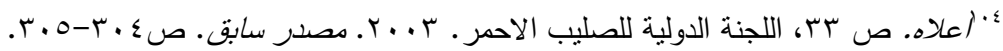
م. ألمصدربن اعلاه.

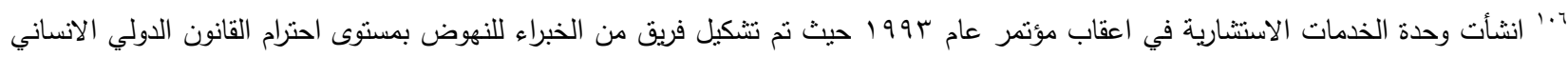
والذي كانت احدى توصياته انثاء هذه الوحدة في العام 990 1، ولتبدأ اعمالها بداية العام 997 الـ ينظر : اللجنة الدولية للصليب الاحمر. الخدمات

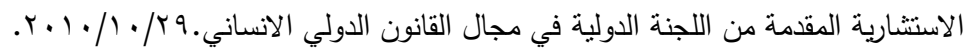
http://www.icrc.org/ara/what-we-do/building-respect-ihl/advisory-service/overview-advisory-services.htm (accessed on Oct.1, 2011).

${ }^{107} / d$.

$$
\text { ^• اللجنة الدولية للصليب الاحمر • موجز وقائع قانونية. • 1 ـ r. متاح على الموقع الرسمي للجنة الدولية للصليب الاحمر . }
$$
http://www.icrc.org/ara/resources/documents/legal-fact-sheet/implementation-ihl-factsheet-2010-10-27.htm

9.1 حول انشاء وتتكيل واساليب عمل اللجان الوطنية المعنية بتتفيذ القانون الدولي الانساني. ينظر : اللجنة الدولية للصليب الاحمر ـ مصدر سابق. $.1 Y q-1 Y \wedge \mu .11$

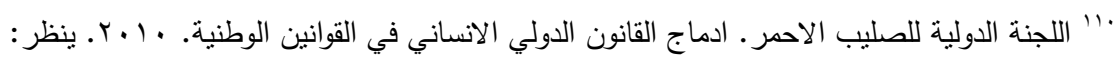
http://www.icrc.org/ara/war-and-law/ihl-domestic-law/overview-domestic-law.htm(accessed on Oct.1, 2011).

${ }^{111}$ International Committee of the Red Cross(ICRC). 2010. Table Of National Committees and Other National Bodies On International Humanitarian Law. available at http://www.icrc.org/eng/assets/files/other/nationalcommittes-icrc-30-09-2010.pdf (accessed on Sep.1,2011).

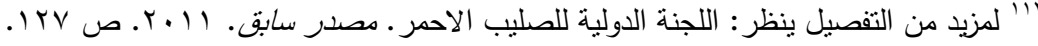

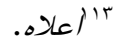

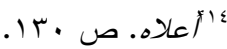

11" وهم: الجرحى والمرضى في الميدان، الجرحى والمرضى والغرقى والمنكوبون في البحار، اسرى الحرب، والمدنيون. وهنالك فئات يقرر لها القانون

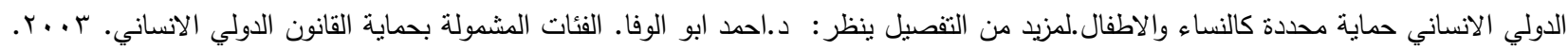

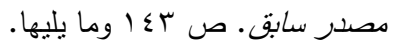

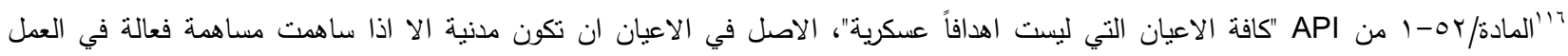
العسكري بسبب من طبيعتها او موقعها او غايتها او استخدامها،والتي يحقق تدميرها التام او الجزئي او الاستيلاء عليها او تعطيلها ميزة عسكرية اكيدة.

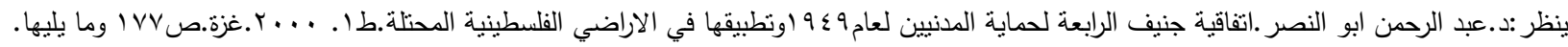

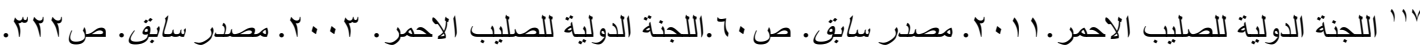




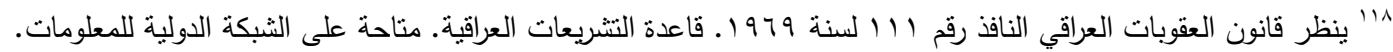
http://www.iraq-ild.org/LoadLawBook.aspx?SP=ALL\&SC=120120012516407 (accessed on August 20, 2011).

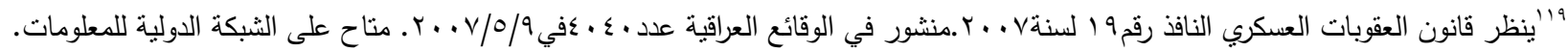
http://www.iraq-ild.org/LoadLawBook.aspx?SP=SUB\&SC=070120089400316\&PageNum=1 (August 2011). ·r' وهم كل من(أ.منتسبي القوات المسلحة العراقية المستمرين بالخدمة. ب.طلاب الكلية العسكرية او المدارس او المعاهد الخاصة بالجيش. ج.الضباط المتقاعدين والمطرودين ونواب الضباط وضباط الصف والجنود المتخرجين او المطرودين او المتسرحين من الجيش او من اي قوة عسكرية اخرى اذا كان ارتكاب الجريمة قد ثم اثثاء الخدمة. د.الاسرى فيما يتعلق بالجرائم التي نرتكب من قبلهم في المعتقلات.

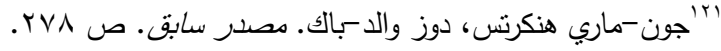

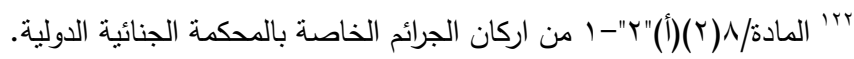

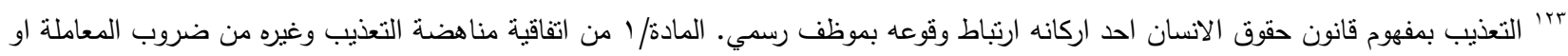

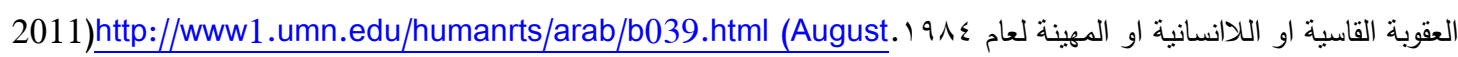
\&المادة/ rrr من قانون العقوبات العراقي النافذ تتص على: "يعاقب بالسجن او الحبس كل موظف او مكلف بخدمة عامة عذب او امر بتعذيب متهم او شاهد او خبير لحمله على الاعتراف بجريمة او الادلاء باقوال او معلومات بشأنها او لكتمان امر من الامور او لاعطائه راي معين بشأنها. ويكون بحكم

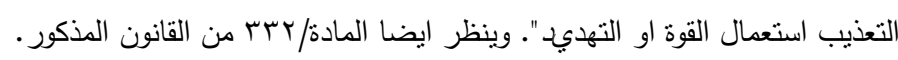

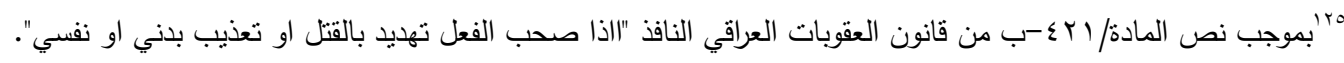

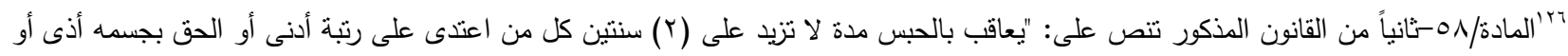
قام بعمل أدى إلى الإخلال بصحته أو ضاعف واجباته دون مبرر مشروع ولقصد التعذيب أو سمح للآخرين بإيذائه."

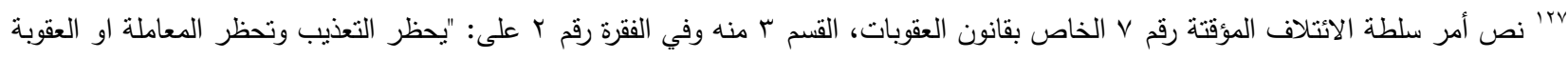
القاسية او المهينة او غير الانسانية".

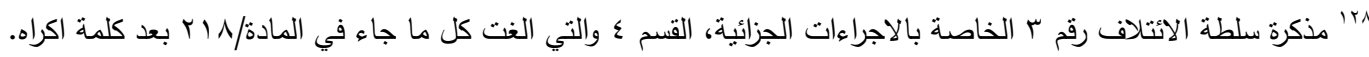

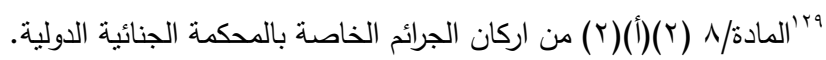

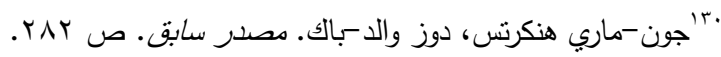

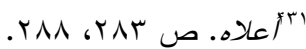

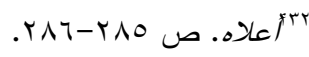
rrri

${ }^{134}$ Commentary to Article 50 of GCI.P. 372. available athttp://www.icrc.org/ihl.nsf/COM/365570061? OpenDocument (accessed on August 2011).

$$
\begin{aligned}
& \text { "أعلاه، د. احسان هندي. مصدر سابق. ص } 9 \text {. } 1 . \\
& \text {. 11.-1. }
\end{aligned}
$$

${ }^{137}$ Commentary to Article 50 of GCI.P. 372.

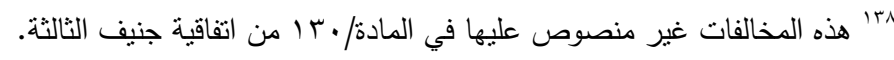

${ }^{139}$ Commentary to Article 50 of GCI.P. 372; Commentary to Article 147 of GCIV.P. 601.

• أتص المادة/هr من اتفاقية جنيف الرابعة على: "يحظر على دولة الاحتلال ان تدمر اي ممنلكات خاصة ثابتة او منقولة تتعلق بافراد او جماعات او بالدولة او السلطات العامة، او المنظمات الاجتماعية او التعاونية، الا اذا كانت العمليات الحربية تقتضي حتماً هذا التدمير". ${ }^{141}$ Commentary to Article 147 of GCIV.P. 601. r\&1 د. احسان هندي. مصدر سابق. ص اسبا.

${ }^{143}$ Commentary to Article 147 of GCIV.P. 601. 
${ }^{145}$ Commentary to Article 147 of GCIV.P. 601.

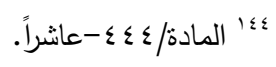

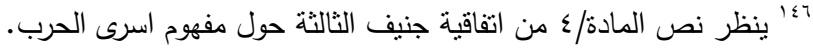

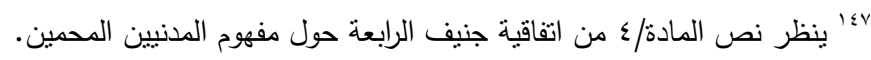

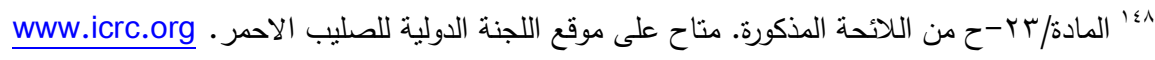

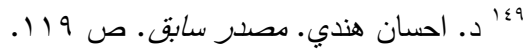

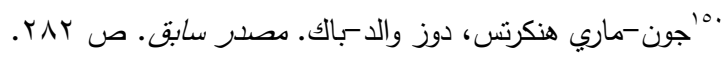

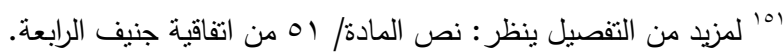

$$
\begin{aligned}
& \text { الم الماد } 10 \mathrm{r}
\end{aligned}
$$

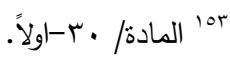

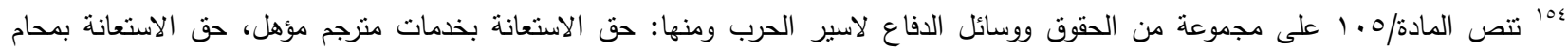

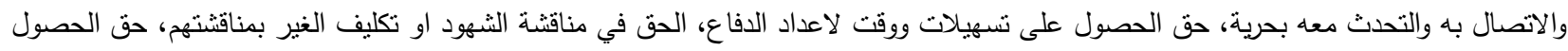
على مساعدة قانونية دون مقابل. المادة/ 100

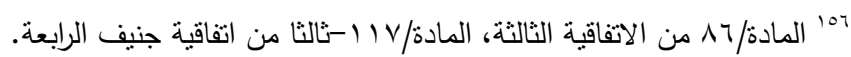

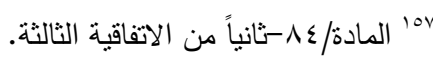

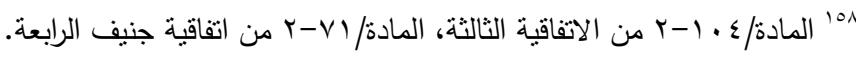

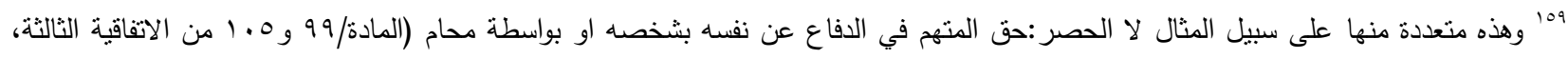

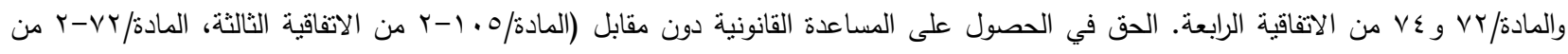

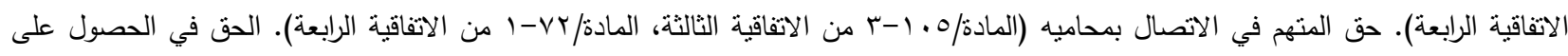

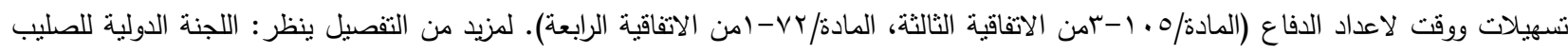

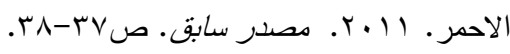

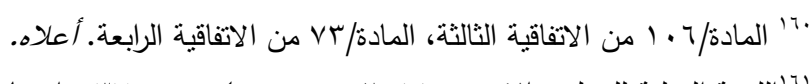

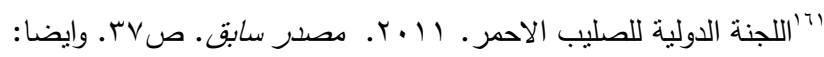

Commentary to Article 147 of GCIV.P. 602; Commentary to Article 130 of GCIII.P. 629.

${ }^{162}$ Commentary to Article 147 of GCIV.P. 598.

${ }^{163}$ John H. Fried. Transfer of Civilian Manpower from Occupied Territory. AJIL. Vol. 40, No. 2, Apr., 1946.P.803. ك

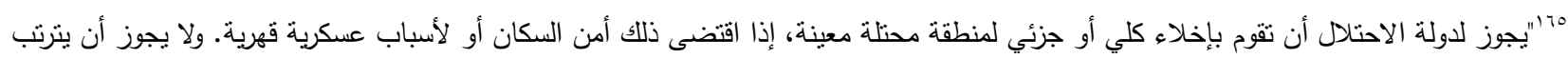

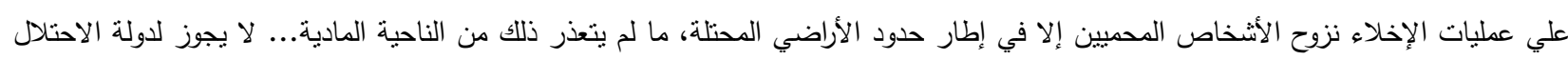

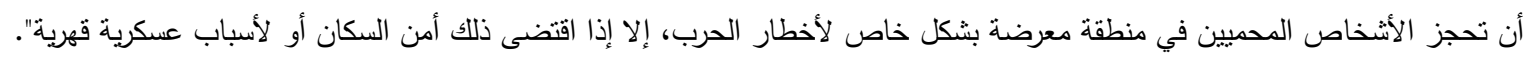

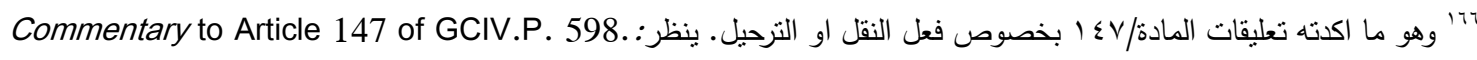

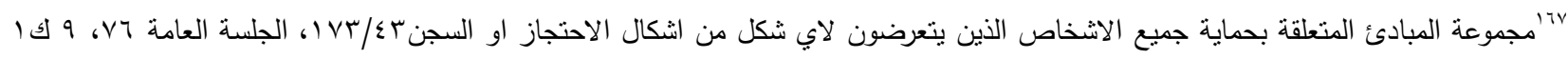

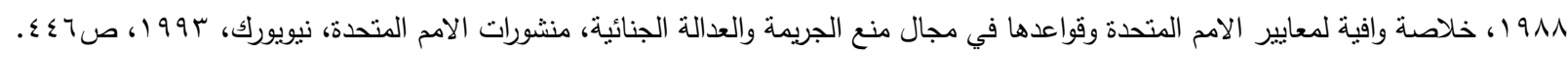

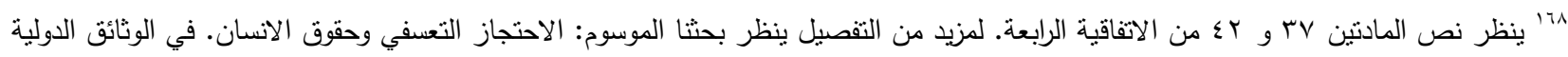

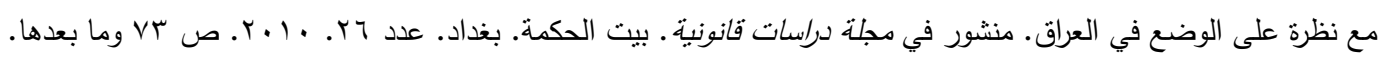


${ }^{169}$ George Duncan's. Massacres and Atrocities of World War II.

http://members.iinet.net.au/ gduncan/massacres.html (accessed on Sep.30, 2011).

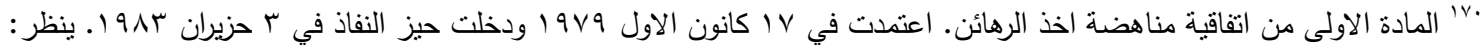
http://www.un.org/ar/sc/ctc/laws.html (accessed on Sep.30, 2011).

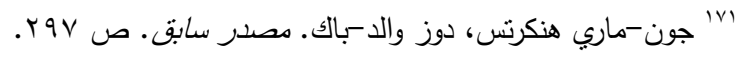

${ }^{172}$ Commentary to Article 147 of GCIV.P. 600.

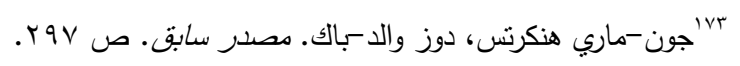

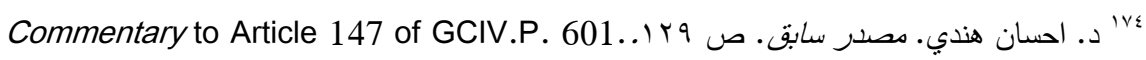

أعلاه. ص rivo 